University of Louisville

ThinkIR: The University of Louisville's Institutional Repository

$5-2012$

\title{
Women in intercollegiate athletics : an exploration of the career development of female senior administrators.
}

Meg C. Hancock

University of Louisville

Follow this and additional works at: https://ir.library.louisville.edu/etd

\section{Recommended Citation}

Hancock, Meg C., "Women in intercollegiate athletics : an exploration of the career development of female senior administrators." (2012). Electronic Theses and Dissertations. Paper 569.

https://doi.org/10.18297/etd/569

This Doctoral Dissertation is brought to you for free and open access by ThinkIR: The University of Louisville's Institutional Repository. It has been accepted for inclusion in Electronic Theses and Dissertations by an authorized administrator of ThinkIR: The University of Louisville's Institutional Repository. This title appears here courtesy of the author, who has retained all other copyrights. For more information, please contact thinkir@louisville.edu. 
WOMEN IN INTERCOLLEGIATE ATHLETICS: AN EXPLORATION OF THE CAREER DEVELOPMENT OF FEMALE SENIOR ADMINISTRATORS

By

Meg G. Hancock

B.A., Randolph-Macon Woman's College, 2003

M.S., Miami University, 2005

A Dissertation

Submitted to the Faculty of the

College of Education and Human Development of the University of Louisville in Partial Fulfillment of the Requirements

for the Degree of

Doctor of Philosophy

College of Education and Human Development

University of Louisville

Louisville, Kentucky

May 2012 
Copyright 2012 by Meg G. Hancock

All rights reserved 
WOMEN IN INTERCOLLEGIATE ATHLETICS: AN EXPLORATION OF THE CAREER DEVELOPMENT OF FEMALE SENIOR ADMINISTRATORS

By

Meg G. Hancock

B.A., Randolph-Macon Woman`s College, 2003

M.S., Miami University, 2005

A Dissertation Approved on

April 13, 2012

By the forlowing Dissertation Committee:

Mary A. Hums, Chair

Melissa Evans-Andris

T. Christopher Greenwell

Anita M. Moorman

Rod P. Githens 


\title{
DEDICATION
}

\author{
For Mom, Dad, and Sissy -
}

We've come a long way since The Real Story of Bunns.

For Bridget -

My training partner in life. 


\section{ACKNOWLEDGEMENTS}

I am forever grateful to my mentor, colleague, and friend, Dr. Mary Hums, for chairing my dissertation and this memorable journey. It has been an honor to work with you and I am thankful I have the opportunity to continue. I would also like to extend my appreciation to my committee: Dr. Melissa Evans-Andris, for pushing me to ask more of myself; Prof. Anita Moorman, for reminding me to define, describe, and explain; Dr. Chris Greenwell, for your willingness to learn from me as I have learned from you; and Dr. Rod Githens, for encouraging me to think at a deeper level.

To my family - Mom, Dad, Emy, Memaw, and Grandy - I am so thankful to be a part of a family that has always supported my dreams and encouraged the development of my talents. I know you thought when I moved back to Kentucky you would get to see me more. Now you will. Thank you for your patience, your encouragement, your love, and support. And thank you for being proud of me. William and Judson, as I write this acknowledgement you aren't yet old enough to read it. By the time you can, I hope I have shown you how important it is to always pursue your passions and dreams. Though you will struggle, the people who love you (especially me) will walk with you on your journey as they have walked with me on mine. And to Bridget - you joined me at the start line of this journey and we will cross the finish together. Thank you for accepting me for who I am and for encouraging me to be better every day.

I would also like to acknowledge Valerie Cushman and Xenia Markowitt. Your words and encouragement never ceased to inspire me. Thank you to my friend and 
colleague, Jason Simmons, for making me laugh, for understanding, and for early morning scholarly talk on the golf course.

This study would not have been possible without the cooperation of fifteen women who volunteered to participate. Thank you for sharing your triumphs and vulnerabilities. You are inspiring. You make a difference.

Finally, I am grateful to the Women's Center at the University of Louisville and the Laboratory for Diversity in Sport at Texas A\&M University for providing funding for this study. 


\title{
ABSTRACT \\ WOMEN IN INTERCOLLEGIATE ATHLETICS: AN EXPLORATION OF THE CAREER DEVELOPMENT OF FEMALE SENIOR ADMINISTRATORS
}

\author{
Meg G. Hancock
}

April 13, 2012

The roles of assistant and associate athletic director have been identified as positions in the "pipeline" to achieving the position of Athletic Director (Grappendorf, Lough, \& Griffin, 2004; Lapchick, 2010). Given the underrepresentation of female Athletic Directors in intercollegiate athletics and the concern that women may experience difficulty accessing such positions, there is a growing need to understand the career experiences and expectations of women in senior-level management positions in intercollegiate athletics.

The purpose of this study was to explore the career development of female assistant and associate athletic directors at NCAA Division I institutions. This study investigated participants' (a) career goals and expectations, (b) supports and barriers to career goals, and (c) negotiation strategies and coping mechanisms for managing barriers and supports in the pursuit of career goals.

Data were collected from 15 senior-level female administrators in NCAA Division I intercollegiate athletics departments. Career goals for participants included (a) contributing to the development of student athletes and (b) advancing within an athletic department to a position of influence. For the majority of participants, a "position of influence" did not include a career goal of achieving the position of Athletic Director. 
Participants identified supports to achieving career goals as relationships with supervisors and mentors, professional development activities, opportunities for career advancement. Barriers to career goals included factors participants associated with a male-dominated industry and organizational structures. Participants perceived, however, the culture of intercollegiate athletics is shifting to one that is more gender inclusive. Moreover, findings suggest the perceived gender typing of positions in an athletic department may be a product of choice rather than a male-dominated industry or organizational structure. Finally, participants negotiated barriers by learning new skills, engaging networks, and through a process of self-reflection.

Study findings provided valuable information for sport managers in intercollegiate athletics, the sport management classroom, and women and men entering intercollegiate athletic administration. 


\section{TABLE OF CONTENTS}

DEDICATION................................................................................................................ii

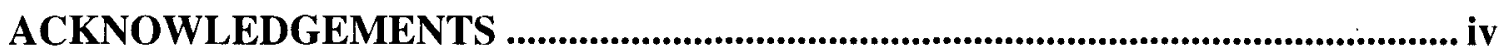

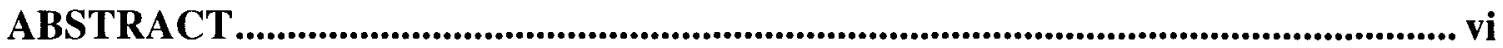

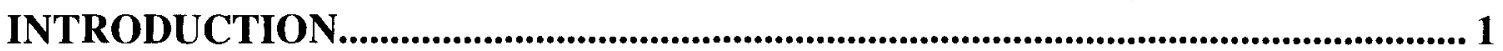

Women in the U.S. Workforce............................................................................... 1

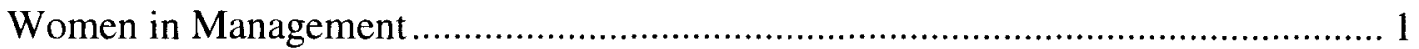

Women's Career Choice and Development........................................................ 5

Careers of Women in Intercollegiate Athletics.................................................... 13

Statement of the Problem ................................................................................................... 14

Purposes of the Study .................................................................................................... 15

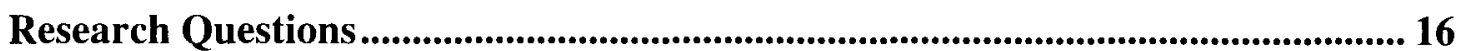

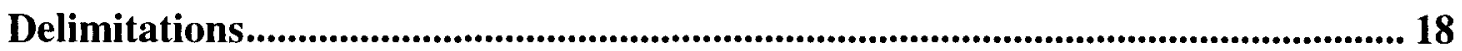

Limitations........................................................................................................................ 18

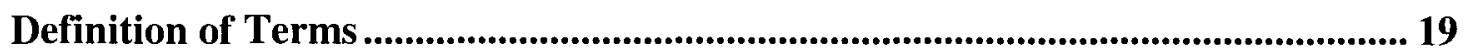

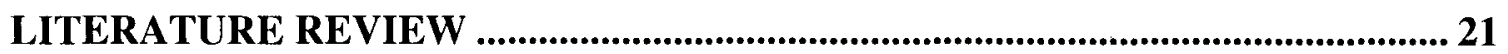

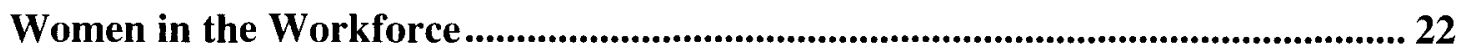

Women in Management Positions .................................................................... 29

Women in Management of College Athletics......................................................... 30 
Career Choice and Development ..............................................................................................5 50

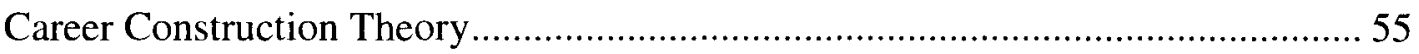

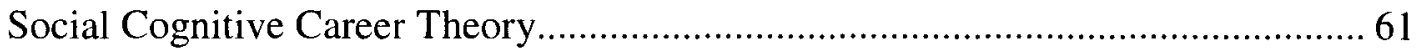

Women's Career Choice and Development............................................................ 67

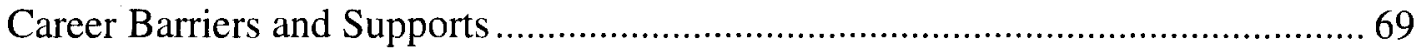

Summary

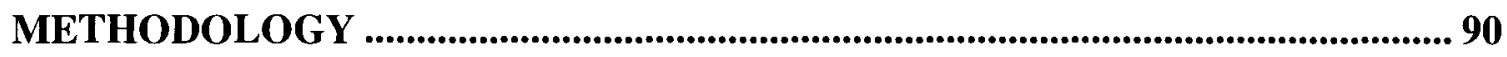

Study Design ................................................................................................................................ 91

Participant Sample.................................................................................................................... 93

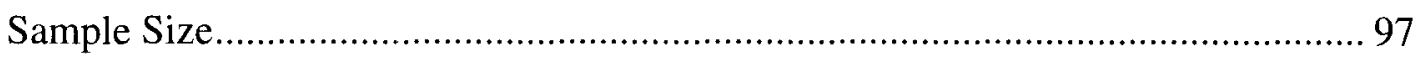

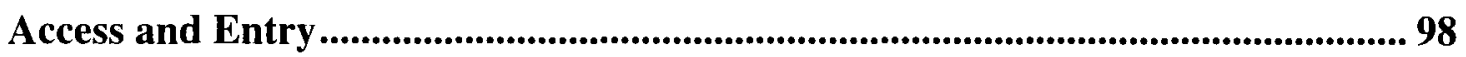

Data Collection ....................................................................................................................... 100

Data Analysis..................................................................................................................... 102

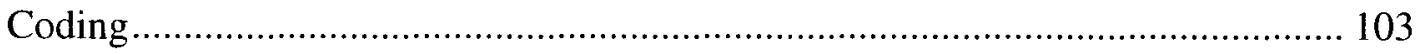

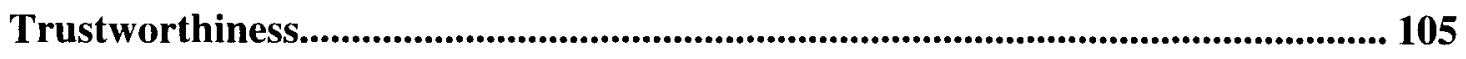

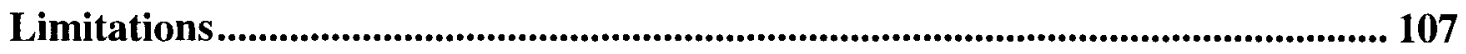

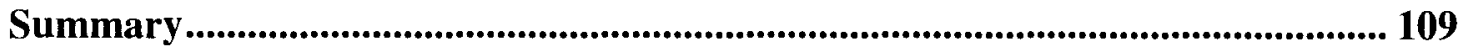

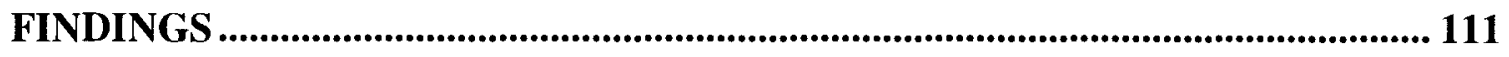

Participant Demographics...................................................................................................... 112

Exploring the Career Development of Senior-Level Female Administrators..... 116

Formation of Career Interests in Intercollegiate Athletics..................................... 117

Perceived Supports to Career .............................................................................................. 127

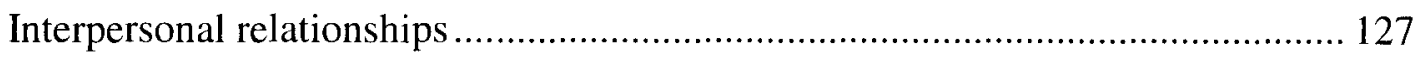


Professional Development Activities

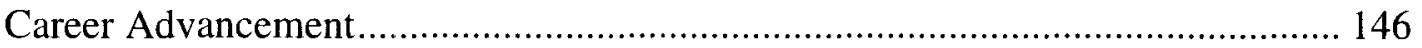

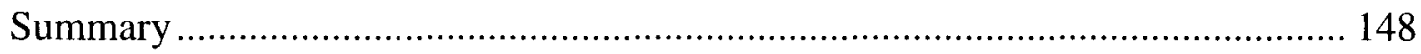

Perceived Barriers to Career ....................................................................... 149

Male-Dominated Industry Culture ........................................................... 149

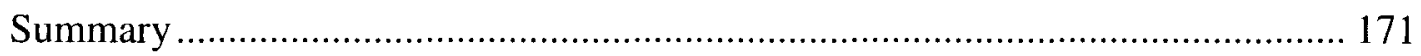

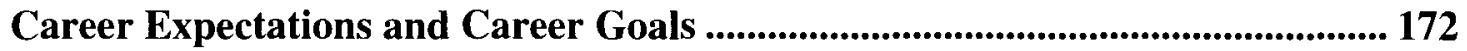

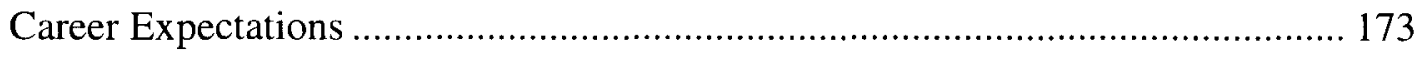

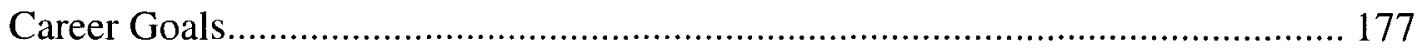

Negotiation and Coping Strategies .............................................................. 179

SUMMARY AND DISCUSSION ........................................................................................ 192

Exploring the Career Development of Senior-Level Female Administrators ..... 193

Supports and Barriers to Career Development ............................................ 195

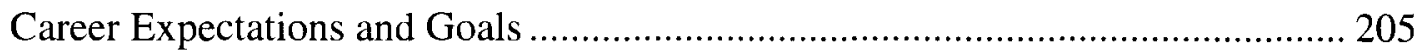

Negotiation of Barriers and Supports ..................................................... 208

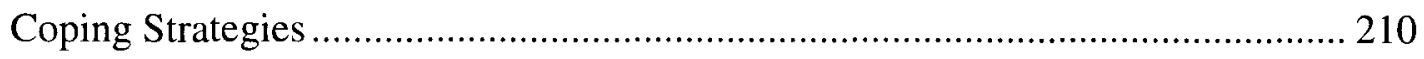

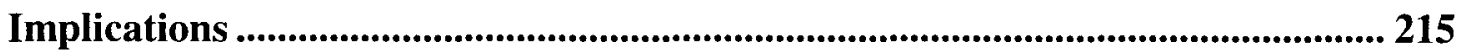

Implications for Career Development Theorists ............................................. 215

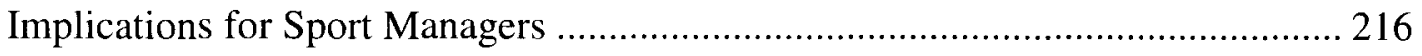

Implications for the Sport Management Classroom ......................................... 218

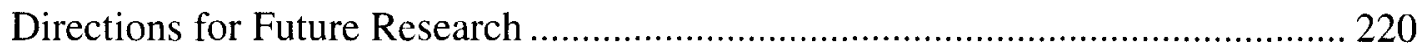

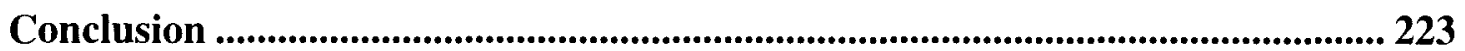

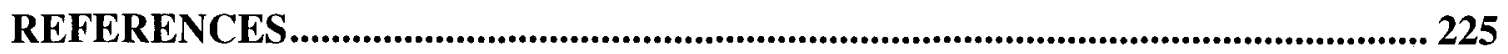




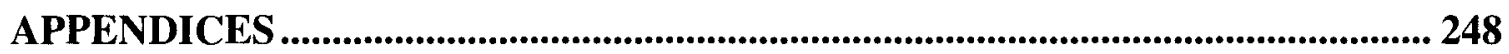

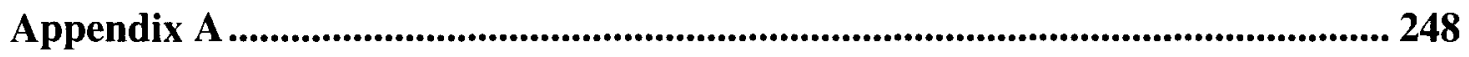

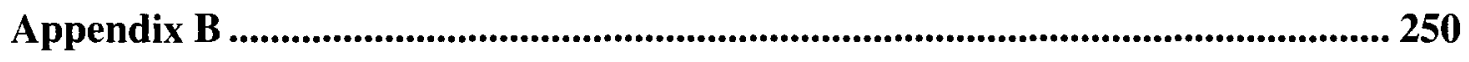

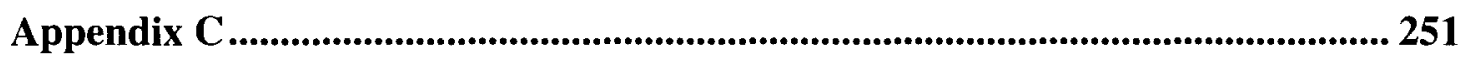

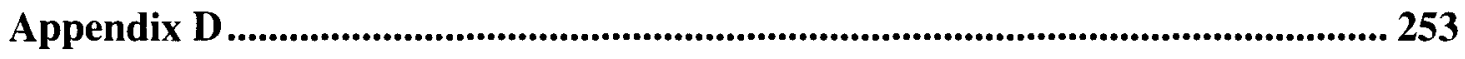

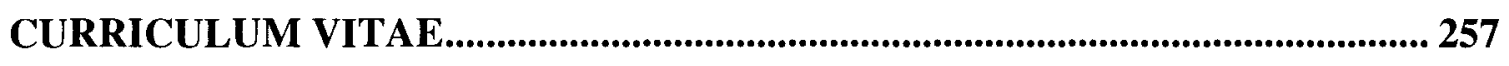




\section{CHAPTER I}

\section{INTRODUCTION}

\section{Women in the U.S. Workforce}

The gender composition of the United States labor force has changed dramatically in the last five decades. Participation by women is on the rise and projections estimate that women will account for $51.2 \%$ of the growth of the labor force by 2018 (U.S. Department of Labor Statistics, 2009). Today, women comprise $46.8 \%$ of the total labor force and more than $50 \%$ of managerial and professional staff positions (U.S. Bureau of Labor Statistics) - an exponential shift from the 1950s and 1960s when women held only $13 \%$ of management positions (Catalyst, $2011 \mathrm{e}$ ). The increase in the number of women in the workforce may be attributed, in part, to women's access to and participation in higher education. For example, women earned $57 \%$ of the bachelor's degrees and $61 \%$ of master's degrees conferred in 2009 (National Center for Education Statistics, 2010), while in 2010 women earning Ph.D.s outnumbered men earning Ph.D.s for the first time in U.S. history (Pellegrino, D’Amato, \& Weisberg, 2011).

\section{Women in Management}

As the number of women earning degrees, participating in the workforce, and serving in management positions increases, one might expect the representation of women in executive management (e.g., chief executive officers, chief financial officers, corporate and executive board presidents) to also increase. To the contrary, women's representation on executive boards, governing bodies, and as chief corporate officers has 
flat-lined and a decline may be imminent (Catalyst, 2011c). For example, in nursing, women constitute approximately $96 \%$ of registered nurses, but account for less than half of management positions (U.S. Department of Health \& Human Services, 2011). Conversely, women represent $72.5 \%$ of all other medical and health services managers despite underrepresentation as physicians and surgeons (32.3\%) (Catalyst, 2011f). Thirty-one percent of lawyers are women, yet women only account for $19.4 \%$ of firm partners (Catalyst, 2011b). In academia, women hold $23 \%$ of the presidencies and $24 \%$ of full professorships at colleges and universities in the United States (Catalyst, 2011d).

Women in science occupy positions such as biological scientists $(45.8 \%)$, medical scientists $(53.7 \%)$, chemists $(33.5 \%)$, and computer scientists/mathematicians $(25.8 \%)$, yet hold only $21.6 \%$ of the managerial positions (Catalyst, $2011 \mathrm{f}$ ). Only $2.8 \%$ of Fortune 500 companies are under the leadership of women (Catalyst, $2011 \mathrm{~b}$ ). Moreover, women hold only $15.4 \%$ of the board seats in Fortune 500 companies despite the finding that companies with three or more women on the board performed significantly better socially and financially than companies with two or fewer female board members (Catalyst). In other words, men often dominate managerial positions in organizational structures. Of interest in the current study is one traditionally male dominated arena - the sport industry.

The most recent Racial and Gender Report Card (Lapchick, 2011) reported that in the last decade (2001-2010), the representation of women in executive management positions declined in five of the six major North American professional sport leagues [i.e., National Football League (NFL), Major League Baseball (MLB), National Hockey League (NHL), National Basketball Association (NBA), Major League Soccer (MLS)]. 
The Women's National Basketball Association (WNBA) was the only exception reporting an increase of $21 \%$ of women in executive management (Lapchick, 2010). Executive management in sport organizations includes positional titles such as chief executive officer, president, general manager, vice president, and Athletic Director (Lapchick). Although the sport industry includes numerous segments such as professional sport, health and fitness, facility management, and event management, this study focuses on intercollegiate athletics.

The number of women working in intercollegiate athletic administration has increased over the last decade (Acosta \& Carpenter, 2010). For example, between 2008 and 2009, women accounted for 42.5\% (NCAA Division I), 43.5\% (NCAA Division II), and $46.2 \%$ (NCAA Division III) of professional administration positions in intercollegiate athletics - an average divisional increase of 8.6\% (Lapchick, 2010). While the increase of women in professional staff positions in intercollegiate athletic programs is impressive, research suggests (Grappendorf \& Lough, 2006; Grappendorf et al., 2004; Whisenant, Pederson, \& Obenour, 2002) these positions are not in the managerial "pipeline."

The pipeline refers to senior-level title positions of assistant athletic director and associate athletic director (Grappendorf et al., 2004; Lapchick, 2010). Individuals holding senior-level positions are perceived to be more likely to achieve an Athletic Director position than those in professional administration because the skill sets associated with senior-level administration, such as budgeting, fundraising, and supervisory responsibility, are perceived to be more transferable to the position of Athletic Director (Grappendorf \& Lough, 2006; Grappendorf et al., 2004; Lapchick, 
2010). Thus, senior-level positions are perceived as "training grounds" for the executive level Athletic Director position (Lapchick).

While more women work in intercollegiate athletics than ever before, the proportion of women as senior- and executive-level managers in general is declining (Acosta \& Carpenter, 2010; Lapchick, 2010). For example, in the last five years, the percentage of female senior-level administrators in Division I has increased by $2.7 \%$, while Divisions II and III have experienced declines of $8.5 \%$ and $7.1 \%$ (Lapchick, 2010). Between 2008 and 2010, the overall percentage of female Athletic Directors at NCAA institutions declined from $21.3 \%$ to $19.3 \%$ (Acosta \& Carpenter, 2010). Moreover, $13.2 \%$ of NCAA intercollegiate athletic departments have no female representation at the executive or senior levels of administration (Acosta \& Carpenter, 2010). As such, sport scholars and practitioners have grown increasingly concerned about the underrepresentation of women in administrative decision-making roles in intercollegiate athletics (Burton, Grappendorf, \& Henderson, 2011; Cunningham, 2008; Grappendorf \& Lough, 2006; Grappendorf et al., 2004).

Women seeking careers in management often contend with deeply entrenched perceptions and notions about social, work, and familial roles (Gatrell \& Cooper, 2007). Studies in sport management have attributed low numbers of women in managerial positions to male-dominated organizational structures and the gender stereotypes they perpetuate (Bruening, Dixon, Tiell, Osbourne, Lough, \& Sweeney, 2008; Burton, Barr, Fink, \& Bruening, 2009; Burton et al., 201 1; Grappendorf \& Lough, 2006; Inglis, Danylchuk, \& Pastore, 2000; Moore, Parkhouse, \& Konrad, 2001; Sartore \& Cunningham, 2007; Whisenant et al., 2002). While organizational structures and 
stereotypes affect women's work experiences, perhaps the experiences of women in intercollegiate athletic administration warrant a more holistic perspective to better explain the underrepresentation of women in senior management positions and as Athletic Directors. Theories on career choice and development provide helpful frameworks for understanding how entrenched perceptions, social roles, and organizational structures affect a woman's mobility in the workforce. One way to examine this is through the lens of selected career development theories. Career development theories provide an interpretive framework for understanding the career experiences of women in intercollegiate athletics.

\section{Women's Career Choice and Development}

Initial career development theories were grounded in the psychological constructs and social experiences of White men (Holland, 1959; Parsons, 1909; Weiss et al., 1967). In the 1960s and 1970s, psychologists began to study the career development of women to gain a better understanding of the intersection between career and family orientations (Farmer, 2006). Similar to career research conducted on men, initial studies on women focused on psychological characteristics such as personality, intellect, motivation, and occupational "fit" (Psathas, 1968), but did not address what, how, or why social contexts affected the career orientation of women. Furthermore, career development studies attributed differences in occupational choices to differences in gender and the construction of self-concept (Richardson, 1975), but did not address how or why the differences existed.

Sociologists and social psychologists studying career development argued that social contexts and the identities associated with such contexts are likely to significantly 
impact career decisions and trajectories (Astin, 1984; August \& Quintero, 2001; Brown, 2002; Lent, Brown, \& Hackett, 1994). People make sense of the world through social contexts and identities. Therefore, social contexts and variables contributing to the construction of personal and professional identities are important to consider when examining the career development of individuals, especially women (Astin, 1984; Betz \& Fitzgerald, 1987; Coogan \& Chen, 2007; Fagenson, 1990; Forrest \& Mikolaitis, 1986). Several researchers have argued that exploring a woman's career development and decision making is important because those processes are much more complex than a man's because women (Betz, 1994; Betz \& Fitzgerald, 1987; Coogan \& Chen, 2007; Farmer, 1976; Forrest \& Mikolaitis, 1986). Women must contend with gendered social and work expectations (Betz \& Fitzgerald). Further, traditional career theories do not adequately address the nuanced experiences of women (Betz \& Fitzgerald; Coogan \& Chen, 2007).

In recent decades, researchers have emphasized a more subjective approach to observing career choice and development (Astin, 1984; Elder \& O’Rand, 1995; Johnson \& Mortimer, 2002; Savickas, 2002, 2005). The subjective approach recognizes the influence of individual identities (e.g., gender, race), social roles (e.g., employee, mother, spouse), relationships (i.e., collegial, familial, peer), and organizational structures (e.g., opportunity for advancement, hiring practices, formal and informal networks) on career decisions. Two career development theories - career construction theory (Savickas, 2002) and social cognitive career theory (SCCT; Lent et al., 1994, 2000) - can help us better understand how individual, organizational, and social forces influence a career life course. Thus, career construction theory and SCCT are useful modern career theories for 
exploring career development. Additionally, exploring the perceived supports and barriers to a woman's career, particularly in a male-dominated field, is useful for examining the interconnection between individuals, social roles, relationships, and organizational structure.

Career construction theory. Career construction theory focuses on what career decisions people make and why people make such decisions (Savickas, 2002, 2005). Uncovering the meaning of factors influencing career development has the potential to reveal exactly how and why people make decisions (Savickas, 2005). In other words, career construction theory was not designed to predict career paths, but to interpret and understand the decisions and choices individuals make based on their perceptions of social realities in the context of career development. Career construction theory is comprised of three components - (a) vocational personality, (b) career adaptability, and (c) life themes.

Vocational personality consists of the career decisions an individual makes based on career-related abilities, needs, values, and interests (Savickas, 2005). Career adaptability "deals with how an individual constructs a career whereas vocational personality deals with what career they construct" (Savickas, 2005, p. 48). Adaptability represents an individual's ability to cope with current and future developmental tasks, career transitions, and personal traumas (Savickas, 2005). Life themes influence individuals to make meaningful choices about work roles (Savickas, 2005). For example, Eccles (1994) advised, "occupational choices are not made in isolation of other life choices, such as the decision to marry and have children, and the decision to balance one's occupational behaviors with one's other life roles..." (p. 605). Therefore, 
uncovering the meaning of factors such as work-related responsibilities, job transitions, and personal life experiences has the potential to reveal why people make certain career decisions (Savickas, 2005).

Career construction theory offers a framework for interpreting a person's career life course through the integration of vocational personality, career adaptability, and life themes. It is unclear, however, how personality, adaptability, and life themes affect an individual's career expectations and career goals. Social Cognitive Career Theory (SCCT; Lent et al., 1994) attempts to explain the "dynamic processes and mechanisms through which (a) career and academic interests develop, (b) career related choices are forged and enacted, and (c) performance outcomes are achieved" (p. 80).

Social cognitive career theory. SCCT recognizes social realities are different for each individual based on personal characteristics (e.g., gender), contextual factors (e.g., organizational structures, social relationships), and behavior (i.e., negotiation of context; Lent et al., 1994, 2000). Personal characteristics, contextual factors, and behavior are interconnected mechanisms contributing to a person's career decision-making process and environment as they relate to (a) self-efficacy, (b) outcome expectations, and (c) career goals (Lent et al.).

Self-efficacy refers to the manner in which people assess their abilities to carry out specific courses of action to achieve a performance level or goal (Bandura, 1986). Self-efficacy helps people make decisions about situations in the contexts of particular environments. Researchers also suggest that self-efficacy determines responses to personal and professional obstacles (Bandura, 1986; Lent et al., 1994, 2000). Outcome expectations are personal beliefs about anticipated consequences of particular behaviors 
(Lent et al., 1994). For example, if a person performs well on a job task, he/she may expect the performance to result in organizational advancement or an increase in pay. A person who performs poorly on a task, may be less likely to attempt that task in the future thus inhibiting opportunities for professional growth and advancement. As a result, expectations are often predicated on assessments of self-efficacy.

Perceptions of self-efficacy and outcome expectations provide not only a bridge for understanding past and future behavior, but also an understanding of how and why career goals are formed. Career goals aid in the organization of behavior such as career plans and the likelihood that desired career expectations will be achieved (Lent et al., 1994). For instance, a person may set a career goal of becoming an intercollegiate Athletic Director. Therefore, the individual aligns him/herself with positions in the Athletic Director "pipeline." The person assumes that successful task performance will lead to advancement through the organizational hierarchy and eventually attainment of the career goal of becoming an Athletic Director. Lent et al., however, contended that personal and contextual variables influence self-efficacy, outcome expectations, and career goals.

In SCCT, personal variables include gender and gender role construction, education, career interests and values, and socialization. Contextual variables perceived barriers and supports within a given environment (Lent et al., 1994) - should be considered when evaluating a career decision in a given situation. Contextual barriers and supports - real or perceived -may include structural (e.g., opportunities for advancement and promotion, discriminatory hiring practices, organizational policies 
inhibiting work/life balance) or social relational determinants (e.g., relationships with supervisors, colleagues, family and friends; informal networks).

Career barriers and supports. Barriers and supports are real features of an industry or an organizational environment, but they are also subjective perceptions defined by an individual's lived experience (Albert \& Luzzo, 1999; Astin, 1984; August \& Quintero, 2001; Kanter, 1977; Lent et al., 1994). In other words, the mere perception of a barrier can affect the career decision-making process (Albert \& Luzzo; Lent et al., 1994). Career construction theory and SCCT emphasize the influence of personal and contextual factors on behavior and individual choice as integral to understanding career development.

Personal factors. Personal factors include a range of "intrapersonal influences on career development" (Patton \& McMahon, 2006, p. 153). Studies on personal factors in career development emphasize gender and gender role socialization (Astin, 1984; Betz \& Fitzgerald, 1987; Eagly, 1987; Gottfredson, 1996); personality (Betz \& Fitzgerald; Ritchie, Fassinger, Linn, Johnson, Prosser, \& Robinson, 1997; Wentling, 2003; White, 1995); the acquisition and development of human capital such as education, formal skills/abilities, and job tenure (Burke, 2007; Knoppers, 1992); and self-efficacy (Betz, 2004; Lent et al., 1994).

Eccles (1994) posited, "Understanding women's occupational choices requires a broad view of the options and roles available to women" (p. 605). The educational and occupational choices made by men and women are not done in isolation (Astin, 1984; Eccles; O’Neil \& Bilimoria, 2005). Gender role socialization, cultural expectations, and individual interests influence the decision-making process. Likewise, gender roles affect 
core personal values, long-term goals and aspirations, and an individual's self-efficacy (Astin, 1984; Betz \& Fitzgerald, 1987; Eccles, 1994; Gottfredson, 1996; Beatty, 2007). Understanding the personality characteristics of women in executive management positions has been widely studied (Richie et al., 1997; Wentling, 1996, 2003; White, 1995). Women in leadership positions have been described as committed, dedicated, passionate, and self-confident. Additionally, O’Neil, Bilimoria, and Saatcioglu (2004) identified career locus as another personality characteristic perceived to promote or inhibit career development. Career locus is the belief that a person is responsible for his/her own career success. Women's career loci changes over time which may explain why, despite describing themselves as "driven" and "committed" or touting work ethic and competence as strengths, studies of women in executive management positions attributed success to external factors such as being in the right place at the right time (Andrew, Coderre, \& Denis, 1990; Corby \& Stanworth, 2009; O’Neil \& Bilimoria, 2005; O’Neil et al., 2004; Richie et al., 1997).

Self-efficacy is an important factor in career development because self-efficacy helps people make decisions about situations in the context of a particular environment (Lent et al., 1994; Savickas, 2002). For example, repeated, successful completion of a task in various conditions enhances an individual's perception of ability on a given task thus reinforcing stronger notions of self-efficacy and the likelihood a person will attempt the task in the future (Bandura, 1986; Betz, 2004; Lent et al.).

Contextual factors. Contextual factors are perceived as both barriers and supports within a given environment (Astin, 1984; Kanter, 1977; Lent et al., 1994). Also known as environmental factors, contextual factors are influenced by personal behavioral 
actions and consequences resulting in a "dynamic, constantly evolving person environment interaction" (Richie et al., 1997, p. 137). Real or perceived contextual factors are comprised of structural and social determinants (Astin, 1984; Kanter, 1977; Lent et al., 1994). Structural determinants include gender role stereotyping, occupational sex segregation, opportunities for promotion and advancement, homologous reproduction and perceived discriminatory hiring practices, and organizational policies that inhibit work/life balance. Social determinants include networking opportunities, mentoring and role modeling, and work-life balance. Structural and social-relational determinants may influence self-efficacy, outcome expectations, and career goals (Lent et al.). Studies on female coaches and female Athletic Directors also suggest personal and contextual factors including social-relational and structural determinants have the potential to affect career expectations and career goals for women in intercollegiate athletics (Grappendorf, Pent, Burton, \& Henderson, 2008; Inglis et al., 1996, 2000; Knoppers, 1992; Sagas \& Cunningham, 2004a).

As discussed, more women work in intercollegiate athletics than ever before, the proportion of women as senior managers and executives is declining (Acosta \& Carpenter, 2010; Lapchick et al, 2009). If more women are working in the sport industry, why are they absent in senior levels of management? Is something happening in a woman's career development that precludes her assent to the position of Athletic Director? The following section explores career-related literature pertaining to women in intercollegiate athletics. 


\section{Careers of Women in Intercollegiate Athletics}

Research on the careers of women in intercollegiate athletics has focused primarily on three populations: (a) coaches (Inglis et al., 1996, 2000; Knoppers, 1992; Pastore, Inglis, \& Danylchuk, 1996), (b) women who serve in the role of the senior woman administrator (SWA) (Claussen \& Lehr, 2002; Grappendorf et al., 2008; Hoffman, 2010, 2011; Sagas \& Cunningham, 2004b; Tiell \& Dixon, 2008), and (c) female Athletic Directors (Grappendorf et al., 2004; Grappendorf \& Lough, 2006: Judd, 1995; Whisenant et al., 2002). These studies have identified barriers to women's career development in intercollegiate athletics including (a) gender and gender role stereotypes (Burton et al., 2009; Burton et al., 2011; Grappendorf et al., 2004; Grappendorf et al., 2008), (b) homologous reproduction (Aicher \& Sagas, 2009; Whisenant et al., 2002), (c) skill development (Grappendorf et al., 2008; Hoffman, 2010; Judd, 1995; Quarterman, Durpree, \& Willis, 2006), (d) networking and mentoring relationships (Bower, 2008, 2009; Lovett \& Lowry, 1994), and (e) work-life balance and support (Bruening et al., 2008; Bruening \& Dixon, 2007; Dixon \& Bruening, 2007; Sagas \& Cunningham, 2004b).

Other studies have found factors perceived to support and promote the career development of women. Mentoring relationships (Bower, 2008, 2009) and collegial support (Inglis et al., 1996, 2000), industry knowledge and experience (Cunningham, Sagas, Dixon, Kent, \& Turner, 2005; Grappendorf et al., 2004), and networking (Greenhill, Auld, Cuskelly, \& Hooper, 2009; Hums \& Sutton, 1999) have been found to contribute to women's interest and tenure in intercollegiate athletics.

While these studies shed light on women's experiences, research germane to women in intercollegiate athletic administration has focused primarily on female Athletic 
Directors or the role of the Senior Woman Administrator (SWA). These studies reflect the experiences and perceptions of women who have achieved an executive level position and/or the title of SWA, yet they do little to help us understand the experiences of women who have not attained executive positions. Furthermore, studies on female Athletic Directors presume the position of "Athletic Director" is a career goal for women in the intercollegiate “pipeline.” A few studies (Grappendorf et al., 2004; Sagas \& Cunningham, 2004b), however, have suggested that promotion and advancement to executive positions in intercollegiate athletics is not a career goal for women. Yet to be explored are the career experiences and expectations of women in the intercollegiate athletic administration "pipeline."

\section{Statement of the Problem}

To date, few studies have examined women's work experiences in senior-level (i.e., assistant and associate athletic director) intercollegiate athletics positions as they pertain to career development, career expectations, and career goals. The roles of assistant and associate athletic director have been identified as positions in the "pipeline" to achieving the position of Athletic Director (Grappendorf et al., 2004; Lapchick, 2010). Given the underrepresentation of women in executive-level positions in intercollegiate athletics and the concern that women may experience difficulty accessing such positions (Bruening et al., 2008; Burton et al., 2011; Grappendorf et al., 2004; Inglis et al., 1996; Moore et al., 2001; Sagas \& Cunningham, 2004b; Whisenant et al., 2002), there is a growing need to understand the career experiences and expectations of women in seniorlevel management positions in intercollegiate athletics. 
Further, personal factors and contextual factors such as organizational structures and social relationships may act as barriers or supports in the career development of women (Lent et al., 2000). The current study sought to identify barriers and supports women perceive and experience in their roles as senior-level administrators in intercollegiate athletic departments. Considering studies on women in intercollegiate athletic administration have focused almost entirely on executive-level female Athletic Directors, the barriers and supports identified in these studies may not be applicable to women in senior-level administration. In other words, barriers and supports may be a function of managerial rank (Russell, 2006).

Career theorists (Astin, 1984; Gottfredson, 1996; Lent et al., 2000; Savickas, 2005) suggest women negotiate barriers and supports by either (a) compromising career aspirations and goals or (b) developing coping efficacy. Few studies on women in intercollegiate athletics have attempted to collect information on how and why women negotiate barriers and supports. Moreover, little research exists on how negotiating barriers influences career expectations and goals of women in intercollegiate athletics.

\section{Purposes of the Study}

The literature on women working in intercollegiate athletics has looked at women as coaches, senior woman administrators, and Athletic Directors. There is a gap in the literature when it comes to the experiences of women as they move through the pipeline of senior-level administration. Therefore, the purposes of this study were to

(a) explore the career experiences and expectations of women in senior-level intercollegiate athletic administration

(b) identify perceived career barriers and supports 
(c) gain a better understanding of how the negotiation of barriers and supports influences career development, expectations, and goals.

\section{Research Questions}

An overarching research question was developed to guide this study: What are the career experiences of women in senior-level management positions in NCAA Division I intercollegiate athletics? Additional research questions guiding this study will address:

1) What factors do participants perceive as supports to their career development?

2) What factors do participants perceive as barriers to their career development?

3) How do participants negotiate supports and barriers?

4) In what ways did participants' perceptions of barriers and supports influence career outcome expectations?

5) In what ways did participants' perceptions of barriers and supports influence career goals?

6) What coping strategies do participants employ to reconcile potential differences between career aspirations and career realities?

\section{Study Significance}

This study was significant for a number of reasons. First, studies conducted on women in intercollegiate athletics have focused on female Athletic Directors, the role of the SWA, or female head coaches or assistant coaches. Very little, if any, research has been conducted on the experiences of women as assistant and associate athletic directors. Therefore, this study extends the literature on careers in intercollegiate athletics to women who occupy the "pipeline." That is, women in senior-level positions including assistant and associate athletic directors. 
Second, much of the literature on women in intercollegiate athletics has focused on women who have "made it to the top" (Grappendorf et al., 2008; Grappendorf \& Lough, 2006; Whisenant et al., 2002). The findings of these studies and the advice forwarded by current female Athletic Directors implicitly assume women want to attain executive levels of management. Women in these studies identified barriers they encountered and somehow overcame to achieve the position of Athletic Director. What is less clear is how the women employed coping mechanisms to negotiate barriers and supports. Moreover, what these studies fail to consider is that barriers and supports may be a function of managerial rank (Russell, 2006). The present study explores barriers, supports, and the role of negotiation strategies and coping mechanisms in the pursuit of career goals for women in senior-level administration.

Third, U.S. Department of Labor (2009) statistics indicate the number of women entering the workforce will only continue to increase. Studies on college sport (Lapchick, 2010) and women in intercollegiate athletics (Acosta \& Carpenter, 2010) also suggest the number of women seeking positions in college athletic departments will rise. The findings from this study can help sport management academics and practitioners prepare women entering intercollegiate athletics for issues they might face in their careers, as well as how to adjust to issues while keeping professional expectations and goals in mind. Similarly, an understanding of potential barriers and supports may help women who have already established careers in intercollegiate athletics make more proactive career-related decisions.

Fourth, the insights gleaned from this study may be used to provide recommendations - to academic programs and industry leadership - for the recruitment, 
retention, and advancement of women in intercollegiate athletics. Finally, this study contributes to the larger body of literature on women's career development by contributing insight into women's experiences in an often-overlooked male-dominated industry - the sport industry.

\section{Delimitations}

This study has the following delimitations:

1. Only female assistant and associate athletic directors in NCAA Division I intercollegiate athletics are included in the population

2. The women interviewed for this study must currently hold the title of assistant or associate athletic director at an NCAA Division I member institution.

Participants for the study were selected using criterion sampling.

3. This study will only address women's career experiences up to the final date of data collection, February 2012.

\section{Limitations}

This study has the following limitations:

1. The study is limited to women employed as senior-level administrators in intercollegiate athletics at NCAA institutions in Kentucky, Indiana, and Ohio, and who are members of National Association of Collegiate Women Athletic Administrators (NACWAA).

2. I, the researcher, was employed as an assistant athletic director before engaging in this research project. Thus, my previous experience could affect the objectivity of the findings. 
3. Given the qualitative nature of this study, results are not generalizable to female assistant and associate athletic directors not included in this study.

\section{Definition of Terms}

Barriers: "negative contextual influences, with the understanding that contextual barriers are often functionally related to, yet conceptually distinct from, detrimental person factors" (Lent et al., 2000, p. 39).

Career: "A subjective construction that imposes personal meaning on past memories, present experiences, and future aspirations by weaving them into a life theme that patterns the individual's work life" (Savickas, 2005, p. 43).

Career development: "lifelong psychological and behavioral processes as well as contextual influences shaping one's career over the life span" (Niles \& Harris-Bowlsbey, 2002, p. 7)

Career goals: "organize and guide behavior to increase the likelihood that desired outcomes will be obtained" (Lent et al., 1994)

Executive -level administrators: position title of Athletic Director (Lapchick, 2010). Outcome expectations: personal beliefs about "imagined consequences of performing particular behaviors" (Lent et al., 1994, p. 83)

Professional staff administrators: position titles include "academic advisor/counselor, compliance officer, life skills coordinator, sports information director and assistant directors, strength coaches, and managers for business, equipment, fundraiser/development, facilities, promotions/marketing, and tickets" (Lapchick, 2010, p. 96) 
Self-efficacy: "a dynamic set of self-beliefs that are specific to a particular performance domain and that interact complexly with other person, behavior, and contextual factors" (Lent et al., 1994, p. 83)

Senior-level administrators: position titles of assistant and associate athletic director, which are perceived as the pipeline to Athletic Director position (Grappendorf et al., 2004; Lapchick, 2010)

Senior Woman Administrator (SWA): "the highest ranking female involved with the institutions intercollegiate athletics program" (NCAA, 2006, p. 20).

Supports: contextual variables that "can facilitate the formation and pursuit of individual's career choices" (Lent et al., 2000, p. 42) 


\section{CHAPTER II}

\section{LITERATURE REVIEW}

To date, few studies have examined women's experiences in senior-level (i.e., assistant and associate athletic director) intercollegiate athletics positions as they pertain to career development, career expectations, and career goals. The roles of assistant and associate athletic director have been identified as positions in the "pipeline" to an executive position as an Athletic Director (Grappendorf et al., 2004; Lapchick, 2010). Given the underrepresentation of women in executive-level positions in intercollegiate athletics and the concern that women may experience difficulty accessing such positions (Bruening et al., 2008; Burton et al., 2011; Grappendorf et al., 2004; Inglis et al., 1996; Moore et al., 2001; Sagas \& Cunningham, 2004; Whisenant et al., 2002), there is a growing need to understand the career experiences and expectations of women in seniorlevel management positions in intercollegiate athletics. Such an understanding may provide insight into how and why career experiences in intercollegiate athletics influence decisions to pursue the position of Athletic Director. Therefore, the purpose of this study is to explore the career experiences of female assistant and associate athletic directors in intercollegiate athletics.

This literature review is divided into three sections. The first section explores the history of women in the United States workforce. Section two discusses theories of career choice, career development, and opportunity structures that have been identified as barriers or supports to a woman's career development. Section three provides an 
overview of the literature on women's careers in intercollegiate athletics. A brief summary concludes the review.

\section{Women in the Workforce}

Before the $20^{\text {th }}$ century, data on women's participation in the United States workforce was limited (Anderson, 1992). Men were the primary focus of labor statistics from the time Congress mandated census taking in 1789 (Anderson). Following the Civil War, the government requested changes to the census. The newly requested data would provide more in-depth occupational statistics to account for the changes in the workforce brought on by the Industrial Revolution and capitalism (Anderson). Thus, the Census of 1870 reported nearly $44 \%$ of people were employed in "gainful and reputable occupations" (Anderson, p. 22), a statistic that discounted the contributions of $56 \%$ of the workforce population. However, the superintendent conducting the census, Francis Walker, also reported $91 \%$ of men ages 16 to 59 were employed as were $64 \%$ of men over 60 years of age (Anderson). Unemployed men were either students, disabled, criminals, retired, or "of advanced age" (Anderson, p. 22)

Participation of women in the workforce in 1870 was markedly different - only $14.8 \%$ of women were gainfully employed (Kleinberg, 1999). Women who were not employed (approximately 9.1 million) in reputable professions were assumed to be students or remained "to be accounted for" (Anderson,1992). Of the 9.1 million women "to be accounted for" Walker estimated 7.6 million of those women were "housekeepers." Housekeeping was considered a domestic responsibility rather than gainful employment because "it produced no wage or product" (Anderson, p. 23). 
Ultimately, Walker estimated only 150,000 women in the United States were gainfully employed and running a household (Anderson).

Results of the 1870 census produced concern among women. In preparation for the census of 1880, the Association for the Advancement of Women (AAW) introduced a bill to Congress requesting a more accurate and representative enumeration of women in the workforce. Additionally, the bill requested (a) the recording of wages for men and women, (b) accounting for men and women in disreputable occupations, (c) more accurate social statistics, and (d) a more equitable ratio of women as census collectors (Eastman \& Woolcott, 1878). Despite the requests of the AAW, the role of housekeeper, or "housewife," would not be considered gainful employment (Anderson, 1992). Moreover, the 1.5 million gainfully employed and running a household were negatively perceived by much of society because wives and mothers were "out of place" in the workforce (Anderson, 1992). Labeling working women as "deviant" and prescribing social roles helped establish men as the "dominant sex in the workplace, both in numbers and positions of authority" (Powell \& Graves, 2003, p. 14).

The census of 1890 , however, told a different story. The number of gainfully employed women who also had responsibilities at home had increased from 150,000 in 1870 to nearly one million in 1890 (or 10\% of U.S. women) (Anderson, 1992). In addition to domestic roles, women worked in factories, in schools as teachers, held clerical or secretarial positions, or served as bookkeepers or telephone operators (Betz \& Fitzgerald, 1987; Kleinberg, 1999). According to Kleinberg (1999), “employers preferred women workers for repetitive service positions, believing them to be more polite to customers, easier to control than young men, and cheaper to employ" (p. 112). 
Women could also be found, in very limited numbers, in professions such as chemistry, law, architecture, and business (Catalyst, 2011a).

The rapid increase of women's participation in the workforce may have some connection to women's access to education (Powell \& Graves, 2003). Many state governments legislated mandatory primary school attendance for boys and girls up to the age of 14 (Kleinberg, 1999). While men far outnumbered women in higher education, a few women were attending colleges and universities in the early 1800 s. For example, in 1840 Catherine Brewer became the first woman to earn a bachelor's degree (Catalyst, 2011a). By 1890, 350 of the 582 colleges and universities in the United States admitted women (Kleinberg, 1999). Women often majored in education, social work, librarianship, or allied medical fields such as nursing (Kleinberg). However, women interested in pursuing male-dominated careers such as medicine and law experienced discrimination and harassment. Despite these setbacks, the first medical degree conferred to a woman was Elizabeth Blackwell in 1849 (Catalyst, 2011 a).

By the early $1900 \mathrm{~s}, 19 \%$ of women (compared to $80 \%$ of men) were participating in or seeking jobs in the workforce (Lee \& Mather, 2008). Such participation rates would remain relatively stable for the next 40 years despite important political and social events (Powell \& Graves, 2003). The onset of World War I (WWI, 1914-1918) resulted in the creation of new jobs for women. Women could be found making uniforms and armaments, driving streetcars, and performing more skilled work in offices (Kleinberg, 1999) and received wages comparable to men (Powell \& Graves, 2003). When men returned home from war, however, women were effectively forced to return to domestic responsibilities (Betz \& Fitzgerald, 1987). 
In 1920, Congress passed the Nineteenth Amendment to the U.S. Constitution giving women the right to vote. Despite newly acquired freedoms and legal rights, the opportunity to vote had little to no effect on women's participation in the workforce; the percentage of working women remained a low $21 \%$ (Powell \& Graves, 2003). Following the enfranchisement of women, National Women's Party (NWP) leader and suffragist Alice Paul penned the Equal Rights Amendment (ERA). Proposed as an amendment to the U.S. Constitution, the ERA effectively stated that all people, regardless of sex, should have equal rights in the United States (Alice Paul Institute, 2011). Despite being brought before Congress every year beginning in 1923, the ERA was not passed until 1972. To date, only 35 states have ratified the ERA - 3 states short of the requirement to amend the U.S. Constitution.

The great stock market crash of 1929 and the impending Great Depression resulted in an unemployment rate of $25 \%$ (Powell \& Graves, 2003). Not only did these events affect women's participation in the workforce, the consequences of the economic crisis "contributed to an identity crisis for unemployed men" (Powell \& Graves, p. 15). Unemployed men could no longer provide for their families and many felt as though they lost their authoritative status (Powell \& Graves). Working women, particularly wives, were resented because they were perceived to be taking away job opportunities from men (Powell \& Graves).

The bombing of Pearl Harbor in 1941 was the catalyst to the United States heavy involvement in World War II (WWII). Similar to WWI, women entered the workforce in large numbers to fill jobs vacated by men. Women worked in physically demanding jobs such as construction and manufacturing (Betz \& Fitzgerald, 1987) and "had more access 
to more skilled and higher paying jobs usually held by men" (Power \& Graves, 2003, p.

15). Following the conclusion of WWII in 1945, women remained in the workforce; they did not return to domestic responsibilities as they had after WWI (Betz \& Fitzgerald, 1987). As the roles of women outside the home increased, family sizes shrank and more emphasis was placed on education and work (Kleinberg, 1999). In short, women had begun to establish their place in the U.S. workforce.

The second half of the $20^{\text {th }}$ century saw the roles of women in the workforce and at home change dramatically. Farmer (2006) suggested that several events in U.S. history served as catalysts to women's participation in the workforce including (a) the simplification of homemaking chores through technological advances, (b) contraceptive technology, (c) the civil rights movement and equal rights legislation, and (d) the women's rights movement.

By the early 1950 s, women on average married at the age of 20 - the youngest age of any generation since the turn of the century (Davis, 1999). One million more children were being born each year than during the 1930s (Rosenberg, 1992). Two of every three women who entered college dropped out (Rosenberg), yet women still earned $24 \%$ and $29 \%$ of bachelor's and master's degrees, respectively (Powell \& Graves, 2003). Despite domestic responsibilities, $31 \%$ of women worked outside the home (Powell \& Graves) and comprised over one-third of the labor force (Toossi, 2002). New technologies such as the dishwasher, laundry machines, microwaves, and frozen food reduced time spent on household chores (Farmer, 2006). Thus, more women had time for at least part-time employment (Farmer). Concern still loomed, however, that "higher education and careers... would lead to the masculinization of women with enormously 
dangerous consequences to the home, the children, and the family" (Lundberg \& Farnham, as cited in Rosenberg, 1992, p. 154).

In the early 1960s, women experienced immense social pressure to marry early and bear children shortly after marriage (Davis, 1999). The use of contraception was controversial and illegal in some states (Farmer, 2006). Women who wished to have a career outside of the home did not have access to birth control, which precluded many women from working (Farmer). The legalization of the birth control pill in 1961 offered women more freedom to plan the timing of conception as well as the number of children in the family (Farmer). By 1963, more than two million women were on "the pill" (PBS, 2002).

Increases in the number of women attending college and entering the workforce in the U.S. and around the globe have been attributed to technological advances in contraception (Farmer, 2006; Powell \& Graves, 2003). At the end of the decade, women earned $43 \%$ of bachelor's degrees and $40 \%$ of master's degrees (Powell \& Graves). Additionally, $43 \%$ of women worked full-time, including $42 \%$ in white-collar jobs (i.e., jobs that do not require manual labor) and $16 \%$ in managerial jobs (Powell \& Graves). Discrimination against women in the workforce, however, was rampant (Farmer, 2006). It perpetuated antiquated gender roles and resulted in the segregation of occupations (Powell \& Graves, 2003). For example, newspapers ran classified ads for "women's jobs" and "men's jobs" (Powell \& Graves).

The National Organization for Women (NOW) - founded in 1966 to promote women's equality - pressured the federal government to investigate claims of sex discrimination in federally funded programs (Powell \& Graves, 2003). In wake of their 
findings, the federal government passed equal employment opportunity (EEO) legislation including the Equal Pay Act of 1963, which "made it illegal to pay member of one sex less than the other if they are in equivalent jobs" (Powell \& Graves, p. 21). Title VII of the Civil Rights Act of 1964, an EEO law, followed the Equal Pay Act. Title VII prohibited discrimination in the workplace on the basis of sex, race, color, religion, or national origin, but did not apply to educational institutions (Powell \& Graves). Title IX of the Education Amendments of 1972 banned sex discrimination in educational institutions receiving federal funding (Davis, 1999). By 1980, 50\% of bachelor's and master's degrees conferred were to women (Powell \& Graves, 2003). Further, $56 \%$ of women in the labor force had children under the age of 18 (U.S. Department of Labor, 2010).

In the late $20^{\text {th }}$ century, the role of women in U.S. society had changed. No longer were women expected to stay home with the children. Instead, women contributed economically to the household while also attending to domestic responsibilities (e.g., chores, child-rearing; Davis, 1999). In fact, “in 2008, working wives contributed 36 percent of their families' incomes, up by 9 percentage points from 1970, when wives' earnings accounted for 27 percent of their families' total income" (U.S. Bureau of Labor Statistics, 2010, p. 2).

Today, women earn 57\% of the bachelor's degrees (National Center for Education Statistics, 2010) and female Ph.D.s outnumbered men earning Ph.D.s for the first time in U.S. history (Pellegrino, D'Amato, \& Weisberg, 2011). Seventy-two million women (59.2\%) are employed and account for $46.8 \%$ of the U.S. labor force (U.S. Bureau of Labor Statistics, 2009). Nearly $61 \%$ of women with children under age three work 
(Catalyst, $2011 \mathrm{~g}$ ). Women also comprise $51.4 \%$ of managerial and professional staff (U.S. Bureau of Labor Statistics, 2009).

The statistic that women hold the majority $(51.4 \%)$ of managerial positions in the United States is somewhat misleading. The U.S. Bureau of Labor Statistics began counting women involved in all levels of management in the late 1950s (Catalyst, $2011 \mathrm{~b}$ ). In the $1960 \mathrm{~s}$, women held $15.6 \%$ of all "managers and administrators, except farm." In 1980, the definition changed to "managerial and professional specialty occupations." By 2003, occupations were recategorized as "management, professional, and related" (Catalyst). With each new definition, the number of women in "management" positions increased. The redefinition of management "created a complete break in the comparability of datasets” (U.S. Bureau of Labor, 2009) before 2002. Therefore, it is difficult to determine if $51.4 \%$ is an accurate representation of women in managerial positions as the definition appears to inflate the perception of leadership roles women have in the workforce.

\section{Women in Management Positions}

Research on women in executive leadership positions (Kumra \& Vinnicombe, 2010; Richie et al., 1997; Schein, 2001, 2007; Whitmarsh, Brown, Cooper, HawkinsRogers, \& Wentworth, 2007) suggests that women experience fewer opportunities for promotion, receive less compensation than their male counterparts, and may encounter organizational barriers impeding advancement. As such, women have encountered difficulty achieving top levels of management (Dunn-Jensen \& Stroh, 2007).

Women's representation in management positions differs by industry. However, statistics show women are underrepresented in management positions in the medical field 
(Catalyst, 2011e), law (Catalyst, 2011b), academia (Catalyst, 2011d), science and technology (Catalyst, 2011f), and in corporate business structures (Catalyst, 2011c). Of interest in this study is another traditionally male dominated arena - the sport industry.

Studies have shown that the gender diversity of sport organizations are lagging behind (Acosta \& Carpenter, 2010; Lapchick, 2010). For example, the most recent Racial and Gender Report Card (RGRC; Lapchick, 2010) reported that in the last decade (2001-2010), the representation of women in executive management positions declined in five of the six North American professional sport organizations (i.e., NFL, MLB, NHL, NBA, MLS). The WNBA was the only exception reporting an increase of $21 \%$ of women in senior and executive administration. Although the sport industry includes numerous segments such as professional sport, health and fitness, facility management, and event management, which tend to be male dominated, this study focuses on intercollegiate athletics.

\section{Women in Management of College Athletics}

The passage of Title IX in 1972 resulted in the exponential growth of women's participation in interscholastic and intercollegiate athletics. An unintended consequence of Title IX has been the precipitous decline of female coaches and female athletic administrators. In 1972, the percentage of female head coaches of women's teams was nearly 90\% (Acosta \& Carpenter, 2010). Women also served as Athletic Directors for $90 \%$ of women's intercollegiate athletic programs (Acosta \& Carpenter, 2010). Today, women represent only $42.6 \%$ of head coaches for women's teams, while the percentage of female Athletic Directors has fallen to $19.1 \%$-- a decline of $2.2 \%$ since 2008 (Acosta \& Carpenter, 2010). 
Because of this decline, the careers of women in intercollegiate coaching and athletic administration have received attention from sport management scholars. Cunningham (2008) argued women in various sport settings, including intercollegiate athletics, often face hostile, antagonistic, and discriminatory work environments in sport organizations. Women are more likely to be in professional staff or lower managerial positions (Burton et al., 2009; Burton et al., 2011; Whisenant et al., 2002) and may encounter personal and professional barriers to career progression (Claussen \& Lehr, 2002; Grappendorf \& Lough, 2006; Grappendorf et al., 2004; Hoffman, 2010; Inglis et al., 1996, 2000; Knoppers et al., 1991; Knoppers, 1992) because sport organizations are environments where men and men's activities are valued and rewarded (Cunningham, 2008; Knoppers, 1992; Knoppers et al., 1991).

Research on women in intercollegiate athletics has focused primarily on three populations: (a) coaches (Inglis et al., 1996, 2000; Knoppers, 1992; Pastore et al., 1996; Sagas \& Ashley, 2001; Walker \& Bopp, 2011), (b) women who serve in the role of the senior woman administrator (SWA) (Claussen \& Lehr, 2002; Grappendorf et al., 2008; Hoffman, 2010; Sagas \& Cunningham, 2004b; Tiell \& Dixon, 2008), and (c) female Athletic Directors (Grappendorf et al., 2004; Grappendorf \& Lough, 2006: Judd, 1995; Whisenant et al., 2002). These studies have identified barriers and supports to women's career development in intercollegiate athletics including (a) gender and gender role stereotypes (Burton et al., 2009; Burton et al., 2011; Grappendorf et al., 2004; Grappendorf et al., 2008); (b) homologous reproduction (Aicher \& Sagas, 2009; Whisenant et al., 2002), (c) limited skill development (Grappendorf et al., 2008; Hoffman, 2010; Judd, 1995; Quarterman et al., 2006), (d) networking and mentoring 
relationships (Bower, 2008, 2009; Lovett \& Lowry, 1994), and (e) work-life balance and support (Bruening et al., 2008; Bruening \& Dixon, 2007; Dixon \& Bruening, 2007; Sagas \& Cunningham, 2004a). The following section will discuss what is known about the career experiences of women in intercollegiate athletics.

Career patterns and profiles. Previous research in the career patterns and profiles of female athletic administrators has been sparse. Fitzgerald, Sagaria, and Nelson (1994) (1994) attempted to find a normative career trajectory of male $(n=143)$ and female $(\mathrm{n}=57)$ Athletic Directors in NCAA divisions I, II, and III. The most common, or normative, career path began in varsity athletic participation in college, followed by intercollegiate coaching, and culminated in direct advancement from coaching to the position of Athletic Director (Fitzgerald et al., 1994). Considering, however, the number of women in coaching has declined substantially in the last 40 years (Acosta \& Carpenter, 2010), the proportion of women able to follow such a career path is further reduced. In other words, based on the normative path identified by Fitzgerald et al., women lacking access to head coaching opportunities may also have less opportunity to become senior- and executive- level athletic administrators. Furthermore, Fitzgerald et al. only differentiated between the career paths of male and female Athletic Directors at divisional levels, not by gender.

Today, however, intercollegiate athletic departments embrace a business model, which suggests the path from coach to Athletic Director is most likely different now from when Fitzgerald et al. did their work in 1994. Now a business background is more valued than coaching, particularly in Division I. Grappendorf et al. (2004) applied the "normative" career theory to the career patterns of female NCAA Division I Athletic 
Directors. For women in this study, becoming an assistant or associate athletic director was a prerequisite for achieving the position of Athletic Director (Grappendorf et al.) as opposed to coaching (Fitzgerald et al., 1994). Serving athletic departments in senior managerial positions allowed for the acquisition of a skill set (e.g., fundraising and development, budgeting, negotiating contracts) critical for success in a more executive position (Grappendorf et al., 2004).

Gaining relevant, practical experience and education to obtain a skill set necessary for advancement is a common theme in literature pertaining to the careers of women in sport organizations (Bower, 2008; Claussen \& Lehr, 2002; Hums \& Sutton, 1999; Grappendorf et al., 2004; Hoffman, 2010; Greenhill et al., 2009). In a study on career paths and advice for women in the health and fitness industry, Bower (2008) discovered that building human capital - continuing education and gaining experience - were important "first steps" in pursuing an upper-level management position. Smith (2005) and Grappendorf et al. (2004) had similar findings in which female intercollegiate Athletic Directors suggested appropriate academic credentials were critical for obtaining a job in college athletics. Sagas and Cunningham (2004a) found that intercollegiate administrators with extensive educational histories and practical experience had longer occupational tenure than those who did not. Advanced educational degrees were also perceived as a means to job security, particularly in a university environment (Inglis et al., 2000).

In a study of NCAA Division I female Athletic Directors, Grappendorf and Lough (2006) advocated the importance of education, but their findings suggested "an advanced degree or more education is not (emphasis added) an effective tool for women wishing to 
advance in the intercollegiate administration ranks" (p. 13). Instead, female Athletic Directors recommended gaining experience relevant to ascending the ladder to executive positions in intercollegiate athletics (Grappendorf \& Lough, 2006). Relevant experience may include strategic planning, personnel and human resource management, networking (formally and informally), budgeting, and leadership skills (Grappendorf et al., 2004; Knoppers \& Anthonissen, 2007).

In a study of senior woman administrators (SWA), Grappendorf et al. (2008) found SWAs felt excluded from the financial decision making process (Grappendorf et al., 2008). When women are not provided the opportunity to manage finances or be involved in financial decisions, they are limited in their ability to acquire skills necessary for executive levels of management (Grappendorf et al., 2004; Grappendorf et al., 2008; Grappendorf \& Lough, 2006). Moreover, Claussen and Lehr (2002) suggested that "male athletics directors may be operating under the assumptions that women's sports should be the primary concern of SWAs" (p. 225). Placing SWAs on a "women's track" limits their opportunities to work with men's sport and, often, marketing and promotion opportunities associated with men's sport. This also limits the SWAs ability to acquire skills necessary for advancement in the field of intercollegiate athletics (Claussen \& Lehr, 2002).

Gender roles and gender stereotyping. Similar to the literature reviewed on opportunity structures in the previous section, gender is also considered a major barrier to the advancement of women in intercollegiate athletics administration (Burton et al., 2009; Burton et al., 2011; Grappendorf et al., 2004; Whisenant et al., 2002). Burton et al. (2011) used role congruity theory to examine how perceptions of gender relate to 
prejudice against women in intercollegiate athletic administration. A survey was conducted of male and female athletic administrators working as Athletic Directors, senior women administrators, compliance directors, marketing directors, and directors of academic support services at the NCAA Division I level. The survey consisted of six scenarios in which a male or female candidate applied to a position (i.e., Athletic Director, compliance officer, life skills coordinator) within a large FBS college athletic department. Participants evaluated each candidate on a variety of issues related to the administration of intercollegiate athletics. In addition, participants completed a short version of the Bem Sex Role Inventory for each candidate based on information supplied in the scenario.

Results of the study indicated that participants perceived no difference in the potential for success as an Athletic Director, regardless of sex. Women vying for the position of Athletic Director had similar characteristics to male candidates; however, participants were more likely to select a man for the Athletic Director position. Burton et al. (2011) suggested that this finding underscored assumptions about gender-related attributes required for athletic administration positions.

In a similar study, Burton et al. (2009) examined the gender typing of managerial (i.e., Athletic Director, life skills coordinator, compliance director) subroles within intercollegiate athletics. Findings suggested that masculine subroles (i.e., allocating resources, delegating, managing conflict, strategic decision making, and motivating and inspiring, punishing, disciplining, evaluating employees) were considered significantly more important for an Athletic Director than for a compliance coordinator or life skills 
coordinator. Whisenant et al. (2002) also found that women were more likely to hold positions in compliance and life skills than men.

When gender roles are applied to men and women, work environments and positions within an organization can become sex-segregated as evidenced in a study by the NCAA (2010). At the Division I level, men held nearly 92\% of Athletic Director positions (NCAA, 2010), while women accounted for the majority of professional administrators in academic advising (61.6\%), life skills programs $(74.1 \%)$, and coordinators (53.2\%) (Lapchick, 2010). If masculine characteristics are most important for Athletic Directors, women may be at an immediate disadvantage when vying for an Athletic Director position (Grappendorf et al., 2004).

Based on the findings in each of these studies, it may be possible to conclude the application of gender to managerial subroles has resulted in the perception that positions within intercollegiate athletics are gendered. In short, masculine characteristics are perceived to be of importance for the highest level of management in a sport organization (Burton et al., 2009), while feminine characteristics are more strongly associated with life skills and compliance (Whisenant et al., 2002).

Researchers suggested that power is gendered and often favors men in sport organizations (Knoppers \& Anthonissen, 2007; Sartore \& Cunningham, 2006). Status and power are influenced by the behaviors and attitudes of members of a group or society when organized around a dominant social theme (Sartore \& Cunningham). Shared attitudes and behaviors "led to the development of stereotypes, which often perpetuate traditional social arrangements and structures" (p. 247). Sport has played a key role in developing and perpetuating gender stereotypes. 
For example, Grappendorf et al. (2004) found that female Athletic Directors felt they had to contend with the notion that women are not capable of leadership in a traditionally male-dominated domain. Women may be perceived as less competent for high-level administrative positions because of their perceived feminine subroles including planning and organizing, consulting others, recognizing and rewarding, communicating and informing, and offering support (Burton et al., 2009). Conversely, women may not perceive themselves as professionally qualified for high-level management because they do not possess the masculine characteristics perceived as necessary to lead an organization.

The findings by Burton et al. (2009), Burton et al. (2011), Grappendorf et al. (2004), Walker and Bopp (2011), and Whisenant (2002) substantiate Schein's (2001) argument that "if the position is viewed as a 'masculine' one, then, all else being equal, a male candidate appears more qualified by virtue of sex-typing of the position" (p. 676). Therefore, gender stereotyping (or sex-typing) of individuals and/or administrative positions may limit work roles and positions to which women aspire in intercollegiate athletics. These findings are somewhat in juxtaposition to Kanter's (1977) notion that gender differences in an organization are due to organizational structure, not individual characteristics of men and women. Instead, it would appear that gender role socialization influences perceptions of appropriate administrative roles for men and women in intercollegiate athletics. The proportion of men and women in those positions then reinforces those roles.

Gender role stereotypes are related to numerous other career obstacles with which women contend. Gender roles segregate men and women into professional roles - men 
as senior and executive management, women as support or administrative staff (Burton et al., 2009; Whisenant et al., 2002). In support staff roles, women cannot gain the necessary skills such as budgeting and finance, personnel decisions, and strategic planning to advance (Burton et al., 2011; Grappendorf \& Lough, 2006). When women are not present in executive roles, women in lower positions of management lack access to networks and female role models and mentors (Bower, 2009; Inglis et al., 2000). Finally, the lack of female representation in executive levels of management perpetuates the stereotype that women are not capable of or qualified for substantive leadership roles (Burton et al., 2011; Grappendorf et al., 2004). The stereotype that women lack leadership qualifications may also limit their opportunities to advance thus reaffirming intercollegiate athletics as a male-dominated arena.

Hegemonic masculinity and homologous reproduction. Whisenant et al. (2002) used concepts of hegemonic masculinity, success, and gender to explore their relation to the rate of advancement for intercollegiate Athletic Directors. Hegemonic masculinity is the "acceptance of masculinity as the defining characteristic of Western society that places women in lower social positions" (Whisenant et al., 2002). It also aids in homologous reproduction in an organization (Whisenant et al., 2002). Whisenant et al. found that hegemonic masculinity exists in the ranks of intercollegiate athletics. In short, men hold more positions and at higher levels, thus they have more control and power over athletic departments. Such domination results in continued sex segregation in highlevel management positions in intercollegiate athletics (Whisenant et al.). Furthermore, the authors suggested that women who do gain access to Athletic Director positions often 
do so in "lower, less-esteemed, and less powerful positions at Division II and Division III institutions" (p. 489).

In order to break the cycle of hegemonic masculinity in college athletic departments, Whisenant et al. (2002) suggested that women should be recruited to fill internship, first-line, and senior management positions (e.g., assistant and/or associate Athletic Directors), which may "enable female administrators to fill the pipeline of qualified candidates" (p. 489) for consideration at Division I organizations. Accordingly, women will have the opportunity to build networks with other females in similar positions (Aicher \& Sagas, 2009; Stangl \& Kane, 1991; Whisenant et al., 2002).

While the suggestions by Whisenant et al. (2002) to combat hegemonic masculinity and male-dominated homologous reproduction are noteworthy, they are heavily laden with assumptions. First, Whisenant et al. assumed that the higher proportion of women in Athletic Director positions in Division II (D-II) and Division III (D-III) was a result of occupational segregation rather than personal choice. Perhaps the greater presence of women at D-II and D-III levels has more to do with the fact that women perceived administration at these levels to be a better professional fit.

Furthermore, increasing the proportion of women in lower management positions to create a "pipeline of qualified candidates" also assumes that women enter the sport management profession to achieve a senior management position such as Athletic Director or SWA. Finally, while hiring more women to high-level management positions demonstrates equity, it does not necessarily translate into equality (Stangl \& Kane, 1991).

Other studies have also identified homologous reproduction as a barrier to women's career development and progression within the sport industry (Aicher \& Sagas, 
2009; Fitzgerald et al., 1994; Stangl \& Kane, 1991; Whisenant, 2008; Whisenant et al., 2002). Previous sport management literature suggests that opportunity structures within sport organizations limit women's career development and growth (Grappendorf \& Lough, 2006; Grappendorf et al., 2004; Inglis et al., 2000; Knoppers et al., 1991; Knoppers, 1992). However, as more women enter the field of sport management, they have the potential to alter attitudes and opportunity structures within sport organizations. As such, hiring managers may be more likely to support the hiring and advancement of women (McCammon, Campbell, Granberg, \& Mowery, 2001).

Advancement and promotion. Though scholars suggest hiring more women to fill the "pipeline" to executive positions, few if any of these studies have considered what opportunity to achieve executive positions actually exists. Vertical mobility in the administration of intercollegiate and professional sport organizations is limited (Acosta \& Carpenter, 2010; Lapchick, 2009; Sagas \& Ashley, 2001). For example, only $19.3 \%$ of NCAA (D I, II, III) Athletic Directors are female (Acosta \& Carpenter, 2010), which may imply that executive level positions are limited for women or accessible only to men.

The most common organizational structure of an intercollegiate athletic department is composed of one male Athletic Director, one male assistant or associate athletic director, and one female assistant or associate athletic director (Acosta \& Carpenter, 2010). Moreover, female administrators are completely absent in $13.2 \%$ of intercollegiate athletic administrative structures (Acosta \& Carpenter, 2010). In other words, the lower the proportion of women, the more likely it is women may perceive opportunity for promotion and advancement to be limited (Knoppers et al., 1991). Therefore, women interested in pursuing the highest level of intercollegiate 
administration may re-evaluate their career goals and expectations (Astin, 1984; Lent et al, 1994, 2000; Savickas, 2005) because they perceive limited leadership opportunities. Clopton and Sagas (2009) explored the perceptions of gender discrimination on the promotional opportunities of male and female coaches in women's athletics. Clopton and Sagas explored the "glass ceiling" phenomena for which a "person's expectancies may actuate the extent to which he or she perceive participating in the coaching field" (p. 4). In other words, the mere perception of career and promotional limitations may be a predictor for attrition from the profession. Furthermore, career development theories have suggested that glass-ceiling perceptions may also negatively affect a person's decision to pursue a particular field (Betz, 2006; Betz \& Fitzgerald, 1987; Gottfredson, 1996).

Cunningham and Sagas (2003) explored discrimination as it manifests in the work experiences and outcomes of assistant coaches of women's intercollegiate teams. Results indicated that there were no significant differences between the work experiences or turnover intentions of men and women. Cunningham and Sagas suggested two opposing frameworks might explain these findings. First, it is possible that collegiate athletic departments are, in fact, becoming more inclusive to women and people of different races (Cunningham \& Sagas). On the other hand, the "paradox of the contented woman" (i.e., positive work attitudes despite lower salaries, opportunities for advancement, etc.), may explain these findings. The paradox of the contented woman is especially prevalent in male-dominated professions such as university faculty and intercollegiate athletics (Cunningham \& Sagas). 
Studies by Knoppers et al. (1991) and Knoppers and Anthonissen (2007) also found that male coaches and senior-level sport executives were not likely to leave their positions. Lack of movement from senior level positions implies that advancement and promotion may not be a realistic expectation for men or women. The lack of mobility for women in sport organizations, particularly intercollegiate athletics, should not suggest that women do not aspire to high-level positions (Grappendorf \& Lough, 2006), nor should women be perceived as less committed to their work (Cunningham \& Sagas, 2003). Instead, Knoppers et al. (1991) argued that opportunity is gendered in sport organizations. That is, men may be more likely to perceive more opportunity in sport organizations because they are male-dominated in positions of management (Knoppers et al., 1991). Research in sport management has yet to assess how the perception of opportunity affects the career decisions and development of senior-level female managers.

Networking and mentoring. Several sport management researchers have suggested that participation in formal and informal networks and mentoring is integral for advancement within sport organizations, particularly, for women (Bower, 2009; Grappendorf \& Henderson, 2008; Hums \& Sutton, 1999; Judd, 1995; Shaw, 2006). Informal networks and mentoring opportunities can serve as career facilitators for women and women, and may be critical to the career development of women (Bower, 2009).

"Good ol' girls" networks have the potential to be influential if a member has accumulated power in the organization (Lovett \& Lowry, 1994; Shaw, 2006). Shaw, however, found that women's groups could influence hiring practices and organizational 
policy. The exclusionary nature of "good ol' boys clubs" (Lovett \& Lowry, 1994; Stangl \& Kane, 1991; Shaw, 2006) has several consequences for women in sport management. For example, a study on the effect of organizational factors on career pathways of female coaches (Greenhill et al., 2009) found that men were more likely than women to be selected for an interview because their applications met or exceeded the expectations of an organization's administration. Greenhill et al. suggested that male coaches learned what to include on an application through their informal networks with other male coaches and administrators. Limited access (by exclusion or choice) to networks precludes women from gaining important knowledge about current and future organizations (Shaw, 2006).

Greenhill et al. (2009) suggested that more women in senior positions could affect organizational change while also supporting other females in the organization. Similarly, Whisenant et al. (2002) argued that more women in management positions would result in more mentors and role models for women. Additionally, more women in management positions would also mean more women were qualified to move into senior managerial positions.

Moore, Parkhouse, and Konrad (2004) suggested that the under-representation of women in sport organization managerial positions might be improved by increasing the number of women in sport management preparation programs. Women in sport management preparation programs have access to quality training and professional development experiences, which may also increase their skill development an opportunity to earn management positions in sport organizations (Moore et al.). As previously discussed, power can be accumulated through performance-related activities 
and visibility (Kanter, 1977). Women may feel more pressure to prove their abilities through performance (Grappendorf \& Lough, 2006; Grappendorf et al., 2004) or they may choose to embrace more stereotypical roles (e.g., subordination, silence, "housekeeping") in an effort to be less visible. Furthermore, women are more likely to underestimate their abilities and professional strengths. Research has shown that a lack of confidence may be a self-limiting behavior (Sartore, 2006). In other words, women may not pursue career advancement because they do not feel qualified or adequately prepared.

To this point, gender and gender role stereotypes, homologous reproduction and hegemonic masculinity, opportunities for advancement, and lack of access to networking, mentoring, and role models have all been identified as opportunity structures which act as barriers or supports to women pursuing careers in intercollegiate athletics. In career development literature, gender is a personal factor while others (e.g., stereotypes, homologous reproduction, etc) are contextual and, more specifically, structural. Career development theorists (Astin, 1984; Forrest \& Mikolaitis, 1986) contend that the socialrelational component is critical to consider when assessing a woman's career development. The literature on the social-relational component of women's careers in intercollegiate athletics has focused on two primary areas: (a) work-life balance and (b) supervisor support.

Work-life balance. In the last decade, work-life balance has received a great deal of attention in sport management literature (Bruening \& Dixon, 2007; Bruening et al., 2008; Dixon \& Bruening, 2005; Dixon \& Bruening, 2007; Inglis et al., 2000;

Greenhill et al., 2009). Women, in particular, have difficulty balancing work-life culture 
for several reasons. First, the culture of college athletics has been identified as a barrier for career development particularly for women (Bruening \& Dixon, 2008; Greenhill et al., 2009; Inglis et al., 1996, 2000). With long work hours, irregular schedules, travel requirements, and the negotiation of a gendered workplace, women experience conflict between their roles as employees and family members. Work-family conflict, in particular, is a component of work-life balance that has received considerable attention as a barrier for career progress for women coaching (Bruening \& Dixon, 2008; Inglis et al., 1996), intercollegiate administration (Bruening et al., 2008; Inglis et al., 2000), and professional sport management (Hums \& Sutton, 1999).

Dixon and Bruening (2005) defined work-family conflict as "a type of inter-role conflict wherein at least some work and family responsibilities are not compatible and have resultant effects on each domain" (p. 228). In other words, the demands of work negatively affect time with family and time with family has the potential to negatively affect time spent at work. Greenhill et al. (2009) found that time and family commitments were primary issues for female coaches. That is, the demands of coaching negatively affected time spent with family and time spent with family negatively affected their work as coaches.

When time spent with family and friends impacts a female coaches ability to perform duties adequately, she may be perceived as less committed to her work. When women are perceived as less committed to their work, negative stereotypes about women's roles may be reinforced (Eagly, 1987; Beatty, 2007). Reinforcing gender stereotypes in an organization has several ramifications including the perpetuation of hegemonic masculinity, inaccessible networks and mentoring relationships, limited 
opportunities for advancement and skills development, and further reduction of power in an organization.

Bruening and Dixon (2007) used life course theory to explore the gendered relationships in the lives of 17 NCAA Division I coaches who are also mothers. Similar to career construction theory (Savickas, 2002, 2005), life course theory highlights the socio-cultural and organizational elements, which affect individual choices and pathways. In addition, the theory also includes an examination of the individual's response (i.e., conformity, resistance) to socio-cultural and organizational expectations. More specifically, Bruening and Dixon (2008) focused on the manner in which gender shapes life choices, and how those choices affect career decisions and "life trajectories." Participants explained that spouses/partners were supportive of the coaching lifestyle. The continued support of spouses/partners was a "key ingredient in the successful navigation of a coaching career" (Bruening \& Dixon, p. 17) both before and after having children. Not surprisingly, as the coaches assumed the new role of "mother" the work environment and expectations of supervisors began to play an important role in decisions regarding their career paths (Bruening \& Dixon).

Career development literature as it pertains to women suggested a female's relationship with her supervisor may also be a barrier (O’Neil, Hopkins, \& Bilimoria, 2008; Richie et al., 1997; Wentling et al., 1996, 2003; White, 1995; Whitmarsh et al., 2007). Studies by Bruening \& Dixon (2008) and Inglis et al. (2000) found women perceived various levels of support from athletic administrators. Women were "guarded" in their responses about the support of supervisors and administration (Inglis et al., 2000). Rather than discuss their experiences, the women reverted to talking about other aspects 
of the organization they enjoyed (e.g., relationships with students, love of sports, commitment to work).

Supervisor support, however, has also been identified as a support for women in intercollegiate athletics (Sagas \& Cunningham, 2004). For example, women who perceive support from their supervisors are more likely to be satisfied with their careers (Sagas, \& Cunningham, 2004). Career satisfaction results in retention in administration (Inglis et al., 1996, 2000) and coaching (Inglis et al., 1996, 2000; Sagas \& Cunningham, 2004), which also means women will be less likely to exit the profession. With fewer women likely to exit the profession, the proportion of women in administration may increase leading to more role models/mentors, and greater networking opportunities.

In summary, barriers and supports play an influential role in the careers of women in intercollegiate athletics. Gender and gender role stereotypes were identified as important constructs pertaining to female coaches and administrators in intercollegiate athletics (Burton et al., 2009; Burton et al., 2011; Grappendorf et al., 2004; Grappendorf et al., 2008; Grappendorf \& Lough, 2006; Whisenant et al., 2002). In fact, the findings of these studies suggested that gender may be the single most important barrier to women achieving executive levels of management.

Gender and gender role stereotypes contribute to the perpetuation of hegemonic masculinity (Whisenant, 2002) and homologous reproduction (Aicher \& Sagas, 2009; Whisenant, 2002). Hegemonic masculinity and homologous reproduction in intercollegiate athletic administration ensures men hold more positions and at higher managerial levels, thus they have more control and power over athletic departments (Whisenant et al., 2002). Such domination results in continued sex segregation in high- 
level management positions in intercollegiate athletics. When an organizational structure is dominated by men, it may be perceived as discriminatory with few opportunities for women to advancement (Kanter, 1977). In other words, the lower the proportion of women, the more likely it is women may perceive opportunity for promotion and advancement to be limited (Knoppers et al., 1991). Therefore, women interested in pursuing the highest level of intercollegiate administration may re-evaluate their career goals and expectations (Astin, 1984; Lent et al, 1994, 2000; Savickas, 2005) because they perceive limited leadership opportunities.

The underrepresentation of women in executive levels of management (i.e., Athletic Directors) in intercollegiate athletics continues to be of great concern to academics and practitioners (Burton et al., 2008; Grappendorf \& Lough, 2006; Grappendorf et al., 2004). The proportion of women in the "pipeline" for Athletic Director positions is declining. The pipeline refers to senior-level title positions of assistant athletic director and associate athletic director (Grappendorf et al., 2004; Lapchick, 2010). Women holding senior-level positions are perceived to be more likely to achieve an Athletic Director position than women in professional administration (e.g., academic counselor, life skills coordinator, compliance coordinator) because the skill sets (e.g., budgeting, fundraising, supervisory responsibility) associated with senior-level administration are perceived to be more transferable to executive positions (Grappendorf \& Lough, 2006; Grappendorf et al., 2004; Lapchick, 2010).

Previous research in sport has suggested that increasing the proportion of women in the senior management (i.e., assistant and associate athletic directors) "pipeline" would result in more female Athletic Directors (Moore, 2008; Whisenant et al., 2002). For 
example, at the Division I level, women occupied $28.5 \%$ and $31.1 \%$ of assistant and associate athletic directors, respectively (NCAA, 2010). In Division II, 38.1\% of assistant athletic director positions and $42 \%$ of associate director positions were comprised of women. Women held $39.1 \%$ of the assistant athletic director and $46.1 \%$ of associate director positions in Division III. When divisions are combined, women account for $29.8 \%, 40.2 \%$, and $42.6 \%$ of all assistant and associate athletic directors in Divisions I, II, and III respectively (NCAA, 2010). Compared to other professions, it would appear that women are well represented in senior management positions in intercollegiate athletics. However, the proportion of women in medicine and science, engineering, information technology, and business are increasing (Catalyst, 2001g), while NCAA member institutions reported a decline of women in senior administration (NCAA, 2009).

Gatrell and Cooper (2007) contended, "Women who seek careers in management are battling with deeply ingrained traditions and preconceptions about what the role of women...should be" (p. 61). Perhaps women also battle with what they could be. The careers and career development of women received relatively little attention before the 1970's (Farmer, 2006). Theories on career choice and development provide a helpful framework for understanding how "deeply ingrained traditions" and social roles affect women's mobility in the workforce. One way to examine this is through the lens of selected career development theories. Career development theories also provide an interpretive framework for understanding the career experiences of women in intercollegiate athletics. 


\section{Career Choice and Development}

Though vocation guidance programs were established United States in the late 1880 s, career development theories did not emerge until the early $20^{\text {th }}$ century (Brown, 2002). In his initial theory on choosing a vocation, Parsons (1909) introduced three "factors" for aiding young men in selecting an occupation:

(1) a clear understanding of yourself, your aptitudes, abilities, interests, ambitions, resources, limitations, and their causes; (2) a knowledge of the requirements and conditions of success advantages and disadvantages, compensation, opportunities, and prospects in different lines of work; and (3) true reasoning on the relations of these two groups of facts. (p. 5)

Parsons (1909) specifically outlined an interview approach for helping young men determine their interests, abilities, and aptitudes, as well as their general health and family obligations. The interview questions included "What schooling have you had?" (p. 18) "What endurance tests have you undergone?" (p. 17) "How do you spend your money?" (p. 19) and "Is there anyone dependent on your for support?" (p. 19). Based on answers to these and similar questions, Parsons recommended employment in industry sectors such as agriculture, manufacturing, commerce and business, medicine, law, and engineering. While Parson's career development theory did not address women, he offered a list of "women's ways of earning money, at home and away from home" (p. 66). These jobs included gardening, sewing/knitting, baking/cooking, housekeeping, caring for children, teaching, and social work.

Grounded in aptitudes, abilities, and interests, Parson's (1909) theory is an example of a psychologically based "trait-and-factor" career theory, which stemmed from 
the need to "classify people in some meaningful way and place them into occupations in which they could perform satisfactorily" (Brown 2002, p. 4). Vocational counselors administered aptitude tests and developed scales to assess personality, interests, abilities, and values to help individuals, primarily men, identify their appropriate career fit (Hansen, 2005; Rounds \& Armstrong, 2005). The psychological constructs of trait-andfactor theories imply that people are predisposed to certain career types (Johnson \& Mortimer, 2002). Results of these psychologically based tests evolved into what we now know as trait-and-factor theories.

Early trait-and-factor theories were static. They held firm on the notion that intellect, personality, abilities, and interests were inherent and unchangeable (Brown, 2002). Trait-and-factor career development theories are still widely used today understand and evaluate career selection and appropriate career "fit." However, psychologically based theories often fail to include the influence of the work environment on the individual. This may be attributed to the fact that while trait-and-factor theories have dominated the study of career choice and development, they are often studied from a logical positivist perspective (Brown, 2002). Brown summarized the philosophical assumptions of positivists:

- People can be studied separately from their environments; people can be subdivided into categories for study.

- Human behavior can be objectively observed and measured; behavior operates in lawful, linear fashion; cause and effect can be inferred.

- The tradition of the scientific method is the accepted paradigm for identifying facts about human behavior.

- The contexts (environments) in which people operate are considered neutral or relatively unimportant; thus, the focus of inquiry should be observable actions of 
human beings. (p. 12-13)

In 1959, Holland forwarded a theory of vocational personalities in work environments. Holland's theory described "how individuals interact with their environment and how individual and environmental characteristics result in vocational choices and adjustment" (Spokane \& Cruza-Guet, 2005, p. 25). Shortly after the publication of Holland's (1959) theory, Weiss et al. (1967) developed the Theory of Work Adjustment (TWA). TWA, though still considered a psychologically based theory, was designed to measure job fit by assessing (a) an individual's skills and abilities compared to the requirements of the position, and (b) how well the job satisfies the needs (e.g., pay, working conditions) of the employee (Dawis, 2005).

Rather than simply assessing psychological constructs, theories advanced by Holland (1959) and Weiss et al. (1967) were the first to consider the fit between an individual and the work environment. The recognition that a reciprocal relationship exists between the person and the environment was a critical step in the evolution of career development theories (Swanson \& Fouad, 2010). As such, more contemporary trait-and-factor theories are considered "person-environment fit" theories. Personenvironment fit theories are somewhat limited as they tend to characterize career selection and development as a singular event, rather than a developmental process (Swanson \& Fouad). Furthermore, these theories do not adequately address the dynamic cultural and social contexts (e.g., race, gender, education, organizational structure and culture, relationships) that influence personal and professional development.

Sociologists and social psychologists studying career development argue that social contexts and the identities associated with such contexts are likely to significantly 
impact career decisions and trajectories (Astin, 1984; August \& Quintero, 2001; Brown, 2002; Lent et al., 1994). People make sense of the world through social contexts and identities. Therefore, social contexts and variables contributing to the construction of personal and professional identities are important to consider when examining the career development of individuals, especially women (Astin, 1984; Coogan \& Chen, 2007). Sociologically based career development theories operate from the following social constructivist assumptions:

- all aspects of the universe are interconnected; it is impossible to separate figure from ground, subject from object, people from their environments;

- there are no absolutes; thus, human functioning cannot be reduced to laws or principles, and cause and effect cannot be inferred;

- human behavior can only be understood in the context in which it occurs;

- the subjective frame of reference of human beings is the only legitimate source of knowledge. Events occur outside human beings. As individuals understand their environments and participate in these events, they define themselves and their environment. (Brown, 2002, p. 13-14)

The social constructionist view also suggests that while people define themselves and the environment, a reciprocal relationship exists in which the environment shapes the people, as well (Lent et al, 1994, 2000; Savickas, 2002). People and environments continually evolve through interpretation and adaptation, continuity and change. Therefore, an appropriate framework for understanding career development is to explore what Savickas (2002) calls the career life course.

According to Savickas (2002), the "life course" of a career is the "sequence of occupations in the life of an individual" (p. 151). The life course can be observed objectively or subjectively (Lent et al., 1994, 2000). An objective observation of a life course may include job sequences, position titles, and tenures within an organization. 
Objective observation of a career is useful for deriving occupational responsibilities and career patterns (e.g., tenure, mobility), but tells us little about why or how decisions were made to move to a new position, remain with a particular company, or shift to an entirely new career. In short, objective observations do little to elicit the experiences and decision-making processes of individuals within a more subjective social context.

In recent decades, researchers have emphasized a more subjective approach to observing career choice and development (Astin, 1984; Edler \& O'Rand, 1995; Johnson \& Mortimer, 2002; Savickas, 2002). The subjective approach recognizes the influence of individual identities (e.g., gender, race), social roles (e.g., employee, mother), relationships (i.e., collegial, familial, peer), and organizational structures (e.g., opportunity for advancement, hiring practices, formal and informal networks) on career decisions. Two career development theories - career construction theory (Savickas, 2002) and social cognitive career theory (SCCT; Lent et al., 1994, 2000) - were developed to better understand how individual, organizational, and social forces influence a career life course. Thus, career construction theory and SCCT are useful modern career theories for exploring career development.

Several researchers have argued that exploring a woman's career development and decision making is important because it is much more complex than a man's (Betz, 1994; Betz \& Fitzgerald, 1987; Coogan \& Chen, 2007; Farmer, 1976; Forrest \& Mikolaitis, 1986). Women must contend with gendered social and work expectations (Betz \& Fitzgerald). Further, traditional career theories do not adequately address the nuanced experiences of women (Betz \& Fitzgerald; Coogan \& Chen). Therefore, Astin's (1984) sociopsychological model of women's career choice and work behavior is useful 
for exploring the manner in which the integration of women's social and work roles effects career development.

\section{Career Construction Theory}

According to Savickas (2002), career construction theory was designed to answer two questions: "What do people do?" and "Why do they do it?" Career construction theory explores career development from an integrated constructionist and contextualist perspective. The constructivist perspective suggests people construct representations of reality, but not reality itself (Savickas, 2005). The contexualist perspective asserts that adaptation to various environments drives career development (Savickas, 2005). When examining an individual's career, the integration of constructionist and contextual perspectives "focuses attention on the interpretive [emphasis added] processes, social interaction, and negotiation of meaning" (Savickas, 2005, p. 43). In other words, career construction theory was not designed to predict career paths. Instead, it should be used to understand the decisions and choices individuals make based on the implementation of vocational self-concepts in response to perceptions of social realities. As such, career construction theory is predicated on three components - (a) vocational personality, (b) career adaptability, and (c) life themes. Each component was designed to assess and understand the interaction between self-concepts and perceived social realities in the context of career development.

Vocational personality. Vocational personality consists of "an individual's career-related abilities, needs, values, and interests” (Savickas, 2005, p. 47).

Personalities are first formed and reinforced by environments outside of work, including socialization through family, educational opportunities, and relevant identities (e.g., 
gender, race, socio-economic status). In addition, the influence of personal background and perceived opportunity structures has the potential to limit or expand career possibilities (Astin, 1984; Gottfredson, 1996; Savickas, 2005; Sartore, 2006). For example, the United States Bureau of Labor (2009) reports that certain professions (e.g., science, engineering, construction, technology) tend to be male-dominated, while women dominate others (e.g., teaching, nursing). Career theorists attribute the division of labor to gender role socialization in early childhood (Betz \& Fitzgerald, 1987; Gottfredson, 1996).

Career adaptability. Career adaptability "deals with how an individual constructs a career whereas vocational personality deals with what career they construct" (Savickas, 2005, p. 48). Adaptability represents an individual's ability to cope with current and future developmental tasks, career transitions, and personal traumas (Savickas, 2005). Individuals encounter developmental tasks over the course of a career life span. Savicaks (2005) divided the continuum of developmental tasks into five stages - growth, exploration, establishment, management, and disengagement (Savickas, 2002). Growth focuses on the origin of the individual's vocational personality (e.g., family influence, education, abilities). During exploration, an individual must assess the fit between the perceived self and a particular job or occupation. A clear understanding of attitudes, beliefs, and competencies is critical in this dimension because it allows an individual to compare his/her own interest, abilities, and values to those required in new occupations. In this stage, an individual defines his/her vocational self-concept. The vocational self-concept guides "adaptation by negotiating cultural opportunities and constraints" (Savickas, 2002, p. 166). Vocational self-concepts are comprised of the 
interplay among social expectation and occupational interests, perceived skills and abilities, role modeling (by parent, family member, or mentor), real and perceived opportunities to engage in occupational roles, and peer acceptance in occupational roles. Similar to social contexts, vocational self-concepts are dynamic and often change with time, experience, and relative to role expectations.

Establishment represents stabilization in a job and career. During this stage, an individual seeks to implement a vocational self-concept. During establishment, the vocational self-concept becomes more congruent with the requirements of the social and vocational worlds. As the social and work worlds become more parallel, a person may seek more opportunities (e.g., greater responsibilities, advancement, better personenvironment fit) within his/her organization or in another organization. Toward the end of the establishment stage, an individual may begin to contemplate the "next steps" in his/her career. According to Savickas (2002), "Individuals reach a point where taking care of what they have established, that is, maintaining, becomes more important than advancing in new directions" (p. 179).

During the management stage, an individual may ask him/herself, "Is this the career I want to pursue for the next 25 years?" It is at this stage that occupational responsibilities and the vocational self-concept are re-evaluated. Savickas (2002) describes this process as "re-finding, not refining, the self" (p. 179). Should a person choose a new organization or occupation, she must again cycle through exploration and establishment stages. However, if the choice is to remain in the current position, the vocational self-concept is managed through a process of holding, updating, or innovating (Savickas, 2002). 
Holding consists of meeting the challenges of the changing work force (e.g., other employees, technology) and family demands (e.g, child care, education expenses) while in the latter stages of a career. The expectation of employers is that a person in a holding pattern will continue to perform the same tasks with the same level of competency and commitment. Updating necessitates more energy than holding because this stage of management requires job tasks to be performed at a higher level. Therefore, the individual must strive to stay up-to-date on new technologies and trends in his/her particular career field. Finally, the innovating stage of management means "breaking new ground by doing tasks differently, doing different tasks, or discovering new challenges" (Savickas, 2002, p. 180). Innovation may lead to the construction of a new career path or advancement within an organization, both of which would require recycling through the exploration and establishment stages.

However, as a person nears the end of his/her current job or career, s/he begins to consider life after a work. This process is known as disengagement. 'Disengagement (ages 65 and older) involves decelerating, retirement planning, and retirement living. During this stage, the vocational self-concept is refocused. Rather than thinking about career prospects (e.g., growth, exploration, establishment), an individual reflects on the career path in retrospect. The individual concentrates on the challenges of implementing a new life that does not include vocational responsibilities.

Stages encompass the career life span, but may also be applied to individual jobs within a career (Savickas, 2005). In other words, a person in the "establishment" stage of his/her career life course, may be in the "disengagement" stage of his/her current job. 
The individual is in the process of disengagement because he/se is ready to grow and explore new occupational interests.

Within the five career life stages, are four sequential dimensions of career adaptability (Figure 1) - concern, control, curiosity, and confidence (Savickas, 2005). Adaptive individuals are conceptualized as:

1) Becoming concerned about their future as a worker.

2) Increasing personal control over their vocational future.

3) Displaying curiosity by exploring possible selves and future scenarios.

4) Strengthening the confidence to pursue their aspirations (Savickas, 2005, p. $52)$.

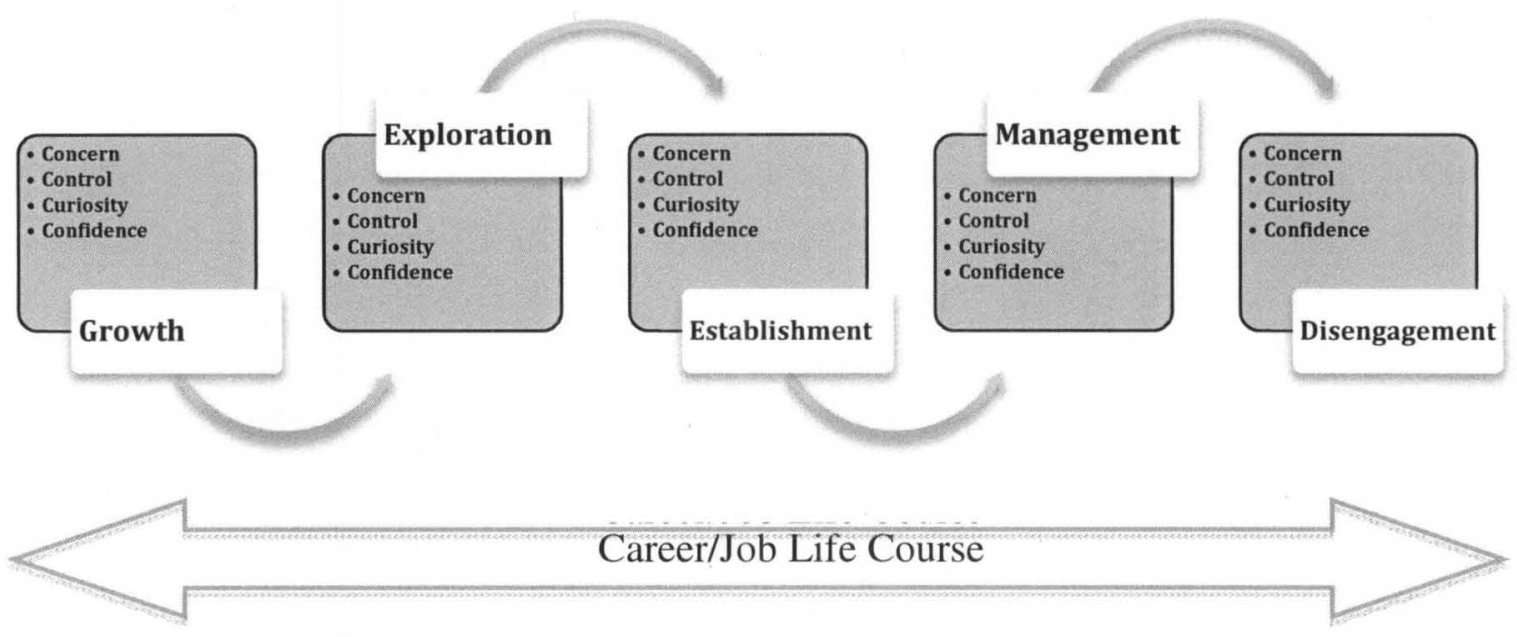

Figure 1. Dimensions of career adaptability within stages of the career/job life course. Adapted from Savickas, 2005.

Career concern is a period of time in which an individual considers his/her future career opportunities. It is time during which a person reflects on past and current career experiences, as well as how those experiences might translate into a more successful 
future. Control is the next important dimension of career adaptability because it suggests that the person is, in fact, responsible for constructing a career. In this dimension, a person must assess his/her level of skill and professional responsibility, effort, determination, and opportunities in the labor market relative to career interests and abilities. Career curiosity is the exploration of the fit between the perceived self and work world. A clear understanding of attitudes, beliefs, and competencies is critical in this dimension, allowing an individual to compare his/her own interests, abilities, and values to those required in new occupations. Finally, confidence "denotes feelings of self-efficacy concerning the individual's ability to successfully execute a course of action needed to make and implement suitable educational and vocational choices" (Savickas, 2005, p. 56). However, personal (e.g., gender) and contextual (e.g., career experiences, professional development opportunities) factors have the potential to either limit or enhance confidence. Because each person experiences and perceives personal and contextual variables differently, career choices and development will vary accordingly.

Similar to the five career stages, the sequential dimensions of concern, control, curiosity, and confidence may occur multiple times over the life course of a career. In addition, the dimensions of career adaptability illustrate the progression of a career decision-making process; however, they do little to address why adaptability is necessary. Therefore, exploring life themes - at work and in personal life - allows the researcher to understand the reasons behind career choices and, ultimately, the adjustment to new roles and responsibilities.

Life themes. Life themes influence individuals to make meaningful choices about work roles (Savickas, 2005). Themes matter in the career life course because life 
themes give people a meaning and purpose to work (Savickas, 2005). Eccles (1994) advised, "Occupational choices are not made in isolation of other life choices, such as the decision to marry and have children, and the decision to balance one's occupation behaviors with one's other life roles..." (p. 605). Therefore, uncovering the meaning of factors (i.e., developmental tasks, job transitions, and personal traumas) influencing career development has the potential to reveal why people make certain career decisions (Savickas, 2005).

Career construction theory offers a framework for interpreting the career life course through the integration of vocational personality, career adaptability, and life themes. It is unclear, however, how vocational personality, adaptability, and life themes affect an individual's career expectations and career goals. Social Cognitive Career Theory (SCCT; Lent et al., 1994) attempts to explain the "dynamic processes and mechanisms through which (a) career and academic interests develop, (b) career related choices are forged and enacted, and (c) performance outcomes are achieved" (p. 80).

\section{Social Cognitive Career Theory}

Similar to career construction theory (Savickas, 2005), social cognitive career theory (SCCT) considers the individual as an active participant in the construction of his/ her career (Lent et al, 1994). Moreover, SCCT recognizes personal characteristics, contextual factors, and behavior (Bandura, 1986) as interconnected mechanisms contributing to the career decision-making process. Lent et al. (1994) identified three social cognitive constructions - (a) self-efficacy beliefs, (b) outcome expectations, and (c) career-related goals - as central to understanding the career development. 
According to Bandura (1986), self-efficacy refers to the manner in which people assess their abilities to carry out specific courses of action to achieve a performance level or goal. Self-efficacy helps people make decisions about situations in the contexts of particular environments. Researchers also suggest that self-efficacy determines responses to personal and professional obstacles (Bandura, 1986; Lent et al., 1994, 2000). Several studies suggested self-efficacy as a predictive element to career related choices (Lindley, 2005; Cunningham, Bruening, Sartore, Sagas, \& Fink, 2005; Stringer \& Kerpelman, 2010) and as a mediator in the perception of career barriers (Byars-Winston \& Fouad, 2008; Cunningham, Doherty, \& Gregg, 2007; Lyons, Brenner, \& Lipman, 2010).

Outcome expectations are personal beliefs about anticipated consequences of particular behaviors (Lent et al., 1994). As a result, expectations are often predicated on assessments of self-efficacy. For example, Cunningham et al. (2005) employed social cognitive career theory (SCCT) to explore student intentions to enter the sport and leisure industry. The study was designed to measure basic tenets of SCCT including selfefficacy, outcome expectations, and occupational choice goals (e.g., vocational interests, barriers, supports). Participants in the study were 197 students enrolled in sport and leisure courses at four universities around the United States.

Results indicated that self-efficacy and positive outcome expectations were related (Cunningham et al., 2005). That is, students with high perceptions of selfefficacy also had higher and more positive ideas about their future careers. In addition, self-efficacy and positive outcome expectations were positively related to choice goals and vocational interests; vocational interests were also positively associated with choice goals. Not surprisingly, barriers held negative correlations with career goals, vocational 
interests, and self-efficacy (Cunningham et al., 2005). Women rated discrimination and lack of advancement opportunities higher than men did. Ethnic minorities rated discrimination higher than Caucasians. Due to the perception of such barriers, women and racial/ethnic minorities were less likely to pursue careers in the sport and leisure industry (Cunningham et al.). Career barriers and supports play an important role in a person's intention to pursue a career in the sport and leisure industry (Cunningham et al.). Negative perceptions may cause a person - particularly a woman or ethnic minority - to prematurely lose interest in the profession.

Finally, goals aid in the organization of behavior (e.g., career plans, decisions) and the likelihood that desired career outcomes will be achieved (Lent et al., 1994). The formation of goals also helps people maintain performance over an extended period of time. Perceptions of self-efficacy and outcome expectations provide not only a bridge for understanding past and future behavior, but also an understanding of how and why career goals are formed. Therefore, individuals have the ability to proactively construct their environment based on their self-efficacy, outcome expectations, and career goals. However, Lent et al. (1994) contended that personal and contextual variables influence each of the three social cognitive constructs.

In SCCT, personal variables include gender and gender role construction, education, career interests and values, and socialization (e.g., parents, peers). Contextual variables (perceived barriers and supports within a given environment) (Lent et al., 1994) should be considered when evaluating a career decision in a given situation. As previously discussed, contextual barriers and supports - real or perceived -may include structural (e.g., opportunities for advancement and promotion, discriminatory hiring 
practices, organizational policies inhibiting work/life balance) or social relational determinants (e.g., relationships with supervisors, colleagues, family and friends; informal networks). In SCCT, contextual factors shape learning experiences and comprise the opportunity structures in which career interests are borne, developed, and implemented (Lent et al., 1994).

Cunningham et al. (2007) employed social cognitive career theory (SCCT) to examine the influence of gender on head coaching intentions among assistant coaches of women's college teams. The study measured basic tenets of SCCT including selfefficacy, career expectations, and career goals. Findings indicated variation in SCCT variables by sex demonstrated a significant multivariate effect. Subsequent analysis revealed significant differences between male and female assistant coaches in career goals, vocational interests, self-efficacy, and positive career expectations. Men had higher vocational interests and career goals when compared to women. In addition, male coaches expressed greater levels of self-efficacy and perceived more positive outcome expectations for their careers than female coaches did. The finding that there were no differences between men and women in perceived barriers and/or supports, however should not suggest that barriers and supports did not exist for coaches in the study.

Gender differences in career goals, vocational interests, self-efficacy, and positive career expectations is an important finding because it implicates gender as an important factor in career development. However, more research is needed to identify how and why gender affects coaching intentions. More broadly, SCCT can also be used as a framework for understanding self-efficacy, outcome expectations, and career goals for female administrators. As such, the present study will use SCCT as a framework for 
examining the negotiation of and adaptation to barriers and supports in women's career choice and development in sport management.

Lent et al. (2000) added coping efficacy as a critical component to SCCT. According to the amended theory, when confronted with difficult contextual situations, individuals "with a strong sense of coping self-efficacy (i.e., beliefs regarding one's capabilities to negotiate particular environmental obstacles) are more likely to persevere toward their goals" (p. 46). Coping efficacy is closely related to Savickas' (2002) concept of career adaptability with one important difference. Coping efficacy implies forward progress toward professional goals, while adaption suggests more of a compromise to circumstance.

When men and women encounter barriers in the life course of their careers, they employ coping strategies to adjust and adapt to new and different circumstances (Lent et al., 2000). Coping strategies are designed to reduce the perception of conflict between the individual and the structure in question (e.g., work, family, organizational policies; Lent et al., 2000; Savickas, 2002). The literature on career development suggested that individuals encounter barriers internal and external to an organization (Astin, 1984; Betz \& Fitzgerald, 1987; Lent et al., 1994). Internal coping strategies deal with barriers encountered within an organization including discrimination, harassment, lower salaries, biased hiring practices, and lack of access to networks (Beatty, 2007; Gatrell \& Cooper, 2007). External coping strategies are exercised when people encounter barriers to their careers as they exist outside of the workplace such as marriage, family, or economic difficulty (Burke, 2007; Hopkins \& O'Neil, 2007). Many individuals encounter internal 
and external barriers simultaneously. Women, in particular, may develop coping strategies to negotiate personal and contextual factors unique to their gender.

Hite and McDonald (2003) broadly stated that women adjust career aspirations and goals due to life circumstance. Wentling (1996) was more specific in her results, which found women lowered their career aspirations for several reasons including relocation of spouse, responsibilities to family, company reorganization, the glass ceiling, burnout, and lack of company commitment to professional advancement. On the other hand, promotion, perception of more opportunity in a new company, and more on-the-job time commitment tended to increase a woman's aspiration to higher levels of management (Hopkins \& O’Neil, 2007; Wentling, 2003). For women interested in seeking positions in senior management, their coping strategies included continued education, demonstrated competency on the job, networking with top-level managers, and experience in other functions of the company (Wentling, 2003).

While career construction theory and SCCT do not specifically address women's career development, Lent et al. (1994) suggested focusing on gender because its social construction has "profound psychological and social significance" (p. 104) on career interests, choices, and development. As career development research and theory has evolved, women's career development has been found to be much more complex than men because women encounter issues not ordinarily faced by men as women balance family, social, and work expectations (Astin, 1984; Betz \& Fitzgerald, 1987; Coogan \& Chen, 2007; Farmer, 1976; Gottfredson, 1996; Richie et al., 1997). 


\section{Women's Career Choice and Development}

Initial career development theories were grounded in the psychological constructs and social experiences of White men (Holland, 1959; Dawes, 1964; Parsons, 1909). In the 1960s and 1970s, psychologists began to study the career development of women to gain a better understanding of the intersection between career and family orientations. Similar to career research conducted on men, initial studies on women focused on psychological characteristics (e.g., personality, intellect, motivation) and occupational "fit" (Psathas, 1968), but did not address what, how, or why social contexts affected the career orientation of women. Furthermore, career development studies attributed differences in occupational choices to differences in gender and the construction of selfconcept (Richardson, 1975), but did not address how or why the differences existed.

One of the first theories (Psathas, 1968) for women's career development proposed the importance of understanding the relationship between a women's occupational role and sex role. The theory was designed to predict how marriage and the husband's perspective on work affected a woman's career development. Psathas' recognized that a woman's career growth could be affected as she balanced the roles of wife, mother, and employee. Betz and Fitzgerald (1987) also identified marital/family status, sex role attitudes, and role conflict (e.g., balancing responsibilities as mother, wife, and employee) as "major variables uniquely pertinent to women's career choices and pursuits" (p. 25). Farmer (1976) explored factors inhibiting women's career achievement and motivation. Astin's (1984) landmark model of women's career choice and work behavior comprised in four major principles: 
(1) Work behavior is motivated activity intended to satisfy three basic needs: survival, pleasure, and contribution.

(2) Career choices are based on expectations concerning the accessibility of alternative forms of work and their relative capacity to satisfy the three basic needs.

(3) Expectations are shaped in part by early socialization through family, childhood play, school experiences, and early work experiences, and in part by perceived structure of opportunity.

(4) Expectations developed through socialization and through early perceptions of the structure of opportunity can be modified by changes in the structure of opportunity and this modification in expectation can lead to changes in career choice and work behavior. (p. 119)

The fundamental premise of the model suggested that early socialization experiences in the workplace and perceived opportunity structures affect the oftendivergent career choices and experiences of men and women. Astin (1984) argued that opportunity structures including sex-typing of jobs and occupational sex segregation, discrimination, organizational policies, work benefits (e.g., salary, time requirements, schedule flexibility), and job requirements were also variables affecting women's career construction and development. A focus on the interplay between opportunity structures and individual factors as career barriers and facilitators was a unique addition to exploring women's career development.

Social cognitive career theory (Lent et al., 1994, 2000), career construction theory (Savickas, 2002, 2005), and Astin's (1984) model of women's career development suggest an intricate relationship among personal and contextual factors which influence career experiences, expectations, and goals (Albert \& Luzzo, 1999). Personal and contextual factors comprise a "perceived opportunity structure within which career plans are developed and implemented" (Albert \& Luzzo). The manner in which personal and 
contextual factors influence an individual's career experience rests in how a person perceives and responds to such factors (Astin, 1984; Lent et al., 1994, 2000). When a person responds to factors, the response implies individual agency - "the capacity that each person has to anticipate and shape outcomes and to plan actions" (August \& Quintero, 2001). In other words, the individual has a choice in how opportunity structures affect career expectations and goals. The following section reviews opportunity structures and their influence on career development.

\section{Career Barriers and Supports}

According to Kanter (1977), opportunity refers to an individual's career "expectations and future prospects" (p. 246). Opportunity structures, then, contain personal and contextual variables that enhance or impede career development, expectations, and goals (Astin, 1984; Kanter, 1977; Lent et al., 1994; Roberts, 2009). Career development literature (Albert \& Luzzo, 1999; Astin, 1984; Betz \& Fitzgerald, 1987; Lent et al., 1994; Savickas, 2002), refers to personal and contextual factors as “career barriers" (i.e., factors that impede career development) and "career supports" (i.e. factors that enhance career development), or "obstacles" and "facilitators" (Andrew et al., 1990). For the purposes of this study, the terms "barriers" and "supports" will be used to capture factors perceived to influence career choice, expectations, and goals.

Barriers and supports are real features of an industry or an organizational environment, but they are also subjective perceptions defined by an individual's lived experience (Albert \& Luzzo, 1999; August \& Quintero, 2001; Astin, 1984; Kanter, 1977; Lent et al., 1994). In other words, the mere perception of a barrier can affect the career decision-making process (Albert \& Luzzo, 1999; Lent et al., 1994). It is important to 
identify the manner in which individuals perceive opportunity structures, as well as how people negotiate structures perceived as barriers or supports to career development. As suggested in SCCT (Lent et al., 1994), Astin's (1984) model of career choice and work behavior, and career construction theory (Savickas, 2002), identifying opportunity structures is helpful in understanding how the perception of personal (i.e., individual) and contextual (i.e., structure, social) factors influence women's career development.

Personal factors. Personal factors include a range of "intrapersonal influences on career development" (Patton \& McMahon, 2006, p. 153). Studies on personal factors in career development emphasize gender role socialization (Betz \& Fitzgerald, 1987; Eagly, 1987; Gottfredson, 1996), personality (Betz \& Fitzgerald, 1987; Richie et al., 1997; Wentling, 2003; White, 1995), the acquisition and development of human capital (i.e., education, formal skills/abilities, job tenure; Burke, 2007; Knoppers, 1992), and self-efficacy (Betz, 2004; Lent et al., 1994). The following section identifies and discusses personal factors as barriers and supports to career development.

Gender. A major barrier to women's career development, particularly within male-dominated professions, is the perception of gender, gender role socialization, and the gender stereotyping of managerial positions (Beatty, 2007; Betz \& Fitzgerald, 1987; Duehr \& Bono, 2006; Schein, 2001, 2007; Wentling, 1996, 2003). Gender and gender role socialization are personal factors (Albert \& Luzzo, 1999; Astin, 1984). Gender stereotypes are contextual and will be discussed later in this chapter.

Gender is the "social construction of roles, attributes, and behaviors that a society considers appropriate for men and women" (World Health Organization, 2011, para. 1). Gender roles are shared beliefs about the attributes of men and women (Eagly, 1987). 
For example, women possess (or are expected to possess) communal characteristics such as nurturance, kindness, submissiveness, expression/ emotion, and compassion (Beatty, 2007; Eagly, 1987). Men, on the other hand, are more agentic - assertive, dominant, aggressive, instrumental, and independent. Society views women as more involved in the private domain (e.g., home, family), while men represent a more public sphere (e.g., work; Beatty, 2007).

Gender role socialization contributes to "gendered patterns of educational and occupational choices" (Eccles, 1994, p. 586). Further, the gender expectations a society has for men and women not only influence an individual's perception of self, but also the perception of the appropriate professional career path (Beatty, 2007; Eccles, 1994; Schein, 2001). Multiple career development theorists (Astin, 1984; Eccles, 1994; Ely, 1995; Farmer, 1976; Lent, et al, 2004; Savickas, 2002, 2005) echo the influence of gender roles socialization on career selection and development because such socialization transcends childhood and adolescence into adulthood. Ely (1995) suggested exploring gender "as an ongoing social construction, the meaning, the significance, and consequences of which vary for individuals across settings" (p. 590).

Eccles (1994) suggested that both men and women have assimilated to culturally defined gender roles, which may unintentionally limit career choices. For example, agentic characteristics have been associated with management because men have long filled such leadership roles in an organization (Betz, 2006). Though many organizations strive to be gender neutral, "the underlying culture and ideology gives preference to [agentic characteristics] and public sides and symbolically to men's ways of being" (Beatty, 2007, p. 40). Managerial positions, then, become stereotyped as male domains; 
therefore, women may perceive they cannot or should not attempt to obtain management positions.

Finally, Eccles (1994) posited, “understanding women's occupational choices requires a broad view of the options and roles available to women" (p. 605). The educational and occupational choices made by men and women are not done in isolation (Eccles). Gender role socialization, cultural expectations, and individual interests influence the decision-making process. Likewise, gender roles affect core personal values, long-term goals and aspirations, and an individual's self-efficacy (Astin, 1984; Betz \& Fitzgerald, 1987; Eccles, 1994; Gottfredson, 1996; Beatty, 2007). Women in male-dominated professions may face discrimination, harassment, or disapproval from peers.

Personality characteristics. While the focus of this study is not to measure personality characteristics, the derivation of personality characteristics by women in management positions is important. For example, Richie et al. (1997) conducted a qualitative study of the career development of high achieving African American-Black and White women in various industries. Women in this study described strength and perseverance, internal standards and judgment, passion for their work, and a relation to others as personality attributes critical to their ascent to high-level managerial positions in male-dominated professions. Similarly, White (1995) found commitment and dedication were important for female executive managers in male-dominated professions. In a study on women in middle management positions, Wentling $(1996,2003)$ identified work ethic, self-confidence, and a "willingness to try new things" as important personality characteristics for women in management. 
Career locus has also been identified as another personality characteristic that may inhibit or promote career development in women (O'Neil et al., 2004). Internal career locus is "reflected in a belief that one is responsible for one's own career success and in charge of managing one's future career" (O'Neil et al., p. 478). An external career locus suggests that career success is due to chance (O'Neil et al.) such as connection to a network or "being in the right place at the right time." O'Neil and Bilimoria (2005) discovered women's career loci changes over time which may explain why, despite describing themselves as "driven" and "committed" or touting work ethic and competence as strengths, studies of women in executive management positions attributed success to external factors (Andrew et al., 1990; Corby \& Stanworth, 2009; O'Neil et al., 2004; Richie et al., 1997).

For example, in a study of women in senior management Corby and Stanworth (2009) found that many women in the study felt as though they had "fallen" into their jobs because many of the women had obtained the positions through informal, word-ofmouth networks. For organizations in business and industry, word-of-mouth is a common recruitment tool. Additionally, the women who advanced to higher levels of management explained that their advancement was the result of "being picked" by a man (Corby \& Stanworth). In short, the women in this study felt as though their employment and subsequent promotion was due to "being in the right place at the right time" rather than professional skill and competence.

Women's behavior in an organization can be attributed to personal factors including gender, gender role socialization, and personality. Researchers (Bandura, 
1986; Betz, 2004; Lent et al., 1994) also suggest self-efficacy determines responses to personal and professional obstacles.

Self-efficacy. Self-efficacy is an important factor in career related decisions because self-efficacy helps people make decisions about situations in the context of a particular environment (Lent et al., 1994; Savickas, 2002). Four sources of information determine and influence self-efficacy: (a) personal performance accomplishments, (b) vicarious learning, (c) social persuasion, and (d) physiological states (Betz, 2004; Lent et al., 1994). Additionally, behavioral consequences of perceived self-efficacy are (a) approach versus avoidance behavior, (b) quality of performance behaviors in a target domain (e.g., job or specific task), and (c) persistence in the face of obstacles or disconfirming experiences (Betz, 2004).

Repeated, successful completion of a task in various conditions enhances an individual's perception of ability on a given task thus reinforcing stronger notions of selfefficacy and the likelihood a person will attempt the task in the future (Bandura, 1986; Betz, 2004; Lent et al., 1994). Conversely, perceptions of low self-efficacy in a given task or job may result in avoidance behaviors (Betz, 2004). Avoidance behaviors can influence career decisions and aspirations ultimately affecting career goals (Betz). Therefore, education and training are critical components to increasing the likelihood of personal accomplishment (Ancis \& Phillips, 1996) and self-efficacy (Betz, 2004).

Education and training have been deemed vitally important to women seeking or already in management positions because these two elements provide the opportunity to develop skills and professional competencies (Corby \& Stanworth, 2009; Wentling, 2003). For example, in a study of the career aspirations of women in middle 
management positions, Wentling $(1996,2003)$ found that women felt they needed additional training in communication, leadership, and negotiation skills; strategic planning; and, financial management. Skills and job competencies are critically important to career development, expectations, and goals (Richie et al., 1997; Wentling, 1996, 2003; Whitmarsh et al., 2007). When women engage in education and training, they develop skills and competencies which may increase performance quality, selfefficacy, and the likelihood women will persist in the face of obstacles (Betz, 2004; Wentling, 2003).

Vicarious learning occurs through observation of other people, while social persuasion is used to encourage people to attempt or continue a particular course of action (Betz, 2004; Lent et al., 1994). For example, research has suggested that exposure to early career experiences gives men and women important information about careers, which they can use to make future career decisions (Lapour \& Heppner, 2009; Stringer \& Kerpelman, 2010). Exposure refers to the "experiences and observations in regards to occupational information as well as values" (Lapour \& Heppner, 2009, p. 485). Shadowing, internships, professional training opportunities, and volunteer experiences have been shown to positively influence career interests, expectations, and goals (Cunningham et al., 2005; Miller, 1998; Richie et al., 1997).

Finally, physiological states may inform perceptions of self-efficacy (Lent et al., 1994). For example, a person who experiences anxiety while speaking to a large group of colleagues may attribute the physiological response to a lack of confidence in public speaking. The next time the person speaks to a large group, feelings of anxiety return and feelings of self-efficacy decrease. While vicarious learning, social persuasion, and 
physiological responses contribute to self-efficacy, personal accomplishments are considered the most influential sources of self-efficacy (Lent et al., 1994). According to Betz (2004), "the effects of self-efficacy on persistence are essential for long-term pursuit of one's goals in the face of obstacles, occasional failures, and dissuading messages from the environment" (p. 342). Eccles (1994) also suggested achievement-related decisions (e.g., seeking advancement in an organization) have immediate and long-term psychological and social consequences. Understanding the role of self-efficacy in career choices is important because it underscores the complex social realities between an individual and his/her contextual environment.

Contextual factors. Contextual factors are perceived barriers and supports within a given environment (Astin, 1984; Kanter, 1977; Lent et al., 1994). Contextual factors are influenced by personal behavioral actions and consequences resulting in a “dynamic, constantly evolving person environment interaction" (Richie et al., 1997, p. 137). Real or perceived contextual factors are comprised of structural (e.g., gender role stereotyping, opportunity for promotion and advancement, discriminatory hiring practices, organizational policies inhibiting work/life balance) and social determinants (e.g., networking, mentoring/role modeling, work-life balance; Astin, 1984; Kanter, 1977; Lent et al., 1994). Structural and social-relational determinants may influence selfefficacy, outcome expectations, and career goals (Lent et al., 1994). In the following section, structural and social determinants are discussed separately. It is important, however, to consider the contextual factors as related given their perceived influence on personal factors, outcome expectations, and goals. 
Structural. Structural factors within an organizational context include gender role stereotypes, discriminatory hiring practices, opportunity for promotion and advancement, and the accumulation of power. In the previous section, gender was identified as a barrier to women seeking executive level managerial positions (Beatty, 2007; Betz \& Fitzgerald, 1987; Duehr \& Bono, 2006; Schein, 2001, 2007; Wentling, 1996, 2003). While gender and gender roles are personal factors, research suggests gender role stereotypes are structural (Astin, 1984; August \& Quintero, 2001; Lent et al., 1994). Understanding the function of gender role stereotypes (Figure 2) in the context of an organization is important because gender defines perception of, meaning of, and response to barriers and supports.

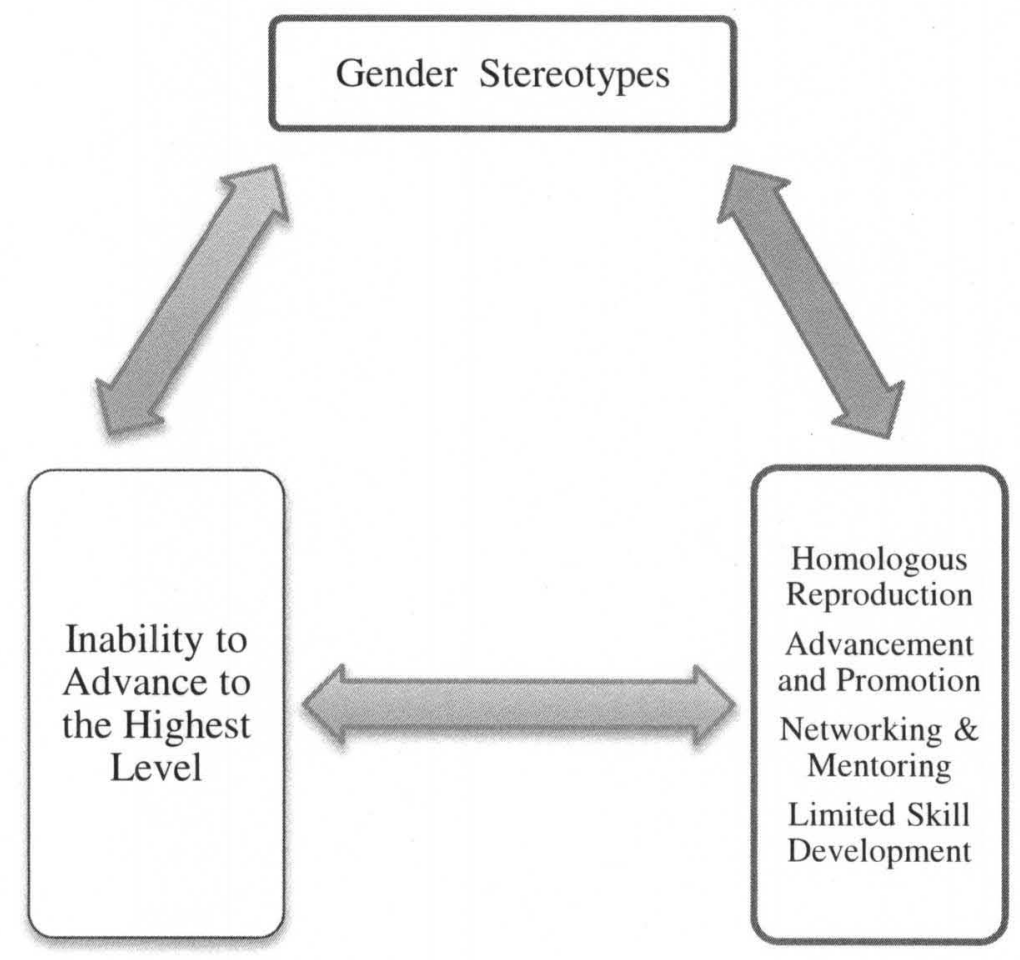

Figure 2. Effects of gender roles and gender role stereotypes on the advancement of female intercollegiate athletic administrators. 
Gender stereotypes incorporate beliefs and perceptions about status, power, attitudes, and behaviors (Schein, 2001, 2007). Stereotypes reinforce traditional social roles, which perpetuate perceptions of power and status (Correll, 2004). According to Schein (2007), "Gender stereotyping of the managerial position fosters bias against women in managerial selection, placement, promotion, and training decisions" (p. 7). Therefore, upholding beliefs and perceptions about certain groups of people helps maintain dominant power structures, which serve to inform men and women about their own sense of self (Correll, 2004).

Opportunity refers to an individual's career "expectations and future prospects" (Kanter, 1977, p. 246). It is synonymous with vertical mobility in an organization and the benefits accompanying professional advancement such as higher salary, status, and access to resources (Kanter, 1977). The perception of opportunity in an organization has been shown to increase career aspirations, work commitment, job satisfaction, and feelings of responsibility for the organization (Astin, 1984; Corby \& Stanworth, 2009; Kanter, 1977; Wentling, 1996, 2003). Conversely, the perception of limited opportunities has the potential to negatively influence career aspirations, commitment, and responsibility to the organization (Astin, 1984; Kanter, 1977; Wentling, 1996, 2003). Wentling (2003), however, discovered that despite the perception of limited advancement opportunities, women still aspired to top-level management positions. Why, then, are women underrepresented in top-level managerial positions?

In a male-dominated organizational structure, men perceive higher levels of opportunity and possess much of the power because of their majority representation in senior management positions (Beatty, 2007; Kanter, 1977). As such male managers 
"guard power and privilege for those who fit in, for those who they see as their kind" (Kanter, p. 48). That is, managers are more likely to hire and share power with individuals they perceive as similar to themselves (Beatty, 2007; Davey, 2008; Kanter, 1977). This process, known as homologous reproduction, is the product of opportunity, power, and proportion (Kanter, 1977). The repercussions of homologous reproduction in a male-dominated environment may include: lower proportions of women in management positions, fewer female role models, the perpetuation of gender stereotypes, and occupational sex segregation. Duehr and Bono (2006) acknowledged gender stereotypes as a "subtle yet powerful" barrier to women's professional advancement. The application of gender role stereotypes may result in occupational sex segregation based on perceived of characteristics of gender (Betz, 2006).

Occupational sex segregation is an organizational process that slows the career development of women (Maume, 1999). Bielby and Baron (1986) suggested, “sex segregation is built into the hierarchy of organizational positions and is sustained by sex stereotypes and work-place social relations" (p. 761). Furthermore, it prevents women from accumulating social capital - skills, networks, and organizational knowledge - and stifles professional growth. Kanter (1977) argued that when women do not have access to informal networks, which offer organization-specific knowledge, women's chances of promotion decrease. In male-dominated professions, women often occupy lower positions in the organizational hierarchy (e.g., support staff, low-level managers; Beatty, 2007; Kanter, 1977), which may preclude them from gaining the skills necessary for advancement. Furthermore, women are not present at the level of strategic planning they are not in a position to discuss issues such as resource allocation, gender equity, or 
organizational policies that may directly affect their position as women in the organization (Burke, 2007; Gatrell \& Cooper, 2007; Gregory, 2009).

When women are not represented in top managerial positions in an organization, they are limited in the amount of power they can accumulate (Kanter, 1977). Kanter defined power as the ability to access the resources necessary to complete tasks and meet organizational and professional goals. Status and power are influenced by the behaviors and attitudes of members of a group or society organized around a dominant social theme (Sartore \& Cunningham, 2007). Sartore and Cunningham suggested status is gendered and often favors men in sport, education, business, and science because these professional and academic fields are traditionally male dominated. If status is gendered and often favors men, is it possible for women to accumulate power?

According to Kanter (1977), power can be accumulated through performancerelated activities, which must be extraordinary and visible (Kanter, 1977). Extraordinary activities may include being a "pioneer" (e.g., the first person in a position), successful risk-taking, and leading organizational change. For women in leadership positions, extraordinary activities are inherently risky because such activities require enhanced visibility.

In a male-dominated profession, visibility is a double-edged sword as it has the potential to result in criticism or praise (Corby \& Stanworth, 2009; Richie et al. 1997; Whitmarsh et al., 2007). Women are highly visible because there are so few in high-level managerial positions. As a result, women in senior management positions may feel pressure to "prove" their abilities to colleagues (Richie et al., 1997; Whitmarsh et al., 
2007). Women in managerial positions are also expected to serve as mentors and role models to women in lower positions in the organization (Richie et al. 1997; White, 1995).

Participants in a study by Andrew et al. (1990) offered that the small number of women in management was the greatest obstacle because there are fewer women in management as advocates and role models for other more junior women who aspire to be managers. Moreover, women in this study advised that the proportion of women in management could be changed, but an increase would require attitudinal changes of colleagues (Andrew et al., 1990).

An attitudinal shift would require first a shift in the culture and socialization of employees in an organization (Ely, 1995; Ely \& Meyerson, 2000) followed by structural changes to organizational policies and practices or even leadership structures (Andrew et al., 1990). Studies (Catalyst 2010; Konrad, 2007) suggested that increasing the proportion of women in lower levels of management would eventually lead to more women in senior and executive levels of management. This suggestion implies more gender parity in an organization would result in a shift of opportunity and power. This perspective, however, fails to consider the deeply embedded social construction of gender as it pertains to the proportion of gender in an organization. In a study on women's social constructions of gender identity at work, Ely (1995) argued that increasing the numbers of women in organizations to reach gender parity has been ineffective to achieving equity and desired developmental outcomes for women because little attention has been paid to where, how, and why inequities occur in an organizational hierarchy.

Ely (1995) discovered that women working in male-dominated law firms were perceived as less valuable than men in the firm and were less likely to achieve success 
(e.g., arguing at trial, making partner) in the firm. As a result, many women attempted to adopt masculine characteristics including aggression, sexism, and task orientation, which perpetuated the devaluation of women and feminine characteristics. Devaluation of a particular gender (in this case women) has the potential to bias hiring practices (Beatty, 2007; Ely, 1995; Kanter, 1977). In a study of male and female managers, Phelan, MossRacusin, and Rudman (2008) found that women who adopted agentic characteristics were perceived as competent, but lacked in social skills. Social skills, rather than job competency, were found to predict hiring decisions (Phelan et al., 2008). In short, hiring managers focused on perceived deficits rather than competence to justify hiring discrimination (Phelan et al., 2008).

Biased hiring practices limits a woman's opportunity to advance in an organization, which also results in fewer female role models for young women aspiring to management positions. These practices also maintain hegemonic structures, which reinforce the power and privilege afforded to men (Gattrell \& Cooper, 2007). Still, Duehr and Bono (2006) argued, that as the number of women in management increases and organizations emphasize diversity, barriers to advancement and perceptions of women in leadership positions are likely to change.

Finally, visibility often requires more time spent at work. For many women, more time at work means less time with family. Frome, Alfeld, Eccles, and Barber (2006) suggested that desire for a flexible job and high time demands of an occupation were the best predictors of women changing their career paths from a male-dominated industry to one that is more gender-neutral or female-dominated. Conversely, women who did not desire a flexible job were more likely to remain in a male-dominated profession (Frome 
et al., 2006). Frome et al. concluded that women who "leak out" of the pipeline in a male-dominated industry often do so because formal organizational policies or informal organizational culture preclude women from maintaining a balance between work and family. Therefore, women will abandon initial career aspirations to accommodate a desire to have a family and a career (Frome et al., 2006).

Women also explained that failure to work long hours would have promotion ramifications (Corby \& Stanworth, 2009). That is, if women did not put in long hours on the job, they would not be considered for higher-level managerial positions, which would then affect their visibility in the organization. On the other hand, several women explained, "failure to be promoted was a price worth paying for not working excessively long hours" (Corby \& Stanworth, 2009, p. 173).

According to Kanter (1977), when people perceive few structural opportunities, they find satisfaction through connections with others. Women, in particular, rely on a variety of social relationships to support their career development (Betz, 2006; O’Neil \& Bilimoria, 2005). Social relationships can provide support for women or can serve as barriers to their career advancement.

Social-relational. Social-relational factors are important to men and women, yet each sex defines the social relation component differently (Forrest \& Mikolaitis, 1986). For example, men tend to be more objective and are likely to differentiate themselves from other based on abilities and attributes (e.g., intelligence, logic, competitive). Women, on the other hand, are more subjective in their definition of the social-relational component. That is, women "reflect their sense of identity primarily in terms of their relation to others" (Forrest \& Mikolaitis, p. 79). In the context of career development, 
social-relational factors include networking, mentoring/role modeling, collegial relationships, and the support of family members. Gender role stereotypes also affect social relationships. Social constructions of gender have contributed to the patriarchal structure of organizations and have often defined the nature of social interactions in the workplace (Beatty, 2007).

Initially, Betz and Fitzgerald (1987) contended that women in male-dominated professions were not likely to have sufficient numbers to develop a significant peer group. Women, however, have shown the capacity to build networks of their own (Corby \& Stanworth, 2009; Ely \& Meyerson, 2000; Whitmarsh et al., 2007). Further, women may accumulate power through informal networks (Kanter, 1977; Shaw, 2006). Informal networks are an important source of organizational knowledge through which trust, reciprocity, information, and cooperation can be cultivated (Kanter, 1977; Gregory, 2009; Kumra \& Vinnicombe, 2010; Wentling, 1996, 2003). Access and participation in networks may help women gain access to organizational and industry resources (Wentling, 2003), which also contributes to the accumulation of power.

Ely and Meyerson (2000) cautioned against gendered networks because they can be divisive to an organization. Gaining access to networks, however, is difficult for “outsiders” such as women (Betz \& Fitzgerald, 1987; Ehrhart \& Sandler, 1987; Kanter, 1977; Russell, 2006). According to Brass (1985), "because men have historically dominated high-level hierarchical positions, women are less likely to be included in these informal, high-level interactions" (p. 329).

When women have limited access to informal networks or choose not to participate, they may be less likely to find out about positions that might enhance their 
skills and professional competencies (Gregory, 2009). Organizational knowledge includes understanding formal and information practices, organizational politics, and identifying individuals with power, which is important to achieving influence and power (Gregory, 2009; Kanter, 1977; Kumra \& Vinnicombe, 2010).

Without power in an organization, women are not included in important organizational decisions (Shaw, 2006). Such collaboration offers women (and men) opportunities for professional skill development (Gregory, 2009). Exclusionary networks preclude women from the benefits of collaboration with men (Grappendorf \& Henderson, 2008). If women are denied opportunities to develop professional competencies and credibility, they are also denied opportunities for advancement (Grappendorf \& Henderson, 2008; Kanter, 1977). When women do not advance to senior management positions, it perpetuates gender stereotypes that women are not qualified for or capable of leading organizations (Hopkins \& O'Neil, 2007). Finally, the underrepresentation of women in leadership positions negatively affects perceptions of opportunity for other women (Gatrell \& Cooper, 2007; Kanter, 1977).

In addition to networks, building a relationship with a mentor is another way for women to accumulate power and reduce the impact of contextual barriers. Kanter (1977) suggested that the primary function of a mentor was "to make introductions or train a young person to move effectively through the system" (p. 181). Kram (1983) suggested that mentors provide two distinct but related functions to their protégés - career and psychological. Career functions prepare the protégé for career advancement and may include career advice, access to networks, and professional protection. Psychological functions include building a protégé's self-confidence, sense of competence, acceptance, 
and friendship. In sum, mentors help women navigate social, cultural, and structural barriers in an organization (Cullen \& Luna, 1993; Eby \& Allen, 2004; Kanter, 1977). Male mentors were more likely to provide career mentoring to women, while female mentors were more likely to provide psychological mentoring (Cullen \& Luna, 1993).

O'Neil et al. (2004) suggested seeking career guidance could result in rapid career advancement and development for women. Cullen and Luna (1993) explored mentoring and its limitations in higher education. Female mentors in the study identified several opportunities for protégés to "get ahead" including promoting sponsorship, coaching the protégé, limited protection, exposure to different and challenging work, role-modeling, and counseling. The mentors in the study also identified barriers to mentoring including (a) the limited number of women in high managerial positions available to mentor women lower positions, (b) time limitations of female mentors due to work roles and responsibilities, (c) and “Queen Bee Syndrome” (Cullen \& Luna, 1993)

Often women in upper management are over-burdened with the perceived expectations and responsibilities of mentoring younger females (Cullen \& Luna, 1993; Richie et al., 1997). Cullen and Luna (1993) also found that women in high levels of management may not be willing to mentor young female professionals due to "Queen Bee” syndrome. Queen Bee syndrome was described as a woman's general unwillingness to help other women out of jealousy or resentment. Moreover, because networks are limited to women and women are underrepresented in executive levels of organizational structures, finding a female mentor is difficult (Corby \& Stanworth, 2009; Richie et al., 1997; Wentling, 1996, 2003; Whitmarsh et al., 2007). 
While networking and mentoring relationships are important supports to women in the workplace, relationships with family and friends are just as important (Whitmarsh et al., 2007). Whitmarsh et al. found that women in male-dominated industries and occupations stressed the importance of support from a spouse or significant other. Women in a study by Richie et al. (1997) discussed the importance of maintaining “interconnectedness" - access to social support and balance between life and work. Participants in studies by Corby and Stanworth (2009), Guillaume and Pochic (2009), Richie et al. (1997) and White (1995) also discussed the importance of spousal support in home and family responsibilities and in career guidance.

Supportive relationships and work-life balance are critical career supports for women (Richie et al., 1997; Wentling et al., 1996, 2003; White, 1995; Whitmarsh et al., 2007) especially when familial relationships and careers are central to women's lives (O'Neil et al., 2008). O'Neil et al. suggested that these social-relational supports represent an interesting paradox in the work lives of women in that "organizational realities demand the separation of career and life" (p. 730).

It is useful to think of the career development theories and opportunity structures discussed in this section as interpretive frameworks for understanding (a) what career decisions people make, (b) why such decisions are made, and (c) how those decisions affect career expectations and goals. Each personal and contextual factor - singular or combined - has the potential to influence career development, expectations, and goals (Astin, 1984; Betz, 2004; Coogan \& Chen, 2007; Lent et al., 1994). The exploration of personal and contextual factors as they pertain to career development, career expectations, and career goals is particularly important for women. Women encounter 
issues not ordinarily faced by men as women balance family, social, and work expectations (Astin, 1984; Betz \& Fitzgerald, 1987; Coogan \& Chen, 2007; Farmer, 1976; Gottfredson, 1996; Richie et al., 1997).

Career construction theory (Savickas, 2005) and SCCT (Lent et al., 1994, 2000) emphasize the role of personal and contextual factors in career development, but also acknowledge the role of human agency and choice. While the choices of women may be constrained (Eccles, 1994) by personal and contextual factors, women still have a choice in how opportunity structures affect career expectations and goals (Fagenson, 1990).

While there are more women in the workforce, the proportion of women at senior and executive levels of management remains low (Catalyst, 2010). Women pursuing careers in intercollegiate athletics do not appear to be an exception (NCAA, 2010). More women are working in intercollegiate athletic than ever before (Acosta \& Carpenter, 2010), yet the representation of women in senior and executive levels of management is declining (Acosta \& Carpenter, 2010; Lapchick, 2010). If more women are working in sport, why are they absent from executive levels of management? What is happening during a woman's career development that could be perceived as a professional plateau? Does the structure and culture of intercollegiate athletics preclude women from advancing professionally? Or are women in intercollegiate athletics exercising personal choice in their career development, expectations, and goals?

\section{Summary}

Much of the literature on women in intercollegiate athletics has focused on women who have "made it to the top" (Grappendorf et al., 2008; Grappendorf \& Lough, 2006; Whisenant et al., 2002). Women in these studies identified barriers they 
encountered and somehow overcame to achieve Athletic Director positions. What is less clear is how the women employed coping mechanisms to negotiate barriers and supports. Moreover, the findings of these studies and the advice forwarded by current female Athletic Directors implicitly assumes women want to attain executive levels of management. What these studies fail to consider, however, is that barriers and supports may be a function of managerial rank (Russell, 2006). In other words, studies on women in intercollegiate athletics have yet to focus on the career experiences of women in the "pipeline." More research is required to understand the career expectations, aspirations, and outcomes of women in senior-level management positions. Furthermore, it is important to examine what barriers and supports exist, as well as how and why barriers and supports affect the career development of women in intercollegiate athletics. 


\section{CHAPTER III}

\section{METHODOLOGY}

To date, few studies have examined women's career development, career expectations, and career goals in senior-level (i.e., assistant and associate athletic director) intercollegiate athletics positions. The roles of assistant and associate athletic director have been identified as positions in the "pipeline" to an executive position such as Athletic Director (Grappendorf et al., 2004; Lapchick, 2010). Given the underrepresentation of women in executive-level positions in intercollegiate athletics and the concern that women may experience difficulty accessing those positions (Bruening et al., 2008; Burton et al., 2011; Grappendorf et al., 2004; Inglis et al., 1996; Moore et al., 2000; Sagas \& Cunningham, 2004a; Whisenant et al., 2002), there is a growing need to understand the career experiences of women in senior-level management positions in intercollegiate athletics. Such an understanding may provide insight into how and why experiences at the senior level influence decisions to pursue executive positions. Therefore, the purpose of this study was to explore the career experiences of female senior managers in intercollegiate athletics.

An overarching research question was developed to guide this study: What are the career experiences and expectations of women in senior level management positions in NCAA Division I intercollegiate athletic departments? Additional research questions guiding this study addressed:

1) What factors do participants perceive as supports to their career development? 
2) What factors do participants perceive as barriers to their career development?

3) How do participants negotiate supports and barriers?

4) In what ways do participants' perceptions of supports and barriers influence their career outcome expectations?

5) In what ways do participants' perceptions of supports and barriers influence their career goals?

6) What coping strategies do participants employ to reconcile potential differences between career aspirations and career realities?

This chapter describes the study's research methodology and includes discussions on the following areas: (a) rationale for study design and approach, (b) description of research sample, (c) methods of data collection, (d) analysis and synthesis of data, (e) ethical considerations, (f) issues of trustworthiness, and (g) limitations of the study. The chapter concludes with a brief summary.

\section{Study Design}

This study utilized a qualitative design to explore the career experiences, expectations, and goals of women in senior level management positions in intercollegiate athletics. A qualitative design was appropriate for this study for a number of reasons. First, qualitative designs are naturalistic, which means data are collected in a real-world environment where a phenomenon occurs (Patton, 2002). Patton suggested naturalistic inquiry allows the phenomenon to unfold naturally without a predetermined course, laboratory control, or manipulated variable (Patton).

Second, qualitative research assumes that the social world is holistic and complex (Creswell, 2007; Marshall \& Rossman, 2011). Thus, a qualitative design is useful in for 
"documenting how structures shape individual experiences, and also how individuals create, change, or penetrate the structure that exists" (Glesne, 2011, p. 39). For instance, researchers have measured career development quantitatively through the administration of aptitude tests and assessments of personality, interests, abilities, and values to help individuals identify the appropriate career fit (Dawis, 2005; Holland, 1997). As research in career development has evolved, career theorists (Lent, et al., 1994; Savickas, 2002) suggested using a qualitative approach to identify and understand the dynamic of cultural and social contexts including race, gender, education, organizational structure, and social relationships that influence personal preferences in career choice and, ultimately, career development. This study explored the manner in which barriers and supports influenced career expectations and career goals. Therefore, a qualitative design offered an appropriate framework for capturing the complexity of the career experiences from the perspective of women in intercollegiate athletics.

Third, a qualitative design also provides framework for the interpretation of the meaning of lived experiences (Creswell, 2007) and how experiences guide actions and interactions (Marshall \& Rossman, 2011; McCracken, 1988). As such, a qualitative design allowed for more in-depth understanding of career experiences, including how and why certain experiences affect career decisions, expectations, and outcomes (Lent et al., 1994; Savickas, 2005). Marshall and Rossman (2011, p. 148) explained qualitative designs focus on the "deep lived meanings that events have for individuals, assuming that these meanings guide actions and interactions." Participants discussed their experiences, which will allowed me to capture and describe the participants' perceptions, feelings, judgments, and meaning-making (Creswell, 2007; Patton, 2002). 
Fourth, career construction theory (Savickas, 2005) and SCCT (Lent et al., 1994, 2000) are interpretive rather than predictive in nature. Thus, using a qualitative design allowed me to understand and interpret the meanings of career experiences, as well as how and why certain experiences may affect career expectations and career goals. This understanding may provide insight as to why women are not better represented in executive positions.

Finally, a qualitative design was particularly suited to exploring the career development of women in intercollegiate athletics because it encouraged women to tell their own stories (Patton \& McMahon, 2006). Research has shown that offering women an opportunity to voice their experiences is particularly important for those working in a male-dominated environment (Creswell, 2007; Gallos, 1993; Hums \& Sutton, 1999). Other qualitative studies on the career experiences of women in sport management include women's perceptions of their careers in parks and recreation (Smith, Santucci, Xu, Cox \& Henderson, 2012), the work-life balance of female coaches (Dixon \& Bruening, 2007), the multiple realities of women's work experiences in coaching and athletic management (Inglis, et al., 2000), and the experiences of female coaches in a male-dominated work place (Walker \& Bopp, 2011).

\section{Participant Sample}

The population for this study included women in senior-level management positions in intercollegiate athletics at NCAA Division I member institutions that are also members of the National Association of Collegiate Women Athletic Administrators (NACWAA). Given the concern by many scholars that women are underrepresented in leadership positions at NCAA Division I institutions, it is important to sample women 
from colleges and universities in Division I to better understand their career experiences and perceptions in the context of career expectations and goals. Several studies in sport management research have selected samples of female Athletic Directors (Grappendorf \& Lough, 2006; Grappendorf et al., 2004; Grappendorf et al., 2008), but only a few have focused on women in senior levels of administration (Hoffman, 2010; Tiell \& Dixon, 2008). Other research suggests that achieving the position of Athletic Director is not a career goal for women in intercollegiate athletic administration (Grappendorf et al., 2004; Sagas \& Cunningham, 2004b).

The sampling frame included senior-level female administrators working at NCAA member institutions in Kentucky, Ohio, or Indiana. I selected this regional sampling frame because it allowed me to interview the majority (10) of participants faceto-face. Face-to-face interaction is important when conducting a qualitative study, particularly when interviews are the primary source of data (Seidman, 2006). Although the experiences of senior-level female managers could vary depending on geographic location, this regional study included a sample from senior-level female managers in Kentucky, Ohio, and Indiana. This region was also selected because of its abundance of colleges and universities representing NCAA Division I. More specifically, there are 31 Division I schools (NACDA, 2011). Of these institutions, 21 are member institutions of NACWAA.

Face-to-face interviews provided the best setting for me to assess a participant's social cues such as body language and tone of voice (Opdenakker, 2006). I interviewed the remaining five participants over the phone to accommodate the work and travel schedules of participants. While phone interviews reduced my ability to assess social 
cues such as body language, I had the ability to listen to tone of voice (Opdenakker, 2006).

I selected NACWAA members to participate in this study because women may benefit from the professional development opportunities NACWAA provides. NACWAA consists of approximately 1,800 members from all NCAA. It is the largest professional organization dedicated specifically to the advancement of women in intercollegiate athletics (NACWAA, 2011). NACWAA provides "educational programs, networking and mentoring experiences, resources and professional and personal development opportunities to its members" (NACWAA, para. 3, 2011) and "promotes the growth, leadership, success, and advancement of women as athletics administrators, professional staff, coaches and student-athletes" (NACWAA, para. 3).

I acknowledge, however, that a participant's affiliation with NACWAA may also be a limitation to this study because members have access to a network and mentors. Studies suggest that women who actively engage in networks and mentoring opportunities may be more likely to ascend through an organizational hierarchy (Andrew et al., 1990; Bower, 2008; Burke, 2007; Powell \& Graves, 2003; Ritchie et al., 1997; Schein, 2001, 2007; White, 1995). Conversely, association with NACWAA does not mean that women seek professional advancement or participate in career development programming.

I selected participants for this study using purposeful sampling. Purposeful sampling is the intentional selection of information-rich cases (Patton, 2002). According to Patton, "information-rich cases are those from which one can learn a great deal about issues of central importance to the purpose of the research" (p. 46). While there are 
several strategies for obtaining a sample, this study used a combination of criterion and stratified sampling. Combination sampling was beneficial for this study because it (a) enhanced trustworthiness, (b) aided in the triangulation of data and sources, and (c) offered flexibility to sample selection (Patton, 2002).

Criterion sampling means that each person meets a specific condition required for participation in the study (Miles \& Huberman, 1994). Creswell (2007) and Marshall and Rossman (2011) also recommended criterion sampling because the qualitative design requires participation from individuals who have worked in similar environments.

Further, the use of sampling criteria aids in the trustworthiness of the study (Miles \& Huberman, 1994).

The criteria for selection of participants in this study were:

- Female,

- Currently employed as an assistant or associate athletic at an NCAA Division I institution,

- Member of NACWAA, and

- At least 30 years of age.

O'Neil and Bilimoria (2005) suggested using age as a primary sampling criterion to explore the life course of women's careers. In addition, women who are 30 years of age or older are considered to be in the "establishment" stage of career construction (Savickas, 2002). Women at this stage have encountered a range of "choice points" (O'Neil \& Bilimoria, 2005) in occupational development (e.g., changing jobs, promotion and advancement) and life development (e.g., starting a family, moving closer to aging parent). Thus, it is likely that women at this age and in this stage of career construction, 
women will be able to articulate experiences contributing to their respective career decisions as they pertain to barriers and supports, career expectations, and goals.

Cross-referencing NCAA member institutions with NACWAA-member institutions (M. Riggs, personal communication, September 21, 2011) yielded a potential sample of 41 senior-level female managers at NCAA Division I institutions. I obtained contact information for each potential participant through the National Directory of College Athletics (NACDA, 2011) and through respective intercollegiate athletic department websites. I contacted and recruited all members of the potential sample via email (Appendix B) in November 2011. I also attached a more in-depth recruitment letter (Appendix A) to the email for participants to reference. I sent a follow-up email invitation one week later to participants who did not respond. Finally, three weeks after the initial invitation, I sent another follow-up invitation to potential participants who had yet to respond. Five women declined participation, 21 did not respond to the invitation to participate. Fifteen women agreed to participate in this study.

\section{Sample Size}

Data collected from the sample ensured research questions were answered and the data collected were credible (Patton, 2002). Guba and Lincoln (1985) recommended sample selection to the point of redundancy, or saturation. Saturation is the degree to which no "additional data are being found" (Glaser \& Strauss, 1967, p. 61). Seidman (2006) also suggested sampling sufficiency. Sufficiency requires the researcher to collect enough data from a range of individuals such that individuals outside the sample can connect to the experiences of the participants in the study (Seidman, 2006). Sufficiency also enhances the trustworthiness of the study. 
To reach saturation and sampling sufficiency in a qualitative design, Ritchie, Lewis, and Elam (2003) suggested an appropriate sample size of less than 50, while Creswell (2007) recommended between 20 and 30 participant interviews. Green and Thorogood (2004) stated, "the experience of most qualitative researchers is that in interview studies little 'new' comes out of transcripts after you have interviewed 20 or so people" (p. 120). Some of the qualitative studies in sport management have included sample sizes between five and 50 participants (Bower, 2008; Bruening \& Dixon, 2007; Grappendorf \& Lough, 2006; Smith et al. 2012). In this study, I reached saturation after interviews with 15 participants.

\section{Access and Entry}

Permission to conduct a study on human subjects was obtained through the Institutional Review Board (IRB) at the University of Louisville in October 2011. Following IRB approval, I contacted qualified participants via email in November 2011 to schedule an interview.

Ethical issues as they pertain to the protecting participants are of paramount concern (Marshall \& Rossman, 2011; Patton, 2002). In order to ensure the protection of participants, I first considered my role in the study. Researchers can assume multiple roles when conducting a study including exploiter, intervener/reformer, advocate, and friend (Glesne, 2011). In this study, I was perceived as a professional colleague given my previous experience in the field and as a member of NACWAA for approximately four years. I acknowledge this type of relationship with a participant may present ethical dilemmas including a participant's willingness to share information about her career and personal life that she may not share with someone other than a colleague. My role as a 
professional colleague was beneficial in that it seemed to inspire a relationship of trust, care, and advocacy for participants in the study.

Participants in this study were required to give informed consent. Through informed consent, I ensured participants were made aware of the following: (a) participation in the study was voluntary, (b) potential risks of participation in the study, and (c) withdraw from the study at any time. In addition, I took several steps to ensure the protection and rights of the participants.

First, women willing to participate in the study were asked to sign a written informed consent form. Participants interviewed over the phone receive the informed consent and study material via email. At the time of the phone interview, I reviewed informed consent materials with the participant. Participants who consented to participate returned their signed informed consent via email or fax.

Second, to maintain confidentiality, I assigned each participant a pseudonym to which they are referred in the results of this study. In addition, I notified participants that identifying information such as conference affiliation, state, or race would not be directly linked to their participation in this study. Third, I informed participants about how the data would be handled, stored, and disseminated. Finally, I discussed measures taken to ensure the secure storage of research related documents such as interview transcripts, resumes, or job descriptions with participants. I stored participant files in a filing cabinet in my home office. I stored electronic transcripts of interviews and other electronic correspondence with participants on a password-protected computer. 


\section{Data Collection}

In qualitative studies, multiple sources of data are typically collected (Creswell, 2007). Data collection from multiple sources provides a more holistic account of the problem or issue being studied (Creswell, 2007; Glesne, 2011; Marshall \& Rossman, 2011). Collecting data from multiple sources aids in the triangulation of data.

Triangulation "is the act of bringing more than one source of data to bear on a single point" (Marshall \& Rossman, 2011). A data source may include an interview, a document, or an observation.

Before conducting interviews with the sample for this study, I performed a pilot study with a female associate athletic director at an NCAA Division I school in the Northeast. I adjusted the order of the interview protocol (Appendix D), wording of questions, and collection of job responsibilities based on the results of the pilot study. For example, rather than having participants write descriptions of their current positions, I asked them to describe their most important job responsibilities during the interview.

Fifteen senior-level female administrators in NCAA Division I intercollegiate athletic departments participated in this study. I collected resumes from each participant before the interview to examine career paths and job responsibilities. When available, I also accessed their professional biographies from the staff directories of their respective department websites. Finally, I asked each participant to describe the day-to-day responsibilities of her job as well as what she perceived to be her most important job responsibilities.

I conducted formal, semi-structured interviews with each participant. Ten interviews were in-person, five interviews were over the phone due to travel schedules of 
the participants. Formal, semi-structured interviews require topics and issues to be determined before the interview occurs (Patton, 2002). Therefore, I conducted the interviews using an interview guide (Appendix D). The interview guide approach has several strengths. First, an interview guide increases the comprehensiveness of the data collected (Patton, 2002). Second, I could anticipate gaps in data and adjust interview questions to close the gap (Patton, 2002; Seidman, 2006). Finally, the semi-structured approach allows for a conversational-style interview, while ensuring the systematic collection of data (Patton, 2002). The use of an interview guide also has limitations. According to Patton, "interviewer flexibility in sequencing and wording questions can result in substantially different responses from different perspectives, thus reducing the comparability of responses" (p. 349). To mitigate this weakness, I wrote field notes during the interview so that I could ask questions for clarification later in the interview or in a follow-up interview, when necessary.

Derived from the literature, the open-ended interview questions address five main areas: (a) career path, (b) perceptions of career supports and barriers in career development, (c) adjustment strategies in career development, (d) career expectations and goals, and (e) advice to other women as they enter and progress through early career stages in sport management. Some of the issues each participant were asked to address included:

- Appeal of work in college athletics

- Previous experiences working in college athletics

- Career expectations, aspirations, and goals

- Career coping strategies in career decision-making. 
Interviews lasted 60 to 80 minutes. All interviews were digitally recorded. Follow-up interviews were necessary with three participants. Those interviews lasted no longer than 15 minutes and were not digitally recorded. A third party transcribed the interviews. Transcript length ranged from 19 to 31 single spaced pages.

\section{Data Organization}

I created files for each participant in the study. Files will included a contact summary form (Miles \& Huberman, 1994), field notes collected during and written after the interview, participant documents (i.e., resume, signed informed consent), and an interview transcript. I recorded dates, times, and locations on field notes, documents, and interview transcripts. Understanding when and where certain information was obtained provides a more holistic picture of the observation experience for a particular field session. In addition, organization of data allowed for more efficient data analysis and enhanced the trustworthiness of the study (Miles \& Huberman, 1994).

\section{Data Analysis}

Data collected from the women participating in this study resulted in several hundred pages of interview transcription, resumes, job descriptions, field notes, analytic memos, and reflexive journaling. Therefore, data reduction was critical to analysis and interpretation (Wolcott, 1994). According to Miles and Huberman (1994), data reduction focuses, sharpens, and organizes data so that conclusions can be drawn and verified. Contact summary forms, field notes, and interview transcripts were compared within and between participants following their respective interviews.

At the conclusion of each interview and upon receipt of transcripts, I studied the results and engaged in constant comparative analysis (Glaser \& Strauss, 1967) to 
generate and/or understand relationships between barriers and supports, life themes, career expectations and career goals. Constant comparative analysis is a method of analyzing and organizing data into codes and emergent themes in four stages (Glaser \& Strauss, 1967):

(1) comparing incidents applicable to each category;

(2) integrating categories and their properties;

(3) delimiting the theory; and,

(4) writing the theory. (p. 105).

The purpose of this study was not to generate theory. The experiences and themes derived from the data, however, served to inform theory on women's career development. I also examined interview transcripts, resumes, and field notes for emerging categories (Glaser \& Strauss, 1967). Codes and themes changed with each new interview and collected document. As codes emerge and change, I added or removed codes on a working code list. Following the final interview, I examined codes for overarching patterns and themes (Glaser \& Strauss, 1967).

\section{Coding}

As suggested by qualitative researchers (Glaser \& Strauss, 1967; Miles \& Huberman, 1994; Patton, 2002), data analysis began immediately following the first interview. I reviewed field notes, transcripts, and documents to determine if a follow-up interview with the participant is necessary. At the end of each interview, I drew maps of participant career paths and noted important career and personal transition points.

Data was coded deductively and inductively to generate common patterns from the data (Cunningham et al., 2007; Dixon \& Bruening, 2007; Marshall \& Rossman, 2011; 
Miles \& Huberman, 1994). Saldana (2009) defines a code as "a word or short phrase that symbolically assigns a summative, salient, essence-capturing, and/or evocative attribute for a portion of language-based or visual data" (p. 3). Codes assist the researcher in understanding the essence of key concepts in the data (Miles \& Huberman, 1994; Saldana, 2009).

Deductive coding stems from themes found in the literature pertaining to women in management, career experiences, and career development theory. Therefore, a "start list" (Miles \& Huberman, 1994) of codes derived from career construction theory, social cognitive career theory (SCCT), and previous research on barriers and supports in women's career development will be developed to aid in data analysis. Inductive coding allows themes and patterns to emerge. These patterns are crucial to understanding complex interactions in the field of study (Creswell, 2008). I added new codes and themes to the code start list as they emerged. The combination of deductive and inductive coding allowed for the emergence of career barriers, facilitators, and adjustment strategies, as well as significant organizational structures and social relationships influencing career development. In addition, this approach to coding illuminated new perspectives on the career development of women in intercollegiate athletics and male-dominated professions.

This study used multiple approaches to coding including attribute, descriptive, and "in vivo." Attribute coding is the documentation of basic descriptive information such as participant characteristics and demographics or the timeframe of an interview or acquisition of a document such as time, day, month, or year (Saldana, 2009). I also used descriptive coding in the analysis of data. According to Saldana, descriptive coding is 
useful when the researcher is attempting to summarize a portion of the transcript text in to a word or a short phrase. Descriptive coding was particularly helpful when analyzing interview transcripts in which participants may speak for several minutes resulting in large blocks of text, often on a particular topic. For instance, several of the participants in this study offered extensive descriptions of experiences or decisions. Descriptive coding was useful summarizing the essence of these experiences. The researcher may also use "in vivo" coding. "In vivo" coding is a word or short phrase "from the actual language found in the qualitative data of record" (Saldana, p. 74). In other words, "in vivo" coding literally captures the words and "voice" of the participant.

\section{Trustworthiness}

Guba and Lincoln (1985) used the terms credibility, dependability, and transferability to assess the trustworthiness of a qualitative study. Each component of trustworthiness is discussed in the next section.

Credibility. Similar to validity in quantitative studies, credibility is concerned with answering the question, "Has the researcher accurately represented what the participants think, feel, and do?” (Bloomberg \& Volpe, 2008, p. 24). I took several steps to enhance to credibility of this study. First, I disclosed my position as a former assistant athletic director at an NCAA Division I institution and member of NACWAA. I also explained that my experience in that job led to an interest in the career development of women in sport management, particularly in intercollegiate athletics.

Second, I wrote in a reflective journal (Bloomberg \& Volpe, 2008). The purpose of the journal was to reflect on personal assumptions, reactions to participant experiences, and notes on future interviews and data analysis (Marshall \& Rossman, 2011). The 
journal was also useful in unearthing potential researcher biases. Third, repeated and sustained time in the field (i.e., 15 interviews) allowed for a more in-depth study of the career experiences of women in intercollegiate athletics (Marshall \& Rossman, 2011). Fourth, triangulation of multiple sources of data including interviews, resumes, and personal job descriptions from multiple participants also enhances the credibility of this study.

Dependability. Dependability is assessed through (a) replication and (b) reflexivity and external auditing (Glesne, 2011; Marshall \& Rossman, 2011). Replication is the concept that another researcher could replicate the study based on data collection methods, analysis, and interpretation (Glesne, 2011). Data organization and management was critical to maintaining study dependability. Thus, I followed the data organization and management system outlined earlier in this chapter.

Reflexivity and external auditing were also important to enhancing dependability (Glesne, 2011). Reflexive activity has three parts - self-reflexivity, reflexivity about those studied, and reflexivity about the audience (Patton, 2002). Through self-reflexivity I reflected on my own knowledge about intercollegiate athletic administration and the experiences that shaped my knowledge. Reflexivity about those studied involves gaining a better understanding of how participants make sense of their careers in intercollegiate athletics based on their personal and professional experiences. Finally, reflexivity about the audience involves the consideration of how readers of this study will receive and interpret the findings.

I also engaged in peer debriefing. Peer-debriefing was useful in the analysis of data. I shared information and perspectives with dissertation committee members who 
were helpful in asking questions to clarify findings. Additionally, debriefing conversations helped me consider the data from multiple perspectives, which will also reduce bias in the coding process.

Transferability. Transferability refers to the ways in which "the study's findings will be useful to others in similar situations with similar research questions or questions of practice" (Marshall \& Rossman, 2011). Lincoln and Guba (1985) suggested that transferability can be achieved through "thick description." In thick description, "the voices, feelings, actions, and meanings of interacting individuals are heard" (Denzin as cited in Ponterroto, 2006, p. 540). For this study, I attempted to capture the shared experiences of women in intercollegiate athletics by including applicable quotes from their transcripts.

\section{Limitations}

This study has several limitations. Data collected from the women in this sample cannot be generalized to all senior-level female managers in NCAA Division I intercollegiate athletics. While common patterns emerged, some of which are reflected in other sport management studies, the perspectives shared were unique to the participants in this study. To address this limitation, I conducted interviews to the point of saturation (Glaser \& Strauss, 1967; Seidman, 2006), and presented findings in a manner that represents the voices, feelings, and actions (Patton, 2002).

This sample involves senior-level female managers who are currently (a) employed by NCAA member institutions and (b) members of NACWAA. Therefore, the women in this study may have more sophisticated career adaptation and coping 
mechanisms to negotiate career barriers and supports. A future study may include women who are not members of NACWAA.

Data collection was limited to one interview, resume, and personal job description per participant. A follow-up interview was conducted with three participants for clarification and/or for a more in-depth understanding of an experience. This study sought to understand the breadth of career experiences and expectations of female seniorlevel managers in intercollegiate athletics. Therefore, Glesne (2011) advised conducting one-time interviews with more people rather than conducting two or three interviews with fewer people over a more extended period. Typically, interviews conducted in the phenomenological tradition occur more than once and over a period of time. Seidman (2006), however, suggested that researchers could alter the number and structure of interviews based on the goals of the study. Further, "the governing principle in designing interviewing projects might well strive for a rational process that is both repeatable and documentable" (Seidman, p. 22).

The semi-structured interview guide was designed to be holistic. Participants in this study shared their perceptions of the career environment in intercollegiate athletics based on their personal experiences. Capturing the nuances of career experiences and the full scope of decision-making processes, however, was difficult. I used of thick description, participant quotes, and triangulation of the data to mitigate this limitation.

In qualitative research, the researcher is the instrument. Building rapport with study participants was important, particularly when interviews are the primary source of data collection. Considering I chose to limit data collection to an interview and 
document analysis, the communication with the participants before the interview and during the interview process was critical. To build rapport with the participants, I:

- Clearly communicated the purpose, timeline, and participant responsibilities (i.e., interview, providing requested job description and resume) of the study during the sample recruitment and selection process;

- Explained informed consent and how the data would be collected, stored, and managed;

- Worked with the participant to schedule an interview at a time that was convenient her and also within my allotted time frame for data collection (November 2011 to February 2012);

- Maintained parameters of confidentiality by assigning a pseudonym to participants or allowing participants to select their own pseudonym;

- Expressed gratitude for the participant's willingness to participate in the study at the time of the interview;

- Sent a follow-up thank you note to study participants.

\section{Summary}

The purpose of this qualitative study was to explore the career experiences of women in senior-level administration in intercollegiate athletics. I used purposeful criterion sampling to identify qualified participants in this study. Data collection consisted of participant interviews and the collection of resumes and personal job descriptions. For data analysis, I engaged in constant comparative analysis and inductive and deductive coding strategies. The trustworthiness of this study was assessed on standards of credibility, dependability, and transferability. 
This study rendered important findings regarding to the career experiences and expectations of female senior level administrators. Practically speaking, these findings offer a better understanding of barriers and supports in intercollegiate athletics as they pertain the career life course. Identifying barriers and supports can help sport management academics and practitioners prepare women pursuing careers in intercollegiate athletics for issues they might face, as well as offer suggestions for coping and/or adjustment strategies while keeping professional expectations and goals in mind. Moreover, the coping and adjustment strategies discussed by women in this study may offer guidance to women with established careers in intercollegiate athletics be more proactive about their career-related decisions. Insights from this study were used to provide recommendations - to sport management faculty and Athletic Directors - for the recruitment, retention, and advancement of women in intercollegiate athletics. 


\section{CHAPTER IV}

\section{FINDINGS}

The roles of assistant and associate athletic director have been identified as positions in the "pipeline" to an executive position such as an Athletic Director (Grappendorf et al., 2004; Lapchick, 2010). Given the underrepresentation of female Athletic Directors and the concern that women may experience difficulty accessing those positions (Bruening et al., 2008; Burton et al., 2011; Grappendorf et al., 2004; Inglis et al., 1996; Moore et al., 2000; Sagas \& Cunningham, 2004a; Whisenant et al., 2002), there is a growing need to understand the career experiences of women in senior-level management positions in intercollegiate athletics. Such an understanding may provide insight into how and why experiences at the senior level influence decisions to pursue the position of Athletic Director (AD). Therefore, this study explored the career experiences of female senior managers in intercollegiate athletics.

An overarching research question was developed to guide this study: What are the career experiences and expectations of women in senior level management positions in NCAA Division I intercollegiate athletics departments? Additional research questions guiding this study addressed:

1) What factors do participants perceive as supports to their career development?

2) What factors do participants perceive as barriers to their career development?

3) How do participants negotiate supports and barriers? 
4) In what ways do participants' perceptions of supports and barriers influence their career outcome expectations?

5) In what ways do participants' perceptions of supports and barriers influence their career goals?

6) What coping strategies do participants employ to reconcile potential differences between career aspirations and career realities?

Fifteen women meeting the sampling criterion participated in interviews for this study. Interviews lasted approximately 55 to 85 minutes. Each interview addressed five main areas, including the participant's (a) career path, (b) perceptions of supports and barriers in career development, (c) adjustment strategies in career development, (d) career expectations and goals, and (e) advice to women as they enter and progress through a career in intercollegiate athletic administration.

This chapter is organized into three sections: (a) participant demographic information; (b) themes derived from the six research questions; and (c) a summary of the findings regarding senior-level female administrators in intercollegiate athletics.

\section{Participant Demographics}

The following section provides demographic information on the 15 women who participated in this study. Table 1 provides aggregated data on study participants. The participants ranged in age from 30 to 61 , and their average age was 42 . Thirteen participants $(87 \%)$ were White and two participants were Black (13\%). The sample is representative of the overall percentages of Whites $(88.5 \%)$ and Blacks $(8.8 \%)$ in Division I intercollegiate athletics (Lapchick, 2011). There were no participants in this study who identified as Asian, Latina, or Native American. In Division I intercollegiate 


\section{Table 1}

Participant Demographics (Aggregated)

\begin{tabular}{ll}
\hline Data & \\
\hline Age & 30 to 61 years (Avg. 42 years) \\
Race & 13 White, 2 Black \\
Education & 13 Master's degrees or higher \\
Marital Status & 9 married/partnered \\
Children & 7 participants w/ at least one child \\
\hline
\end{tabular}

athletics, assistant or associate athletic directors who are Asian, Latina, and Native American comprise $1.8 \%, 1 \%$, and $0.3 \%$ of the population, respectively. Of the 15 participants, nine women were married or partnered and six were single, including one divorcee. Seven participants had at least one child. Thirteen participants held an advanced degree. Two participants held Bachelor's degrees only.

Women in this study worked in intercollegiate athletics from two to 27 years and for an average of 16 years. Table 2 provides aggregated data on participants' careers in intercollegiate athletics. They averaged 4.3 years in their current title position and

\section{Table 2}

Participants' Careers in Intercollegiate Athletics (Aggregated)

\begin{tabular}{ll}
\hline Data & \\
\hline Career length (avg.) & Assistant AD, 11 years \\
& Associate AD, 18 years \\
& 4.3 years \\
Current title (avg.) & 8.8 years \\
Current institutional affiliation & Assistant AD (5), $\$ 50,000-\$ 90,000$ \\
Titles/Salary ranges & Associate AD (3), $\$ 60,000-\$ 100,000+$ \\
& Sr. Associate AD (7), $\$ 70,000-\$ 100,000+$ \\
Areas of responsibility & Internal (12) \\
& External (3) \\
Interest in AD position & Yes (4) \\
& Not sure, but not Division I (3) \\
& No $(8)$ \\
\hline
\end{tabular}


averaged 8.8 years at their current institution. Five women were assistant ADs, three were associate ADs, and seven were senior associate ADs. Six women held the title of Senior Woman Administrator (SWA). The SWA is the "highest ranking female involved with the management of the institution's intercollegiate athletic program" (NCAA, 2011, p. 18). Women at the associate athletic director level (including senior, executive, and deputy) worked in intercollegiate athletics an average of nearly 18 years. Assistant athletic directors had been in the field an average of 11 years.

All of the women in this study worked at NCAA Division I institutions, and represented each of the subdivisions as follows: 11 football bowl subdivision (FBS), one football championship subdivision (FCS), and three non-football schools. Overall, salaries for participants ranged between approximately $\$ 50,000$ to over $\$ 100,000$. Five participants earned over $\$ 100,000$ a year. Assistant AD salaries ranged from approximately $\$ 50,000$ to nearly $\$ 90,000$. Associate AD salaries ranged from approximately $\$ 60,000$ to nearly $\$ 100,000$. Senior associate, executive associate, and senior deputy ADs earned from $\$ 70,000$ to over $\$ 100,000$.

Twelve of the 15 participants had responsibilities in internal operations. Hoffman (2011) defined internal operations as advising and academics, compliance, event management, facilities, academic and student services, sport supervision, and supervision over departments including strength and conditioning and sports medicine. Three remaining participants worked in external operations with responsibilities in fundraising and development, marketing and promotions, sports information, budgeting and finance, ticketing, and media relations (Hoffman). Of the 15, four participants, two of whom work in external operations, indicated a desire to pursue the position of Athletic Director 
at the NCAA Division I level. Eight women stated definitively they had no interest in being an Athletic Director at any level, while three would consider the role at NCAA Division II or Division III institutions.

For six participants, intercollegiate athletic administration was a second career. Barb and Roberta had coaching careers before entering intercollegiate administration. Vera, Cindy, and Martha worked in other areas of higher education. Donna was a venue manager. While the majority of women began their careers in intercollegiate athletics as academic advisors or in compliance, three (Barb, Roberta, Donna) were hired into positions at the associate athletic director level or higher at the start of their careers in intercollegiate athletic administration.

Eleven participants were former college student-athletes or managers for college teams. Only two women, Barb and Roberta, had career paths similar to individuals in a study by Fitzgerald et al. (1994), which suggested a normative career path in intercollegiate athletic administration begins in coaching. The career patterns of thirteen women in this study were similar to those identified by Grappendorf et al. (2004). The study by Grappendorf et al. suggested becoming an assistant or associate athletic director was a prerequisite for achieving the position of Athletic Director (Grappendorf et al.) as opposed to coaching (Fitzgerald et al., 1994). Given the increasing emphasis on Division I athletics as a business operation, the change in the ten years between those two studies is not surprising.

The demographic information provided here presents a simple snapshot of the participants in this study. It offers an objective understanding of the current responsibilities, job titles, salaries, and tenures. Demographic information, however, 
does not account for career experiences, expectations, and goals, which have led women to this point in their careers.

\section{Exploring the Career Development of Senior-Level Female Administrators}

This study explored the career experiences and expectations of senior level female administrators in intercollegiate athletics through the lens of two career development theories - Career Construction Theory (Savickas, 2002, 2005) and Social Cognitive Career Theory (SCCT) (Lent et al., 1994, 2000). Career Construction Theory was designed to understand the decisions and choices individuals make based on the implementation of vocational personality and career adaptability in response to perceptions of social realities (Savickas, 2005). SCCT recognizes personal characteristics, contextual factors, and behavior as interconnected mechanisms contributing to the career decision-making process. Lent et al. (1994) identified three social cognitive constructions - (a) self-efficacy beliefs, (b) outcome expectations, and (c) career-related goals - as central to understanding career development. SCCT compliments Career Construction Theory in that it helps build conceptual linkages between the individual, the context of work, life themes, and perceived supports/barriers on career expectations and goals.

The following section is divided into five parts: (a) formation of career interests in intercollegiate athletics, (b) perceived supports to career, (c) perceived barriers to career, (d) negotiation of career supports and barrier, and (e) career expectations, goals, and coping strategies. 


\section{Formation of Career Interests in Intercollegiate Athletics}

To understand more fully the career development of senior level women in intercollegiate athletic administration, it is important to understand how women in this study entered the field. Savickas (2005) suggested vocational personality is an integral component to career development. Vocational personality is "an individual's careerrelated abilities, needs, values, and interests" (Savickas, 2005, p. 47). Vocational personalities are formed and reinforced by environments outside of work including socialization through family, educational opportunities, relevant identities (e.g., gender, race, socio-economic status), and personality characteristics (Astin, 1984; Richie et al., 1997; Savickas, 2002). Cunningham et al. (2005), Lapour and Heppner (2009), and Miller (1998) also described the influence of early career experiences on the formation of vocational personality. This section will address how socialization, personality characteristics, and early career experiences contributed to the vocational personality of women in this study.

Socialization. In their youth, 14 women in the study participated in recreational and/or high school sports. One participant, Cindy, was not an active in sports, but described her family's affinity for the football program at a large Midwestern state university. She reminisced about wearing school colors and attending football games in the fall. As mentioned in the demographic section, 11 women who participated in high school sport went on to participate in college athletics as student-athletes or student managers for teams including women's basketball and men's wrestling. The four remaining women who did not actively participate in college sport described "falling in 
love" with the intercollegiate athletic environment and sought opportunities to remain connected to sport.

Respondents also discussed the involvement and support of family when it came to watching or participating in sport. Jenny described sport as a part of her family's "culture." Amanda also discussed sport as a family affair, "I can remember as far back as I can my family being Kentucky Wildcat fans. I can remember making signs that we hung in our TV room on game days for Sam Bowie and the 'Twin Towers." Tina, one of five siblings in her family to earn an athletic scholarship, described having sport in her "blood." Sharing the experience of many, Amanda stated, "Sports have always been something that's been a part of my life, whether it's playing in it or watching it." In short, all participants described sport as being "ingrained" in them from an early age either as a participant or a fan.

Fathers and brothers seemed to play a more central role in participants' involvement in sport. Barb described the role her brother played in introducing her to sport, "If we were awake, not doing chores, we were playing whatever sport was in season. I am actually a highly trained wide receiver. My 10,000 hours of mastery is in wide reception, and baseball - first baseman - and then basketball." Jenny described her father as being "invested" in sport. She stated, "When my father would coach a little league team, we were all involved. Even at that level there is an administrative side to sport. Whether it's keeping the book or turning in the line up or paying the officials." When Jenny entered college at her father's alma mater, he helped her get a job working in the athletic department. 
Jane originally intended to major in education so she could coach at the high school level. She described a conversation with her father about her future career in which he told her, "If you're going to school in education just because you want to be a coach, that doesn't seem right. Why don't you look into getting into the sports world?" Growing up in the early 1980s, Tracy explained that she had little access to sport as a young girl, but her father was the football coach and athletic director at a local high school. Her initial involvement in sport resulted from his role at the high school. She learned to score wrestling matches in high school and later served as a student manager for her college's wrestling team.

Despite the important role sport played for study participants as children and into young adult life, only two, Judy and Roberta, had initial career goals of working in intercollegiate athletics. It should be noted, however, many participants discussed a lack of awareness when it came to considering intercollegiate athletic administration was a possible career path. For example, Donna learned about sport administration while searching for Master's programs. Julian began considering intercollegiate athletic administration at the suggestion of her college athletic director, a man. Initially, Amanda had aspirations to become a pharmacist. She worked in an outpatient pharmacy as part of her clinical rotation and quickly tired of "redundant" pharmaceutical work. She recalled that a male professor encouraged Amanda to consider a career in sport psychology after she became bored working in an outpatient pharmacy. Barb's college coach, a man, encouraged her to enter the collegiate coaching profession.

Only two participants described the influence of their mother or another woman on their involvement in sport or sport as a potential career. For example, Judy's parents, 
both avid golfers, gave her a golf club at the age of eight. Her mother assumed the role of head golf coach at Judy's high school so the team would not be discontinued.

Eventually, Judy would play golf on scholarship at an NCAA Division I institution.

Roberta's mother was not her basketball coach, but her mother did help coach her in life.

Roberta explained:

I started playing basketball, didn't like it, wasn't that good at it, $9^{\text {th }}$ and $10^{\text {th }}$ grade really had - I sucked - my mother actually came to one of my games in my $10^{\text {th }}$ grade year and said, "You know what if you're going to continue to play then you're either going to get better or we're taking you off the team." Basically, she said, "You're not going to embarrass the family name."

Roberta went on to play basketball at a Southern NCAA Division I university and, later, earned a contract to play basketball overseas.

Participation in sport and the support and involvement of family and trusted adults helped form the many of the participants' initial interest of sport as a potential career path. Based on participants' accounts, men appeared to have a strong influence over participants' socialization to sport and sport as a potential career path. Studies have shown men, particularly fathers and brothers, play have a strong influence on girls socialization to sport (Dixon, Warner, \& Bruening, 2008; Farrell, Fink \& Fields, 2011; Weiss \& Barber, 1995) and potential careers. Participants discussed the role of female supervisors and mentors in their careers, but offered little about the role of women before entering the field of intercollegiate athletic administration. Socialization, however, is only one component of the formation of a vocational personality. Career theorists (Astin, 1984; Betz \& Fitzgerald, 1987; Lent et al., 1994; Savickas, 2005) suggested individual personality characteristics also influence vocational personality and career choice. 
Personality characteristics. While this study did not measure personality characteristics, several studies (Richie et al., 1997; Wentling, 1996, 2003; White, 1995) suggest personality is an important component to understanding how career decisions influence career development. Therefore, I asked participants to describe personal characteristics that helped them progress to their current positions. When responding to this request, ten women identified work ethic. Participants defined work ethic as being visible in the office and at events and displaying a "whatever it takes" mentality. These women described themselves as "willing to do the dirty work," "worker bees," and "work horses." Additionally, seven participants discussed their "willingness to learn new things." Wentling $(1996,2003)$ found similar personality characteristics in a study on women in middle management positions in Fortune 500 companies.

Participants also described being passionate about working with student-athletes and in a college environment. Participants' descriptions of passion and work ethic suggest a level of commitment and dedication to work, which White (1995) identified as important attributes for women in executive management positions in male-dominated industries. Similarly, Grappendorf et al., (2004) also suggested commitment and work ethic were important for women seeking the position of Athletic Director.

Judy described a conversation with her mother who was upset Judy would not be coming home for the Christmas holiday. She explained:

My mom is super upset that I'm not coming home for Christmas. I'm like "Mom, I love my job. I love the fact that I get to go to this bowl game with this football team and that I'm going to be there, involved and useful. I get to do these things." And she's like "Yeah, I know. I know." You sacrifice Christmas at home because of the things that you like in your job. I'm good with that. I'm okay with that decision. I can't think of another job, right now, where I would love it as much to make that same sacrifice. 
Cindy talked about her passion for working with student-athletes and the importance of commitment:

I think it's really, really important to have a good work ethic. ... It's not about wins and losses, it's not about whether or not I like my athletic director, or not that's pretty bogus. This has to run a lot deeper than that, and you have to really have a commitment and a passion for making a difference in the lives of student athletes. You have to be committed to your department if you're going to be in athletics, and it is what it is. And if you don't want to do this, that's fine - just don't be an athletic administrator.

Barb discussed that she was "wired" to be passionate about working in intercollegiate athletics. She said, "It it's my wiring to feel passionately about (college sports) and it's my wiring to believe in it and then be willing to do whatever it's going to take to get over the hurdles." The ability to "get over hurdles" also suggested the importance of strategic planning.

Eleven participants perceived themselves as visionaries and "big picture" thinkers, while four said they were more comfortable dealing with "minutia." Participants also described themselves as problem solvers because they perceived the primary function of their job to be "putting out fires." As a result, some participants described feeling valued for their contributions to their respective department. They discussed the importance of strategic planning and observation when making decisions and communicating decisions to colleagues.

While strategic planning and decision-making are also skills, they require the ability to relate to others. For example, seven (Jenny, Judy, Roberta, Amanda, Barb, Vera, and Fritz) participants described the importance of being a "team player" and collaborative. They also perceived themselves as relationship builders between the administration and coaches, coaches and student-athletes, and the administration and 
student-athletes. Given her previous experience as a Division I coach, Barb described the importance of a "system of care" for student-athletes and coaches. She explained her role as an administrator: "I' $m$ trying to do every single thing I can to put an army around those (coaches and student-athletes) where you almost can't help but be successful.". Richie et al. (1997) described the ability to relate to and take care of others personality attribute as understanding self in relation to others. Self in relation to others is an important personality attribute that also seemed to act as a career support to women in this study because it allowed them to build relationships with supervisors, mentors, and professional networks. These supports are discussed in the section "Perceived Supports to Career" beginning on page 127.

Despite the fact that the majority of women in this study described a sense of confidence that they were valuable contributors to their respective departments, displayed a strong work ethic, and had strong relationships with colleagues, seven participants attributed career advancement to being "lucky" or "in the right place at the right time." For example, Martha a former development and major gifts office, described her "jump" to college athletics, "I was able to go from development to athletics without starting at the bottom in athletics. And I just tell people, 'I did a good job, and I was lucky.'" This thought process is an example of an external career locus.

An external career locus suggests that career success is due to chance (O'Neil et al., 2004) or luck. For example, Judy stated that despite being well-qualified for a compliance position at a large Midwestern state university she was "just lucky that (she) fell into the (university) position." Other participants, however, acknowledged their work ethic, skill set, and reputation aided in their career success. Such self-awareness and 
advocacy is an example of an internal career locus or, "a belief that one is responsible for one's own career success and in charge of managing one's future career" (O'Neil et al., p. 478). O'Neil and Bilimoria (2005) suggest a woman's career locus changes over time. The results of this study present a snap-shot of participants' perspectives on their careers. Based on the results, however, I cannot conclude if and how career locus changed over time.

Early career experiences. Studies have indicated that early job or work experiences give men and women important information about future careers (Lapour \& Heppner, 2009; Stringer \& Kerpelman, 2010). This process is known as vocational anticipatory socialization (Jablin, 2001). Vocational anticipatory socialization includes the socialization influences about work and industries before the job search process begins (Jablin, 2001). Thus, the information derived from these experiences can be used to make decisions about career expectations, and goals. Early experiences may include volunteer and/or job shadowing opportunities, internships, graduate assistantships, and/or entry-level positions in an organization.

Before beginning their careers in intercollegiate athletics, the women in this study expressed varied career aspirations, including becoming a high school teacher and/or coach (four participants), law (three), medicine (two), intercollegiate athletic administration (two), accounting (one), architecture (one), athletic training (one), and business (one). Participants discussed changing career aspirations for several reasons, but most often changing aspirations due to early career and educational experiences. Of the four women (Jane, Mary, Cindy, Donna) interested in working in high school, three wanted to coach. When participants realized they also had to teach in a classroom, their 
career interests began to shift. Donna explained, "I had a really bad student teaching experience and realized my senior year that I didn't want to be a teacher, so I never went into the coaching field." Similarly, three women (Fritz, Jenny, Tracy) enrolled in law school, but only one finished the degree. The other two described experiences in which summer internships with firms changed their perspectives on law as a career. For example, Jenny, spent time working for a local attorney before attending law school and from the experience she explained, "I realized that was not the career path for me." In terms of sport, three respondents - Amanda, Tracy, and Jane - began their careers working in professional sport, but decided to pursue other avenues in sport following unfulfilling work assignments and office environments. Jane described selling tickets for a Northern single-A minor league baseball team as "pulling teeth." She described a desire to work in an area with a passionate fan base, which she later found in college athletic. After a year of attempting to sell season tickets for a losing Midwestern professional football team and dining at training tables with football players, Amanda said, "Enough of that!"

Initially, Julian wanted to be an athletic trainer. Her senior year in college, she had a "quarter-life crisis" and realized athletic training was not a career fit. She spoke with her father who encouraged her to consider obtaining a Master's in Sport Administration. While working on her Master's degree, Julian interned in a university compliance department where she found her professional niche. Tina, Donna, Jenny, Judy, and Amanda all had similar positive experiences in which internships within athletic departments helped them clarify career interests in working in college athletics. Mary, Vera, and Cindy worked with student-athletes and coaches at their respective 
universities despite working in departments outside of athletics. Their experiences also led them to consider working in an athletic department. In sum, fond memories of sports, interactions with student-athletes, and/or the support family, friends, and colleagues spurred participants to pursue careers in intercollegiate athletic administration.

When entering the field intercollegiate athletics in administrative positions, participants described taking jobs for the sake of learning new skills and earning money. Four participants had internships with the NCAA. Eight participants interned or held graduate assistantships in college athletic departments. Two participants (Barb, Roberta) had coaching experience. In addition to coaching, Roberta also had administrative responsibilities within her department. The majority of participants indicated these early career experiences offered a glimpse into expectations of a career in intercollegiate athletics. They described working in departments in which they were the only female on staff, long work hours, and the enjoyment of working closely with student-athletes and coaches.

As a result of these experiences, nine women described initial career goals in intercollegiate athletics of becoming the Athletic Director for an NCAA athletic department. Twelve women identified "making a difference in the lives of studentathletes" as a goal, while three participants focused on the success of coaches. As careers evolved, participants' expectations and career goals shifted from a focus on professional skill development and title attainment to an interest in providing a contribution to their respective departments. At the time of data collection, only four participants indicated a desire to pursue the position of Athletic Director. Eight women stated they had no interest in being an Athletic Director at any level, while three would consider the role at 
NCAA Division II or Division III institutions. This is a key finding of this study. A more in-depth exploration of perceived career supports and barriers may help explain the shift in career expectations and goals may occur. The following two sections discuss perceived supports and barriers to careers in intercollegiate athletics.

\section{Perceived Supports to Career}

The primary purpose of this study was to understand the career experiences, expectations, and goals of women in senior-level management in NCAA Division I intercollegiate athletics. Understanding the experiences of women at this level may help researchers and practitioners understand (a) why there are so few female Athletic Directors as well as (b) the type of environment in which women's careers may flourish. All participants discussed people, programs, or environments they viewed as supports for their careers. Supports are factors perceived to enhance career development and influence career choice, expectations, and goals (Albert \& Luzzo, 1999; Astin, 1984; Betz \& Fitzgerald, 1987; Lent et al., 1994; Savickas, 2002). From this discussion, three primary supports emerged: (a) interpersonal relationships, (b) professional development activities, and (c) career advancement opportunities.

\section{Interpersonal relationships}

Women rely on a variety of interpersonal relationships to support their career development (Betz, 2006; O'Neil \& Bilimoria, 2005). Career development theorists (Astin, 1984; Forrest \& Mikolaitis, 1986) contend that the social-relational component is critical to consider when assessing a woman's career development. According to Forrest and Mikolaitis, women "reflect their sense of identity primarily in terms of their relation to others" (p. 79). All of the women in this study were quick to identify a specific person 
or group of people as career supports. More specifically, participants attributed relationships with supervisors and mentors as critical factors in career development and success. It is important to note supervisors can also be mentors. Many participants, however, also identified supervisors as barriers to career development. Therefore, supervisors and mentors are discussed separately as to clarify the role of supervisor as a support and, later, as a barrier.

Supervisors. Participants described their supervisors and mentors as confidants, resources, and positive supports. When participants viewed supervisors as confidants, they seemed more able to express professional frustrations or discuss personal difficulties such as work-family balance with them. For example, Barb, frustrated with inequities she experienced as an NCAA Division I coach, expressed her frustration with her Athletic Director (supervisor). Unhappy with the response she received from the AD, Barb sought the guidance of a long-time mentor and former supervisor who advised her to look for a position at another university. Cautious about discussing her family life at work, Julian discussed the role of her supervisor as a support for achieving more balance:

My boss is great. She is very - obviously I just told you that she is yelling at me to take vacation; you don't really have that very often. And it's interesting because she's single, she doesn't have a family and so you never know, I'm always really cautious with that. Because you don't know till you have kids and you don't know till you have a family, the time demands, but she gets it. So I feel she's super, super supportive. (She) is definitely not the cause of my stress.

Additionally, several women indicated the importance of a collaborative, yet autonomous relationship their supervisor as a support. Participants defined collaboration as "being on the same page" with supervisors while also having a "voice" in organizational decisions. For Judy, an associate AD at a large Metropolitan university, a collaborative relationship with her supervisor was important. Judy (p.23) stated, “A 
collaborative relationship with [my boss] allows me to still feel like I'm making a difference." Donna, an associate AD now in her ninth year at her current institution, described her relationship with supervisors as "great." She discussed the importance of feeling as though she had the authority to make decisions, "I feel like I get to determine everything we do here" (Donna, p. 16). Several women in this study echoed the importance of having "authority" to make decisions because they described feeling more able to "make a difference."

Participants perceived supervisors to be a source of positive support by providing guidance and direction, access to professional development opportunities, and encouragement. Early in her career, Julian described feeling as though her boss had taken a risk when hiring her due to her lack of experience. She explained, "He just kind of molded me into what he wanted me to be... he still feels like I' $m$ under his wing and wants to still make sure that I'm guided in the right way." When Tina was hired as a compliance coordinator at a mid-sized urban university, she felt an immediate connection to her supervisor because he was willing to help her develop professionally. According to Tina, her supervisor stated, "If you come in here, you do a really good job, we feel that we're training you to be an administrator, then you will have every right to be the first person to take that role as an Assistant AD and become the SWA." Tina explained that having a supervisor who was willing to invest in her future instilled a level of trust and respect. Additionally, Tina described being motivated to "do the job well and move up the ranks."

All participants were grateful for the professional development opportunities provided by their supervisors. Participants identified professional development 
opportunities as: networking through attendance at regional and national conferences, participation on conference committees and in institutional, regional, and national leadership activities; assuming more responsibility in the department; and/or, being granted a more prestigious title such as Senior Woman Administrator. The SWA title gives women access to participation on NCAA committees, which often leads to networking opportunities.

Participants' descriptions of interactions with supervisors suggested a relationship predicated on trust and understanding. Moreover, several participants described an increasing sense of self-confidence when working with a supportive supervisor. An increase in self-confidence has a cyclical effect. The more self-confidence participants had, the more likely they were to take on additional responsibilities. The additional responsibilities helped women learn new skills, while refining others.

Mentors. In addition to networks, building a relationship with a mentor is another way for women to accumulate power and reduce the impact of barriers (Kanter, 1977; Cullen \& Luna, 1993; Eby \& Allen, 2004; O’Neil et al., 2004). Kanter (1977) suggested that the primary function of a mentor was "to make introductions or train a young person to move effectively through the system" (p. 181). According to Kram (1983), a mentor relationship can enhance the career and psychosocial development of mentor and protégé.

All of the women in this study identified mentors critical to their career progression and development. For participants in this study, mentors fell into one of two categories - conventional or peer. Based on participants' descriptions, conventional mentors are older men or women who have extensive work experience and may sit in 
positions that protégés seek to achieve. For example, Vera's ultimate career goal is to hold the Athletic Director position at an NCAA Division I institution. Some of her mentors were men and women who have held or currently hold the title of Athletic Director at similar institutions. Peer mentors, as defined by participants, are men and women who have several years of experience in the field, but hold positions similar to the women in this study. Jenny described the importance of peer versus conventional mentors:

I look around and the people who I work with now, in the age range that I'm in. They've all continued to rise up ladders and are on the cusp of being in really big positions in our field. Those relationships across have been more influential, in terms of relationships. They provided a more comfortable place for me to figure out how I wanted to interpret the roles I was in. How I wanted to work according to my principles and values, the decisions I needed to make along the way. I might take those pieces from the more traditional mentors and then discuss with my lateral mentors, my peers, and figure it out in a way that worked for me and the role I was in at the time. Because what I learned too is that the mentors that are older have taken a different path. A lot of them didn't come up the way that I'm coming up. (Jenny, p. 9)

The participants' definitions of peer and conventional mentors are similar to definitions coined by Kram and Isabella (1985). Regardless of the type of mentor, conventional or peer, women identified mentors as supports for several reasons.

Many women identified mentors as career supports based on their willingness to provide professional advice, guidance, and feedback. For Fritz, Martha, Barb, and Vera, all aspiring Athletic Directors, mentors provided strategic career advice. Fritz relayed a story about working with a male mentor who offered her strategic advice regarding her "next step" professionally. The mentor told Fritz, "A lot of women go into student welfare and compliance. If you want a new experience that would probably put you in a 
better position to vie for an athletic director position, I would recommend going the business route."

Martha had a similar experience with another male mentor. While in conversation with her mentor, Martha expressed her desire to be an Athletic Director and sought a mentor willing to take her "under his wing." The mentor agreed to work with Martha and offered advice on joining a new athletic department, "There's a lot more layers of the onion between your position to the athletic director at that (University) than there would be between you and me at (this University)." The "layers of the onion" not only provided Martha insight into departmental hierarchy, but also alluded to the type of decision-making authority she might have. Additionally, Martha explained her mentor has been "fantastic" by giving her more responsibilities in the department, but she felt professional development opportunities in terms of networking and attending conferences were "lacking."

Barb left her coaching position with a United States national level sport team to work as an administrator in college athletics. An Athletic Director at an NCAA Division I athletic department relentlessly pursued her. He later became her supervisor and mentor and taught her the importance of a "silent partner." A silent partner is the "number two" person in the office who can build relationships and credibility with student-athletes, coaches, university faculty, and community members. Barb's reputation as an outstanding "silent partner" and "number two" has garnered national attention from athletic departments at large NCAA Division I FBS institutions. Conversely, Barb learned from another mentor - a female AD at a large Division I FBS school - that she should consider the job of AD "with caution." Barb explained her female mentor 
described the AD job as "not worth it" especially "if you're in a great number two spot with the right person (as AD) who is already compensating you at a certain level." Currently, Barb earns in excess of $\$ 100,000$ a year.

For the 11 women in this study not interested in pursuing the title of Athletic Director, mentors were still vitally important for career guidance and development. While the majority of women in this study specifically identified male mentors, about half ( 7 participants) also discussed the impact of one or more female mentors. Five women discussed the "first visual" of seeing a woman in athletic administration. That visual provided the "initial push" or interest in pursuing a career in intercollegiate athletics. As a student-athlete, Tina described having a female athletic administrator as a mentor, "She was what I aspired to be. She wanted to help student-athletes succeed. That's what I wanted to do."

Jenny described her experience with a female mentor while working at the NCAA. The mentor "shared her authority" and offered Jenny "greater visibility" by allowing her to work on major organizational projects and giving her a voice in the decision-making process. Cindy also learned the importance of visibility in an athletic department from her mentor who "set the tone" for other women in the department. She explained, "I learned a long time ago, the more you're in the office, the better administrator you're going to be."

Jane's mentor (and supervisor) provided opportunities that pushed Jane out of her “comfort zone." For example, Jane's mentor asked her to facilitate departmental meetings attended by 300 staff members. Initially, Jane doubted her ability to conduct the meeting, but her mentor said, "Yes, you can." Jane found that she enjoyed 
conducting the departmental meetings. Moreover, her success with the meetings led her mentor to give her more responsibility and "ownership" over projects. While Jane said she did not intend to become an Athletic Director, her mentor encouraged her to be more visible and assume more responsibility. In turn, Jane indicated she gained more confidence in her work and in her role as an administrator.

Mentors acted as sounding boards for participants when they wanted to explore new job opportunities. Julian referred to her mentor, a woman, as a "lifeline" that helped her "get (her) foot in the door" for various positions in intercollegiate athletics. Additionally, Julian relied on her mentor for honest advice; "She'll give it to me straight. If I have no business going for a job, she'll say, 'No. What are you doing?" Other participants had similar experience with their mentors. Amanda discussed the importance of having mentors who were willing to share career advice: "I think always having someone you can talk to openly is a great support. Event if their path has been different from yours, it's someone you can trust and talk to."

Both male and female mentors provided professional guidance, but participants were more likely to discuss seeking personal guidance from female mentors. For example, Martha explained she has one mentor, a female, she "trusts enough to be able to bounce ideas or frustrations off of." Julian also felt more comfortable discussing personal difficulties managing responsibilities of her family with her female mentors. Tina sought comfort in a female mentor when her male AD told her she "didn't have the face for college athletics."

Two participants in this study discussed feeling as though women were not always readily available as mentors. This finding, similar to other studies (Andrew et al., 
1990; Richie et al., 1997; White, 1995), might suggest that women expect other women to serve as role models and mentors or as one participant described, "shepherds," in a the male-dominated college sport industry. Participants perceived women were unavailable because (a) of the dearth of women in senior- and executive-level positions, or (b) women were not willing to serve as mentors for a variety of reasons. Judy explained:

Most of the people, who I have looked to and turned to and asked for advice from in terms of my career, have been men. A part of that is just that it is the nature of there are no women in the business. But as I've grown in the business and observed more and paid more attention I also feel like women are not as supportive of other women. (Judy, p. 8)

Vera described the positive influence of male mentors early in her career. As time progressed, however, she proactively sought out women. Vera discussed that women "need to do a much better job of networking women, learning from women, being mentored by strong women."

Eshner, Thomas, and Murphy (2001) suggest protégés need to develop clarity and expectations around their expectations for mentors. Additionally, protégés should develop a network of mentoring relationships and "consider the accessibility of a mentor" (p. 434). Mentor accessibility is particularly important to consider in intercollegiate athletics. Judy explained that finding a female mentor was difficult if not disappointing. She explained, "I would speak to a woman who was strong and successful. I would ask them if I could reach out to them and contact them. I would do it and then I wouldn't get a response." Young and Perrewe (2000) suggest mentors have multiple time constraints and responsibilities. Thus, taking on a protégé perceived as an additional task (Young \& Perrewe). 
In sum, mentors provided career guidance and support (Cullen \& Luna, 1993; Eby \& Allen, 2004; Kanter, 1977; Kram, 1983; Kram \& Isabella, 1985). More specifically, mentors for aspiring Athletic Directors offered strategic career guidance. They offered feedback to help participants align their career paths with their ultimate career goal of becoming an Athletic Director. Mentors for women who did not wish to become an AD provided opportunities for professional growth and advancement by encouraging work on projects that would lead to greater visibility and strategic decision-making. They also served as a source of support when women struggled with issues such as work-family balance or a difficult situation at work. In addition, mentors helped instill confidence by encouraging women to explore professional interests and step out of their comfort zones to assume more responsibility.

Male mentors were more likely to provide career mentoring to women, while female mentors were provided psychological and career mentoring. These findings are similar to studies by Cullen and Luna (1993), Eby and Allen (2004), Kanter (1977), O’Neil et al. (2004). Furthermore, Kram and Isabella (1985) suggested primary functions of peer mentoring included information sharing, career strategizing, job-related feedback, and confirmation. Results of this study suggest more conventional mentoring relationships functioned similarly. Finally, O’Neil et al. (2004) and Bower (2008) suggested mentoring relationships could result in rapid career advancement for women in management and sport administration. While participants identified mentors and supervisors as career supports, it is not clear if career advancement occurred at faster rate for women with mentors as opposed to women without. 
The role of interpersonal relationships as a career support is further substantiated by the finding that women in this study described the importance of self in relation to others - a personality characteristic. Not only do they seek to take care of others, women in this study build relationships, in a sense, to also be taken care of. Moreover, male mentors seemed to play a more critical support role to participants. Perhaps this is a reflection of the role fathers, brothers, and interactions with other male figures played in socialization to sport and sport as a potential career field. More research is needed to understand the role of male and female mentors in the vocational socialization of women in intercollegiate athletics.

\section{Professional Development Activities}

Professional development activities as components to career development and success have been studied in varying degrees in intercollegiate athletics (Cunningham \& Sagas, 2002; Cunningham, Sagas, \& Ashley, 2001; Sagas \& Cunningham, 2004a, 2004b). Sagas and Cunningham (2004a) suggested professional development activities included the accrual of social capital and human capital. Social capital includes "resources acquired through individual's networks with subordinates, superiors, and peers" (Sagas \& Cunningham, p. 413). Human capital is the accrual of job-related investments including education, experience, training, and specific competencies (Sagas \& Cunningham).

In the context of this study, participants defined professional development activities as a combination of social and human capital including networking and opportunities to gain experience and develop skill sets. Access to and participation in networks may help women gain access to organizational and industry resources 
(Wentling, 2003). Skills and job competencies are critically important to career development and achieving career expectations, and goals (Richie et al., 1997; Wentling, 1996, 2003; Whitmarsh et al., 2007).

Networking. Several sport management researchers have suggested participation in formal and informal networks is integral for advancement within sport organizations, particularly, for women (Bower, 2009; Grappendorf \& Henderson, 2008; Hums \& Sutton, 1999; Judd, 1995; Shaw, 2006). Forrett and Doughtery (2004) defined networks as a person's "attempt to develop and maintain relationships with others who have the potential to assist them in their work or career" (p. 420). In addition to supervisor support and mentoring opportunities, networks can serve as career facilitators for women and may be critical to women's career development (Bower, 2009). Networks are an important source of organizational knowledge through which trust, reciprocity, information, and cooperation can be cultivated (Kanter, 1977; Kumra \& Vinnicombe, 2010; Sagas \& Cunningham, 2004; Wentling, 1996, 2003).

Each participant identified networking as an integral component to her career progression and development. To illustrate, all of the participants indicated they are in their current positions because of their professional networks. Barb met her current supervisor while coaching at a Western state university. As Barb and her supervisor moved to various institutions over the course of their careers, they maintained contact. One day, he called her with an opportunity that would change the course of her career from coach to administrator. She explained:

My (soon-to-be) boss said, "Come back here, let me pay you a decent salary. We're going to build this, everything that's ever been wrong with college athletics; we're going to fix it here."Okay now that interests me, because that's 
building.

Not only is networking a key component to employability, but developing relationships was also perceived to be critical for creating and managing career (Forret $\&$ Dougherty, 2004). In each case, the women had network contacts at their current place of employment or a network contact that encouraged them to apply for the position. Julian, described a situation in which she had applied for a position at another school, but never heard anything back from the hiring department. A few months later, her mentor became an associate athletic director and Senior Woman Administrator in the department to which Julian had applied. Julian sent her mentor a congratulatory email to which the mentor responded, "Are you still looking to get out of (university)? I think I might have something for you." Julian explained she had applied for the job, but sent new application materials. She was hired and moved two weeks later.

Participation at a conference or on an NCAA committee was also identified as an important networking opportunity. A person in a high-ranking position in the athletic department, however, must initiate committee participation at the conference or national level. For example, Jane participates on a conference championships committee at the suggestion of her supervisor. Her supervisor is well known in the industry and holds a high-ranking position in her athletic department and serves on one of the most influential committees in the NCAA. Additionally, attendance at regional and national conferences helped women build and extend their networks with individuals in powerful positions. As Julian explained:

When I was at the (conference) it was great because the meetings that I would have to go to were always with athletic directors, SWAs, and faculty reps, which are your big dogs on campus. And so I got to know all of them.... It was a huge networking opportunity for me. To get outside of the box a little bit, to meet 
some folks outside of compliance, which was an unbelievable opportunity. (Julian, p. 13)

Several participants indicated the importance of networking outside of their respective areas of expertise. For example, at her institution, Donna served on committees that had nothing to do with athletics so she could network beyond the athletic department. This relationship served to build a bridge between athletics and other departments on campus. In addition, the extended institutional network has served her "very well" when working on student-athlete issues.

Attending conferences and committee participation, however, does not automatically result in an expanded network. Some studies suggested that women have difficulty accessing networks (Gregory, 2009; Kanter, 1977; Kumra \& Vinnicombe, 2010). Accessing networks, however, can prove challenging without the help of supervisors and mentors (Kanter, 1977; Sagas \& Cunningham, 2004). Only one woman in this study, Martha, expressed frustration at her inability to access networks:

Unless you travel with your teams from school to school and meet people there, at the conference level and the NCAA level, you cannot get on the committee unless you' re the AD, senior woman administrator, or faculty athletics representative. And I find that extremely limiting and so there's a challenge that I-there's a roadblock that we have. If you're sitting on a conference committee or an NCAA committee, you're building a network which is going to spread, but if you're not, you just don't have any pipeline what-so-ever (Martha p. 9)

Martha's frustration is a product of a barrier she perceives to be impeding her ability to reach a career goal - becoming an Athletic Director. While Martha recognized the opportunity to network with other Athletic Directors and SWAs at national conferences, she perceived those opportunities to be limited. Participation on a committee at an NCAA or conference level offers prolonged engagement with potential employers and 
mentors, while annual attendance at a conference does not. Without the title of AD, SWA, or faculty athletics representative, Martha described feeling "capped."

It is important to note men may also have difficulty accessing conference and NCAA committees. When considering the proportions of male Athletic Directors (91.7\%) and male faculty athletics representatives (68.5\%) at the Division I level (Lapchick, 2010), it would appear women are underrepresented. Studies have identified gender as a barrier to accessing networks, but limitations to national networks are more a function of organizational structure. The committee structure created by the NCAA has the potential to "cap" both men and women.

Conversely, Vera did not feel her networking opportunities were limited. Instead, she perceived "getting to know people" and "attending conferences and engaging in committee structures nationally" were important to enhancing her skill set, leadership style, and experience. Vera's statement epitomizes the importance of networking and professional development activities for many women in this study. All of the women identified professional development opportunities as key experiences in which they expanded networks through participation on committees and attendance at conferences. It should be noted, however, Vera is a senior associate AD and SWA. By virtue of her title, Vera has access to networking opportunities that participants like Martha do not. Martha's frustration, then, may be a product of her career goal - becoming an Athletic Director. No other participant felt limited in her networking possibilities.

In this study, participants perceived networks to be an important support to career development. Networks provided opportunities to develop relationships with peers and potential employers in intercollegiate athletics. Research suggests even though women 
can benefit from networks, networks tend to be less beneficial for women than for men (Forret \& Dougherty, 2004; Kumra \& Vinnicombe, 2010). Sagas and Cunningham (2004a) found that men were more likely to "reap the benefits" (p. 419) of networking. They also suggested women might be experiencing discrimination in the promotions process. In this study, participants perceived networking to be valuable to their career development. In addition to networking, participants perceived skill acquisition as vital to career development and success. Based on the findings of this study, there is little evidence to suggest discrimination in the hiring and promotions process.

Skill acquisition. Acquiring skills through a variety of experiences was perceived as another key component to the professional development of women in this study. Skills and job competencies are critically important to career development, expectations, and goals (Richie et al., 1997; Wentling, 1996, 2003; Whitmarsh et al., 2007). When women engage in education and training, they develop skills and competencies that may increase performance quality, self-efficacy, and the likelihood they will persist in the face of obstacles (Betz, 2004; Wentling, 2003). Gaining relevant, practical experience and education to obtain a skill set necessary for advancement is also a common theme in literature pertaining to the careers of women in sport organizations (Bower, 2008; Claussen \& Lehr, 2002; Grappendorf et al., 2004; Greenhill et al., 2009; Hoffman, 2010; Hums \& Sutton, 1999).

Participants discussed the importance of learning technical and interpersonal skills. Participants identified technical skills such as crisis management, decisionmaking, effective problem solving, budgeting and finance, compliance and eligibility, and facility operations as critical for professional success. From her experience at NCAA 
institutions and with a major intercollegiate governing body, Jenny explained the importance of technical skills in career development. She said, "Follow the money. Understand complex revenue packaging. Know how to deal with crisis and work on decision making skills." Vera also discussed the importance of particular technical skills:

I knew I had to develop the skills in the areas of fund raising. I knew that was really important. I didn't have an MBA. I didn't have the business background. I thought really working on the fundraising side on behalf of the university and also the department, I thought was an area I could develop some skills.

To acquire technical skills, participants described accepting positions early in their careers to "learn as much as possible" while wearing "many hats." Often early career experiences included positions in small departments at various NCAA divisional levels. Developing a relationship with a supervisor or mentor was also important because the supervisor/mentor not only had the capacity to offer advice on acquiring necessary skills, but often provided access to positions or projects where women could develop and hone skill sets. For example, Amanda suggested she is still learning despite the length of her career:

Even though I've been here for almost 15 years, I'm still learning new things. Once (an associate AD) left, I didn't necessarily replace his Associate AD title for external affairs. But, I was given the opportunity to be in the Monday morning executive staff meetings, so I'm in there with all Associate ADs and Senior ADs, but I'm the only marketing representative that's in there. (Amanda, p. 11)

Amanda's experience is far from unique. Over half of the participants discussed the importance of having access to senior staff meetings for the networking opportunities, but also to gain a better understanding of the departmental decision-making process. For some participants, being present "at the table" parlayed into having a voice in the department's decision-making process. As Jenny described, having an influential voice in the decision-making process helped her communicate and execute plans more 
effectively. Vera discussed "taking on" new responsibilities that will help her continue to grow, while also preparing her for "the chance to sit in the Athletic Director's chair within a couple of years."

In addition to technical skills, interpersonal skills were identified as critically important for managing and leading people. Participants perceived a combination of technical and interpersonal skills were important because intercollegiate athletics is a "multidimensional business" that affects the lives of student-athletes, coaches, administrators, and spectators. The skills identified by women in this study were similar to those identified by female Athletic Directors in studies by Grappendorf et al. (2004) and Knoppers and Anthonissen (2007).

Interpersonal skills were described as important for facilitating effective communication with student-athletes, coaches, administrators, and network contacts. Participants suggested important interpersonal skills included honesty, delegating responsibility, understanding various constituencies, and trust. Developing interpersonal skills with various constituencies takes time and can be a hard lesson learned. For example, Judy described a time when she approached a men's basketball coach about a compliance issue. She left the coach's office in tears. As a result, Judy described how her approach to working with coaches changed:

Learning how to get what you need from them without annoying them or making them angry. Knowing how to deal with people comes in handy because you deal with a head football coach differently than you deal with your softball coach. You just talk to them differently. You listen differently. You respond to them differently. (Judy, p. 13)

Cindy discussed the importance of "timing" when sharing information with coaches and administrative staff. Timing was a skill she learned through working with 
people over an extended period. She described timing as a combination of understanding personal relationships and communicating important information. Developing personal relationships to better understand how to communicate and manage people also involves a level of trust. Barb suggested trust was a "commodity" earned through action and visibility. She explained, "I have no ego about doing something differently. ... I feel like I never deal with a residual of (coaches) going, "What the hell is she doing?" Trust is the most important commodity you have as a co-worker. I'm always very mindful of that, so I'm not fucking with it."

Interpersonal skills also incorporate personality characteristics. Vera described herself as intuitive, approachable, friendly, attractive, and energetic. She explained, "I think those things don't hurt you in this profession." Other participants described themselves as having "worker bee" personalities. A "worker bee" is someone with a strong work ethic who is also visible in the organization. Participants perceived a strong work ethic and visibility as mechanisms to build trust and credibility among coaches and other administrators. Credible relationships were perceived as essential when managing coaches or leading a department.

Conversely, several women described their work ethic as a metaphorical willingness to work "in the trenches." Often work in the trenches consisted of performing lower skill tasks, which should have been handled by entry-level employees. While these behaviors may seem egalitarian and laudable, "working in the trenches" may lead to the perception that a woman is not able to delegate responsibilities. Women identified delegation as a critical skill for career progress. The perception of being unable to delegate may limit a woman's opportunity for advancement. Furthermore, the 
worker-bee mentality and the willingness to work "in the trenches" may also be indicative of women attempting to "prove" themselves in a male-dominated environment. This type of behavior is typical of "token" women in male-dominated professions (Kanter, 1977; Richie et al., 1997; Whitmarsh et al., 2007), including sport management (Claringbould \& Knoppers, 2008; Grappendorf \& Lough, 2006; Grappendorf et al., 2004)

Skill acquisition and development are important because women in this study perceived them to be essential for career advancement. The idea of advancement is complex. For some women, advancement equated to vertical mobility in a specific athletic department or movement to progressively more responsible roles in various departments based on job availability. Other women in this study considered advancement as the opportunity for continuous development as a professional. These women perceived continual development as a catalyst for making a greater impact, or contribution, to student-athletes, coaches, and the department.

\section{Career Advancement}

According to research, building networks and gaining practical experience to obtain a skill set necessary for advancement are common themes in literature pertaining to the careers of women in sport organizations (Bower, 2008; Claussen \& Lehr, 2002; Hums \& Sutton, 1999; Grappendorf et al., 2004; Hoffman, 2010; Greenhill et al., 2009; Sagas \& Cunningham, 2004). In this study, participants defined advancement as vertical movement through the organizational hierarchy and/or assuming more responsibilities within the department or athletic conference.

For Martha, opportunities meant "some upward mobility and promotion in terms of being recognized for service and work." Fritz suggested moving "early and often" as a 
way to gain a variety of experience and "move up" in a department. Judy took her current position because it was a better title, more money, but also an opportunity to supervise staff and coaches.

Judy cautioned, however, "it's not always about the title." For example, Jenny had the opportunity to leave her current institution for a position with a bigger title and more money in a more prestigious athletic conference. She chose to stay in her current position because her supervisor and the Athletic Director offered to develop her as an administrator by providing opportunities to work on special projects and administrative responsibility for a varsity sport. Jenny said she has no intentions of becoming an Athletic Director.

For Jenny and other women interested in assuming more responsibility, skill acquisition was perceived as an important component of advancement. For example, Donna's first position in intercollegiate athletics was as an associate athletic director at the Division II level. While the learning curve was steep, Donna quickly readied herself to assume more responsibility. She asked for more opportunities including budget management and sport supervision, but her supervisor would not delegate the responsibilities. Donna understood not having these responsibilities would affect her ability to advance in college athletics. She soon looked for a position at another institution. Moreover, the majority of women (12) described their initial experiences in intercollegiate athletics as opportunities to "learn the industry" and get their "feet wet" by working in a variety of areas. As their careers progressed, the women described becoming more deliberate about looking for positions that would better fit their interests and personal and professional goals. 
Additionally, research suggested advanced educational degrees were critical for obtaining a position in intercollegiate athletics (Grappendorf et al., 2004; Smith, 2005). Thirteen women in this study have advanced degrees. Ashley, an assistant athletic director and the youngest participant in this study, expressed interest in earning a master's degree in "the next few years." Other research has shown that experience, not education, is a more "effective tool for women wishing to advance in intercollegiate athletics (Grappendorf \& Lough, 2006). Barb, an executive senior associate athletic director, has her Bachelor's degree. She explained that she never finished her Master's degree and "never had to" because she entered college athletics at a time when "a tsunami of opportunity was coming for women." She continued:

I hear people say it's critically important, but I know that I'm not looking at people's academic body of work when I go to hire them. (I want to know), what can you do? I don't care how you were trained - whether it's through academics or through experience. (Barb, p. 3)

Advancement, whether conceptualized through vertical movement in an organizational hierarchy or assuming more departmental responsibility, was contingent upon other supports mentioned in this section. Rarely did women seek out or consider new positions without the guidance of a supervisor or mentor. They engaged networks to learn about other opportunities and find support when dealing with difficult personal and/or professional issues. All of the participants in this study attributed their career advancement to (a) the relationships built with supervisors, mentors, and through networks; and (b) a refined skill set.

\section{Summary}

In this study, career supports gave participants the confidence to assume more job responsibility, consider new professional opportunities, and develop professional 
interests. Understanding the function of career supports is important because supports provide insight into mechanisms that help women navigate a complex industry. Participants perceived the cultivation of interpersonal relationships and participation in professional development activities as critical to career advancement. Studies beyond the context of sport management (Richie et al., 1997; Wentling, 1996, 2003; Whitmarsh et al., 2007) and in sport management (Inglis et al., 1996, 2000; Sagas \& Cunningham, 2004; Smith et al., 2012) also suggest the supports identified in this study are important to women's career development. While supports are important to career development, the identification of barriers are equally so. The next section identifies factors women perceive as barriers to their career development.

\section{Perceived Barriers to Career}

Barriers are factors that can impede career development and the achievement of career goals (Albert \& Luzzo, 1999; Astin, 1984; Betz \& Fitzgerald, 1987; Lent et al., 1994; Savickas, 2002). Barriers may consist of structural and/or social determinants (Astin; Lent et al.). Participants in this study identified the male-dominated culture of intercollegiate athletics and its myriad challenges as barriers to career development. The combination of these factors in addition to extra-work responsibilities (e.g., children, spouse, parents, friends) presented challenges to participants in their career development, expectations, and goals.

\section{Male-Dominated Industry Culture}

"It is a male dominated business, not just from a numbers game but a perspectives game" (Roberta, p. 15). The majority of women in this study echoed Roberta's observation. Some participants referred to college athletics as "male-dominated," an 
environment of "masculine traits," or a "good ol' boys network." While participants acknowledged there appear to be more women in the field - particularly in more entrylevel positions - participants perceived men dominate middle and upper-level management positions both in numbers and organizational decisions. Statistics on men in intercollegiate athletic administration support this perception (Lapchick, 2010). For example, men represent $91.7 \%$ of NCAA Division I Athletic Directors and occupy early $70 \%$ of associate athletic director positions.

According to Jenny, "The judgment and the projection that comes from a primarily masculine or male-dominated mindset is something that is constant." Jenny went on to explain that while women are actively participating in the governance and administration of intercollegiate athletics, women are not reflected in the culture. Furthermore, women in intercollegiate athletic administration still contend with gender stereotypes, which may also affect the positions they seek in athletic departments.

Gender. Several studies on management have identified gender as a barrier to women seeking executive level managerial positions (Beatty, 2007; Betz \& Fitzgerald, 1987; Duehr \& Bono, 2006; Schein, 2001, 2007; Wentling, 1996, 2003). Similarly, studies on women in intercollegiate athletic administration have also identified gender as a barrier (Burton et al., 2009; Burton et al., 2011; Grappendorf et al., 2004; Whisenant et al., 2002). All of the women in this study perceived gender as a barrier to their careers in intercollegiate athletics for three reasons. First, some women perceived "being a woman" as a barrier primarily because of the manner in which men perceive gender. Other participants suggested women created barriers for each other by not offering more career support and guidance. Finally, participants perceived another barrier to be the limited 
experience women have in high levels of intercollegiate athletic administration. In other words, if women have the opportunity to assume an Athletic Director position, "Are we ready?"

Several women in this study suggested being a woman in a male-dominated industry was a barrier to career development. Stereotypes associated with gender have the potential to act as "subtle yet powerful" barriers to women's career development (Duehr \& Bono, 2006). Women identified experiences in which they perceived their physical attributes or personality characteristics were viewed negatively because they were women. For example, Tina - a self-described larger woman - was told by a male Athletic Director she "didn't have the face for college athletic administration." Roberta, a minority, also offered, "The women that get promoted a lot of times in this business are not the women who look like me." Such statements could lead one to assume only women of a certain level of attractiveness and are suitable for administrative roles.

Early in her career, Jane said she was afraid to speak in staff meetings because she was afraid of being perceived as a "bitch." Vera described how some women get branded as a "battle ax" when they voice opinions. Judy acknowledged her "overbearing and bossy" personality as an issue while also identifying why such a personality type might be a barrier for women:

I know sometimes personality is a factor and strong women often times have what is perceived as overbearing and bossy personalities. I certainly have that and I've had to work on that over the years. That's one thing, especially my male mentors have pointed out. "You are a strong woman. You have to be able to curb that in certain situations or you alienate the people that you're trying to get to." (Judy, p. 13)

Roberta also discussed her perceptions of why certain types of women succeed: 
The women that get promoted in intercollegiate athletics, I believe, are the women that men feel comfortable with and that they will find solutions that are appeasing to the people who they should please. Women come to this business trying to please and at the point that you try to please I think then you have gotten into the whole vicious cycle of the all boys' game. Because that's what you're expected to do is to please. (Roberta, p. 18)

As such, Roberta perceived her gender to be a barrier because she felt she did not meet the aforementioned expectations of male administrators. Vera explained, "Men seem to have a comfort level with certain types of women" such as those who are perceived to be team players, approachable, and friendly.

When asked if Barb wanted to pursue an Athletic Director position, she responded, she said she would consider leaving her position "with caution." She described the relationship with her boss as a "day marriage" in which she suggested, "If this marriage is still working for him, then we're good." Furthermore, Barb's metaphor equating her job to a marriage implies certain gender roles and power. Barb perceived the networks and influence held by her supervisor to be far deeper and more powerful than her own. In addition, Barb alludes to the notion that her supervisor - not her - has the power to decide the future of her career. This perception could be a function of gender stereotypes and/or organizational structure.

Participants also described stereotypes regarding marital status as a "doubleedged sword." Fritz told a story about a time when she was an associate athletic director. Her department was renting tuxedos for male administrators to attend a formal dinner at a bowl game. She asked if she could use apply the $\$ 100$ rental fee toward purchasing a dress for the event. The assistant to the Athletic Director asked, "Well why would you get to do that?" Fritz never received the $\$ 100$ credit toward a dress, but after she married, the department would rent tuxedos for her husband to attend events with her. 
Jenny also described the tension she felt as a female administrator:

I definitely think that being female is a barrier because (male administrators) look at me and they either think, like early on, "She's going to get married and have kids and leave us." or now that I'm still single and not married and have no children "She's got something against being a family person. We don't want that because she's not a family-oriented person." (Jenny, p. 13)

Vera also suggested if women want to have a family it is an "added challenge. It's really hard when you're competing against the guys around the room." Julian told of comments made by male colleagues when she left the office early to pick up her son from school. Moreover, women in the study said they felt men did not have to contend with family responsibilities because they have wives who take care of the children. I discuss this perception more fully in a subsequent section on work-life balance.

Finally, three women in this study described feeling as though the men in positions of authority (e.g., Athletic Director, university president, boards of trustees) were "leery" of hiring women as Athletic Directors or even associate athletic directors. Martha surmised, "I don't think that (men are) confident—or I think they are confident that women can't supervise football, or handle a football coach, or a high profile men's basketball coach."

Women in this study did not use the word "stereotype" or "discriminate," though several women offered examples of stereotypical and discriminatory behavior based on perceptions of gender. Studies (Ruggerio \& Marx, 1999; Ruggerio \& Taylor, 1995, 1997) on the perceptions of stereotypical and discriminatory behavior suggest, stigmatized individuals are not likely to consider discrimination a barrier to their careers unless they are "virtually certain they have been discriminated against" (Kaiser \& Miller, 2001). While one could perceive participants' experiences as discriminatory and 
stereotypical, perhaps perceptions are indicative of the fact women have not reached positions in which they have proved competence.

Barb was concerned women are not positioning themselves competitively in the market. She maintained, along with Vera and Fritz, that university presidents are actively seeking women to fill the position of Athletic Director. Barb, Fritz, Vera, and Martha feel that gender has been a catalyst for their career success. Barb explained that athletic departments are looking for talented women. As such, women have to be savvy about the opportunities they are asked to consider. For example, the president of a large university approached Barb about becoming the next Athletic Director. The university had recently signed a new football and men's basketball coach to long-term deals. From Barb's perspective, the president set the new Athletic Director up for failure:

Is a woman going to survive that? He goes, "Shit." I go, "Call me when there's opportunities for change and I'll be your girl." "I understand that. That's why we want you, you think like a business person." I go, "You're damn right, call me back when that opportunity lines up." But I'm not going to sit there in the middle of mediocrity and pay $\$ 10$ million in contracts because (former AD) got himself in a tight spot. I'm not going to do it. This is what I'm saying, it's not a lack of opportunity it's a lack of are we really ready, and if we get catapulted too fast and we don't do the time the way the men do the time, and when you get that opportunity, cause you'll get it, you'll get your block knocked off. I think that's still the challenge is-are we ready? (Barb, p. 29-30)

Perhaps the question should not be if women are ready to assume the position of Athletic Director, but rather are women ready to assume a failing situation that must be turned around?

The pressure to succeed has the potential to affect the career development of women in athletic administration. As if women would not encounter enough scrutiny as Athletic Directors, Fritz suggested women have "extra pressure" to succeed in those roles because there are so few. She contends, "If (women) go in there and you're not prepared 
to hit it out of the park on all fronts, personal and professional, then you don't want to handicap women who come after you." In other words, if a woman is not successful as an Athletic Director, an athletic department is less likely to consider another female to be her successor. A few participants suggested the success or failure of one woman has a ripple effect on the way in which all other women will be perceived.

The "extra pressure" of being "ready" described by participants in this study may be a product of a male-dominated profession in which women in high-ranking positions are more visible. (Andrew et al., 1990; Kanter, 1977). Visibility is a paradox as it has the potential to result in criticism or praise (Corby \& Stanworth, 2009; Richie et al. 1997; Whitmarsh et al., 2007). As a result, women in senior management positions may feel pressure to "prove" their abilities to colleagues (Grappendorf \& Lough, 2006; Grappendorf et al., 2004; Richie et al., 1997; Whitmarsh et al., 2007) through extraordinary activities such as successful risk-taking or leading organizational change (Itzin \& Newman, 1995; Kanter, 1977). For women in leadership positions like Athletic Director, extraordinary activities are inherently risky because such activities require enhanced visibility.

As previously discussed, women in this study perceived visibility as important for setting the tone for other women in the department. Participants achieved visibility through work on major departmental project and/or through spending more time in the office, at sport events, or traveling with the team. Though participants recognized visibility as important to their jobs, many described the extended hours required to be visible presented barriers to their health and work-life balance. 
"Grinding and pounding." Every participant mentioned the time commitment required to work in intercollegiate athletics. Participants identified long workdays, weekend commitments, travel requirements, and other after-hours engagements (e.g., fundraisers, community benefits) as challenges. For some, the long work hours contributed to burn out or boredom, while other participants described stress-related health problems. Some of the health problems included insomnia, hives, high blood pressure, and anxiety. Vera described college athletics as a culture of "grinding and pounding," while Roberta considered the industry "a fast-paced, all in your face, all day long business." The long hours caused audible frustration for Vera, "You have to put in so many hours to be perceived that you're doing something, which I think is crap."

When describing day-to-day responsibilities, many of the women mentioned administrative responsibilities for varsity sports. It was not uncommon for a woman to serve as the sport administrator for at least eight varsity sports. One participant, Barb, was responsible for 18 of the 21 men's and women's varsity teams, in addition to supervisory responsibilities for five departments. Tracy described her role as a compliance officer, SWA, and sport administrator, "I dealt with issues for all 23 sports and traveled with most of them post-season. It just got a little crazy" (Tracy, p. 8). Roberta (p.12) echoed managing her responsibilities with a stressful schedule:

We have events every night - we had one Monday, we had the Christmas party yesterday. There is a basketball game tonight. There is a women's basketball at noon that we were coordinating to do a little lunch for a Christmas lunch. It doesn't stop. Last week I think I spent four nights here. And then weekend stuff.

As a result of the long work hours, irregular schedules, and travel requirements, the women in he study described experiencing conflict between their roles as employees and family members. As Judy explained, "You sacrifice at home because of the things 
that you like in your job." This conflict illustrates the intersection between the culture of college athletics and the desires of women to have a more balanced life. (Bruening \& Dixon, 2008; Inglis et al., 1996, 2000).

Work-life balance. In the last decade, work-life balance has received a great deal of attention in sport management literature (Bruening \& Dixon, 2007; Bruening et al., 2008; Dixon \& Bruening, 2005, 2007; Greenhill et al., 2009; Inglis et al., 2000). Women, in particular, have difficulty balancing work-life culture in intercollegiate athletics for several reasons. First, the culture of college athletics has been identified as a barrier for career development particularly for women (Bruening \& Dixon, 2008; Greenhill et al, 2009; Inglis et al., 1996, 2000). Work-family conflict, in particular, is a component of work-life balance that has received considerable attention as a barrier for career progress for women in coaching (Bruening \& Dixon, 2008; Inglis et al., 1996), intercollegiate administration (Bruening et al., 2008; Inglis et al., 2000), and professional sport management (Hums \& Sutton, 1999).

Several participants relayed stories of former female colleagues who chose to leave college athletics because of burn out or because they wished to have a family. Even though seven participants had children, all participants perceived a career in intercollegiate athletics as contradictory to a family life and vice versa. Therefore, the tension between balancing a career in intercollegiate athletics and a family was perceived as a barrier to career development. For example, when asked about barriers for women in college athletics, Cindy immediately identified "family." Cindy, married to a former intercollegiate coach, does not have children, but she described her experience as Chair 
of an NCAA Division I sport committee, "No one on that committee either has children or young children. You can't do it."

Other participants discussed the impact having a child had on their careers and decisions. Amanda and her husband chose not to have a second child because of her long work hours. She explained, "Pawning two or three kids off on my husband when we don't have any family here is kind of selfish." Tina also stated she and her husband would like to have more children. She discussed her next position within intercollegiate athletics would more than likely be one in which she could adequately balance her responsibilities at work, as a mother, and a wife.

Julian and Jane were apprehensive about discussing work-family balance. Both women offered examples of instances in which male colleagues commented on their "early exits" from work. While these women offered examples of their work ethic and instances in which work ethic was applauded, they discussed feeling as though their achievements were undermined by family responsibilities. For several women, the tension between work and family has caused a re-evaluation of respective career paths, including movement to a position that requires less time at work to leaving the profession all together. Studies in sport management have identified work-life balance as a reason for attrition from the field (Bruening et al., 2008; Bruening \& Dixon, 2008; Inglis et al., 1996, 2000).

Several women in this study did not perceive work-life balance to be an issue for men. Participants described men as more likely to have wives that "stop working once the men hit a certain income level" and "put up Christmas decorations, fix dinner, and take kids to soccer games." Jenny, a single woman, explained: 
Where I see a lot of women struggle is that their support network and their family lives don't set them up in the same way as the men I work with. I work with a lot of men who have wives that maybe work or maybe don't, but if they do their careers are secondary to the men.

Vera suggested that male administrators who held early morning meetings either did not have children or were not responsible for "getting them up for school, lunch packed, and to school." Julian offered:

If men struggle with (work-life balance), they don't show it as much as (women) do. I'd like to think, especially knowing some of the guys we work with and how close they are with their families, it goes through their heads, but I just don't know.

Roberta, however, suggested men in intercollegiate athletic administration also face challenges with work-life balance. She relayed a story in which a male colleague sat in his car talking to a coach while his son celebrated his birthday party at Chuck E. Cheese's. Roberta contended work-life balance is not a gender issue, but an issue with the culture of intercollegiate athletics. Studies also found men are concerned with worklife balance and seek more flexible work practices (Emslie \& Hunt, 2009; Latham \& Swiercz, 2009). Men, however, may be less likely to voice their struggles due to social constructions of gender, including the perception that a man's primary responsibility is work rather than home (Beasley, Lomo-David, \& Seubert, 2001; Emslie \& Hunt). Regardless of marital status or children, all participants in this study perceived work-life balance to be a major issue in the careers of women in athletic administration. Julian articulated the struggle many of the women seeking work-life or work-family balance. For women attempting to "have it both ways":

The biggest challenge: time. There's not enough time in the day to do both well. ... So I have moments of feeling like I do both 50\% and that's not really good enough for me because that's just how I am. So then I have anxiety attacks about it, which one needs to suffer. And neither one of them can suffer. That's the 
problem. (Julian, p. 9)

Several participants identified their "next steps" professionally included moving closer to family, including aging parents and siblings. Roberta described making time before an evening basketball game to have dinner and a glass of wine with friends. Jane and Julian described feelings of "guilt" when leaving work to attend to matters with children. Jane reported men made comments such as "it must be nice to leave before five" when she leaves early to pick up her children from school. She attributed the comments to the "kidding" nature of colleagues, but also suggested a "stigma" exists about leaving work "early."

While women struggle with work-life balance, Tracy contended, "It's something you've got to figure out. It never goes away." Tracy achieved better balance by accepting a good position in a small town in which she lives a mile-and-a-half from campus. She stated, "I can go home for dinner before a basketball game on a Tuesday night. It makes my day a lot shorter and that's made a big difference for me." Julian also discussed accepting a job that was "8000 times more stressful" because she perceived the stress in her home life - as a married mother of two - would "decrease by $1,000,000 \%$."

Nevertheless, whether discussing the care of elderly parents, children, or relationships with spouses or friends, the women seemed resigned to the notion that athletics is a "lifestyle" that inevitably affects relationships. One participant described working in college athletics as an "addiction." A few participants described how the lifestyle has affected their relationship status. Three women discussed how their single and/or divorced relationship status may be a function of the demands of their jobs because work-life balance is "very difficult." Vera, a divorced single mother, explained 
how she often put the demands of her job before the demands of her marriage. Roberta explained that she has questioned whether her status as a single woman is the result of working in college athletics. She commented, "I don't know that to be true but I can tell you, it didn't help." Judy described herself as a "relatively attractive, heterosexual, single woman" who also alluded to her single relationship status as a function of the time commitment to college athletics. She admitted, "I haven't been able to have a significant relationship. I wouldn't change it, but I acknowledge it."

On a more positive note, Tina described how her work at odd hours led to an encounter with her future husband:

I could work, literally, 24/7... and people kind of look at me crazy. Let me give you an example. My now husband was working second shift at the arena when I met him at three o'clock in the morning by a soda machine. I had to make the decision at that point if I wanted another soda or if I was going to try to go home to get some winks. (Tina, p. 4)

Tina chose to stay and have another soda. She also acknowledged that having a spouse who supported her career was important.

Supportive relationships are critical career supports for women (Richie et al., 1997; Wentling et al., 1996, 2003; White, 1995; Whitmarsh et al., 2007) especially when familial relationships and careers are central to women's lives (O'Neil, Hopkins, \& Bilimoria, 2008). O'Neil et al. (2008) suggested that these social-relational supports represent an interesting paradox in the work lives of women in that "organizational realities demand the separation of career and life" (p. 730). Frome et al. (2006) concluded that women who "leak out" of the pipeline in a male-dominated industry often do so because formal organizational policies or informal organizational culture preclude women from maintaining a balance between work and family. Women will therefore 
abandon initial career aspirations to accommodate a desire to have a family and a career (Frome et al., 2006). While women in this study have not chosen to leave the field of intercollegiate athletics, the struggle to maintain balance is a barrier they have to confront when thinking about career expectations and goals.

Given their previous experience in professional sport, Tracy and Amanda acknowledged college athletics offered a better opportunity for work-life balance because they perceived college athletics to be a more family-friendly environment. Amanda did not want her child to become a "gym rat," but felt comfortable bringing her child to an athletic event. Several other women also suggested college athletic departments tended to be more family-friendly, though the environment was entirely dependent on the culture created by the athletic administration. Tina, for example, described the juxtaposition between her current institution and an institution at which she interviewed. She said,

If I go to (West coast university), am I going to be able to supervise softball and have my daughter right next to me cheering for them? No. As the manager, I'm probably going to have to be in the press box where kids shouldn't be. Are they going to allow me to bring my kid to a booster thing? No. No kids are allowed in those things. Here at (current university) they bring their children to dinners for our basketball team.

Tina went on to suggest the department was more family friendly because the senior associate athletic director was a woman with children. When Fritz achieved a high-level position in which she could make change, she instituted more equitable policies for men and women in her department. Tina's suggestion an environment was family-friendly because of the influence of a woman in a high position and Fritz's actions to achieve equity raise an important question - are women victims of a male-dominated industry culture or do they have the power to set the culture? 
Itzin and Newman (1995) found that "numbers alone" do not bring about organizational change. Business and industry, however, are undergoing a period of "massive cultural change" resulting in a "transformation of existing structure and hierarchies, which open up spaces in which women can seek to influence the organization of the future" (Itzin \& Newman, p. 11). A shift in industry culture will eventually lead to a change in organizational structure. Several participants suggested a shift in the culture of intercollegiate athletics is occurring, but organizational structure was still identified as a barrier to career development. The perceived cultural shift is discussed in the following section.

Organizational structure. Organizational structure refers to factors within an organizational context including but not limited to include organizational hierarchies and opportunities for promotion and advancement (Lent et al., 1994). Organizational structure is often a function of the context of a particular industry. For example, Acosta and Carpenter (2011) found the most common administrative organizational structure in intercollegiate athletics was comprised of four people - one male Athletic Director, two male assistant or associate athletic directors, and one female assistant or associate athletic director. In other words, men outnumber women three to one in the administrative structure. Research has shown that a male-dominated organizational structure has the potential to perpetuate gender role stereotypes (Burton et al., 2009; Burton et al., 2011; Grappendorf et al., 2004; Grappendorf et al., 2008). Findings of the present study suggest gender stereotypes exist for both men and women. In terms of organizational structure, gender role stereotypes may result in occupational sex segregation based on perceived of characteristics of gender (Betz, 2006). 
Occupational sex segregation is an organizational process that slows the career development of women (Maume, 1999) because women often occupy lower positions in the organizational hierarchies in male-dominated professions (Beatty, 2007; Bielby \& Baron, 1986; Kanter, 1977). Therefore, women are limited in their abilities to learn new skills and access networks. Research in sport management suggests sex segregation exists in intercollegiate athletic departments (Burton et al., 2009; Burton et al., 2011; Hoffman, 2010). The findings of this study, however, suggest that while women tend to gravitate toward particular positions, they do so by choice not necessarily because of industry culture or the perception of limited opportunities for advancement.

Studies suggest (Burton et al., 2009; Burton et al., 2011) characteristics associated with soft, internal positions are more likely to be attributed to women. Internal positions are perceived to require more communal and feminine characteristics, while external operations including finance, budgeting, and leadership are perceived to be more masculine (Burton et al., 2009). Similar studies have attributed the high number of women in internal positions to gender stereotyping and a male-dominated organizational structure (Burton et al., 2009; Burton et al., 2011; Claringbould \& Knoppers, 2007; Grappendorf et al., 2004; Whisenant et al., 2002).

In this study, women expressed a concern about being "typecast" or "pigeonholed" into roles pertaining areas perceived to be "soft," such as academic advising, compliance, life skills, event management, and supervision of other internal departments (e.g., strength and conditioning, athletic training). Interestingly, 12 of the 15 participants in this study held internal operations positions. Of the 12 participants in internal operations positions, all expressed a greater interest in working "behind the 
scenes" or as a "number two." Participants indicated positions in internal operations

offered more interaction with student-athletes and coaches. Judy, who once aspired to be

an $\mathrm{AD}$, offered:

I really like the internal aspect of (intercollegiate athletics). The interaction with student athletes. I can do that without being an AD. I can be a senior associate or an SWA or whatever and still do all of that internal. I don't want to lose the day to day interaction with the students. I want to make sure that I still have that interpersonal connection with the students, with the coaches. That's why I got into the business in the first place.

Furthermore, they did not want the responsibility of having to make the "final" decision or perceived their personalities to be a mismatch for a position in external operations. These findings are similar to other studies on women in male-dominated industries (Corby \& Stanworth, 2009; Oplatka \& Tamir, 2009; Richie et al., 1997; Wentling, 1996, 2003)

While many women preferred internal operations, there was recognition that such roles may limit networking opportunities or professional advancement. To illustrate, Roberta expressed concern that even women holding the title of SWA do not have the necessary skill set to advance. She perceived women were "limited" to internal operations by a "good ol' boys" network rather than by choice:

How in an organization are you the most senior woman and you don't know what our budget is? How do you not know what your revenue streams are? How do you not know where the money is? Well, because it's a good old boy's network. You have an SWA that holding title only and the good old boy's make their decisions and shut the door.

Certainly, participants' perceived attraction to internal operations may be attributed to societal constructions of gender roles perpetuated in a male-dominated industry (Beatty, 2007, Eagly, 1987; Schein, 2001, 2007). If we consider the role of 
personal agency, however, it is important to note participants in internal operations perceived those positions as more closely aligned with their personality characteristics, career interests, and goals. Similarly, women in external operations enjoyed their roles as "friendraisers" and in creating the "image" of their respective athletic departments.

Several studies in sport management have explored the effects of the "good ol" boys" network (Lovett \& Lowry, 1994; Stangl \& Kane, 1991). The "good ol' boys" network is perceived to contribute to a culture and structure of hegemonic masculinity and homologous reproduction (Lovett \& Lowry, 1994; Stangl \& Kane, 1991; Whisenant et al., 2002). A few participants in this study discussed the existence of the "good ol' boys" network, but none perceived the network was a barrier. Instead, some women described the changing culture of intercollegiate athletics. Vera explained:

(Administrators) need to make connections with the people and feel comfortable in when they experience and do. To be able to get out of that "I've got to be one of the good ol boys" mindset to be considered legitimate or credible in this profession. (Vera, p. 15)

Despite the existence of the "good ol' boys network," there was a sense the culture was evolving. As more women enter the field of intercollegiate athletics, participants suggested a shift in the culture and power structure of the NCAA and athletic departments. The shift, however, can only happen if more women are present in seniorlevel positions with decision-making responsibilities. For example, participants in this study held 17 of the $50(34 \%)$ assistant or associate athletic administration positions ate their respective institutions. This proportion is higher than the most popular intercollegiate administrative structure (three men, one woman), which may be evident of a shift in culture. 
Several women, however, discussed feeling responsibility for changing the industry culture from one that is male-dominated and perceived to be a "good ol' boys" network to one that is gender inclusive. Jenny explained, "I think it's (women's) job to change the culture and the structure. Anything I would offer you as an answer to that is summarized by that statement." Vera, while acting as interim Athletic Director, attempted to change the culture of her department. She explained, "We didn't have eight o'clock meetings because for me to get out of the house, get my kids to daycare, and be somewhere sitting fresh at 8:00 a.m. that wasn't ideal for me. I didn't do eight o'clocks." When Fritz, a senior deputy athletic director, reached her position in the athletic department and assumed responsibility over human resources, she described having the authority to evaluate policies and make appropriate changes. She said she listened to male and female staff members and implemented family-oriented policies "fair for the whole family. Fair for a male and fair for a female."

Because intercollegiate athletics is a male-dominated industry, so too are the structures of intercollegiate athletic departments. In this study, however, the type of positions women held, job responsibilities, and perceived opportunities for advancement reflected career development as a function of choice rather than organizational structure. Despite the increased proportion of women in athletic administration represented in this study and the perception the culture of intercollegiate athletics is shifting, a majority of participants perceived limited opportunities for advancement.

Limited opportunities for advancement. As discussed in the section on career supports, opportunities for professional advancement include vertical mobility through organizational hierarchy and/or the opportunity to develop new skill sets. The small 
number of women in intercollegiate athletic administration leads to the perception that may only be a limited number of positions for women (Acosta \& Carpenter, 2011).

Eleven women identified limited opportunities for advancement as a barrier to their career development.

Several women spoke of accepting positions in which they had been "promised" responsibilities within the department that would enhance their respective skill sets. Over time, women perceived they were denied those opportunities because either the supervisor did not wish to delegate or an administrative change in reporting lines also changed job responsibilities. Tracy described a situation when she was hired at a midsized school in the Northeast:

The AD put me in a position where we had some issues with academics. He wanted me to supervise (the coaches) but wasn't willing to give me the power to supervise them. He wanted me to watch over them and do things with them but didn't put me in a position to really be able to do it. (Tracy, p. 10)

Tracy's situation, like many others in this study, is an example of the "principle of responsibility with equal authority" (Chelladurai, 2005). The principle of responsibility with equal authority states, "An employee must be given the necessary authority to carry out an assigned responsibility" (Chelladurai, p. 196)

Julian moved from a Division II school to a Division I in a major conference. While working in Division II, Julian's position was generalized with oversight of compliance, student services, and academics. When she arrived in Division I, the scope of her position became more specialized. Similar to other women in this study, Julian quickly tired of her work and felt "bored." She described herself as the "low man on the totem pole" in both position and skill. Julian left her position to learn more and get her "hands into other stuff." Experiences described by Tracy and Julian were echoed by 
other participants. They felt limited in their opportunities to refine or develop new skills. Therefore, participants were likely to pursue opportunities at other institutions. For example, Amanda explained her experience working with a major intercollegiate marketing company:

I wasn't going to go anywhere with (marketing company), as far as my responsibilities were concerned, unless I moved. If I moved, I would probably have had to go back to being a sales person. I felt like this was the best opportunity for me to grow professionally and to use what I've been able to learn throughout my career, put and all of my focus on marketing. (Amanda, p. 9)

In a study on women in business, Wentling (2003) found women aspired to toplevel management positions. Other studies (Astin, 1984; Kanter, 1977; Wentling, 1996, 2003) suggest the perception of limited opportunities has the potential to negatively affect career aspirations and responsibility to the organization. While the majority of participants in the present study do not aspire to the position of Athletic Director, they do seek some career advancement in terms of upward mobility and more advanced responsibilities.

While Fritz advocated for moving from position to position to gain a skill set, lateral job moves take time and have the potential to inhibit vertical job movement. If women progress through the organizational hierarchy at a slow rate, they may be perceived as less competent for higher-level positions (Bielby \& Baron, 1986; Maume,, 1999). This awareness is evidenced by the strategic timeline many women often described when considering or accepting a new position. Judy described her second job as a "two to three year" position, while Tracy described her assistant athletic director role at a mid-major as a "max of four years." The perception is that if a person spends an extended amount of time in a particular position, she has not mastered the skill set and is 
not ready to move up in an organization, or that she is complacent in her role and not interested in developing further as a professional. While these perceptions are often incorrect, career theorists (Lent et al., 1994, 2000; Savickas, 2002, 2005) suggest that judgments about individuals are predicated on perception rather than reality.

Judy suggested that women feel threatened by each other when there are only a few positions available. She explained, "Because it is male dominated field, we feel like we can't help the other women in our offices grow without hurting our chances, which is wrong." Four women discussed how the role of the SWA contributed to this perception. Jenny explained:

The SWA position has had an interesting evolution. At the risk of sounding as if I don't appreciate the opportunities I've had, I will say to you that I'm very conflicted about that position. I understand the role it served initially and I appreciate that. I think that was important and so I get that people who are in roles like mine and senior administrative positions in the athletic departments are here because of that place holder from the previous generation as so many departments folded together. That notwithstanding, I think it's become a bit of a contributor to the glass ceiling because it's a place to put somebody. It's also a position of which you can push off the operational and what are often considered to be housekeeping elements of the department. The SWA positions, for example in the conference I am in, tend to be Olympic sport managers and/or student service managers, internal operations managers.

Roberta, Fritz, and Vera noted that the SWA role has become a goal for women because it gives women a "seat at the table." Vera cautioned

I really believe it's changing but we're all fighting for that one seat, that senior women administrator's seat. Everybody is fighting for the same seat as opposed to really working to create more seats at the table. I think we spend the most time competing against each other.

While Judy's perspective did not involve the role of the SWA, she shared a similar sentiment about women:

If there are only so many openings that you can have, at some point you're going to get beat out so you've either got to be as strong as the male candidates that 
you're competing against or you have to push the others out of the way to get to that position.

Vera contended women must be more purposeful in helping each other, "we need to do a much better job, as women in this field, of networking women, learning from women, being mentored by strong women" (Vera, p. 9). Judy, however, suggested many women - particularly "pioneer" women - often say the right things and have the best intentions, but do not follow through with action. She offered several examples of speaking to "strong and successful" women at conferences who indicated a willingness to provide guidance. When Judy reached out to those women, she would not get a response. Jenny, however, offered a positive experience she had working with another woman:

(She) was willing to share her authority and share projects and things that otherwise would have given her greater visibility. She was willing to share that with me, which I find incredibly generous but also is not something that enough women do for other women. (Jenny, p. 10)

In short, women become barriers to themselves and each other when they perceive only a few "seats" at the administrative table. Women may limit themselves if the title of SWA is a goal. Additionally, women purport the importance of supporting each other, yet there is a perceived dissonance between intention and action. If women fail to support the advancement of other women, the ability to acquire new skills and ascend through administrative ranks may slow to an interminable pace. As a result, fewer women may reach positions with decision-making power.

\section{Summary}

In this study, participants indicated career supports as interpersonal relationships with supervisors and mentors, professional development activities, and opportunities for career advancement. Barriers to women's career development included elements of 
industry culture including long work hours, work-life balance, the perception of a maledominated profession. Gender and organizational structure were also identified as barriers. Barriers are reflective of the challenges women have faced over the course of their careers in intercollegiate athletics. For the women in this study, the respective barriers are not yet insurmountable. The next section explores the manner in supports and barriers influence career goals.

\section{Career Expectations and Career Goals}

It is useful to think of career development theories and the interplay of supports and barriers discussed in this section as interpretive frameworks for understanding (a) what career decisions women make and (b) why such decisions are made. This section explores how those decisions affect career expectations and goals. Each support and/or barrier - singular or combined - has the potential to influence career development, expectations, and goals (Astin, 1984; Betz, 2004; Coogan \& Chen, 2007; Lent et al., 1994). The exploration of supports and barriers as they pertain to career development, career expectations, and career goals is particularly important for women. Research has suggested women encounter issues not ordinarily faced by men as women balance

family, social, and work expectations (Astin, 1984; Betz \& Fitzgerald, 1987; Coogan \& Chen, 2007; Farmer, 1976; Gottfredson, 1996; Richie et al., 1997).

Career construction theory (Savickas, 2005) and Social Cognitive Career Theory (Lent et al., 1994, 2000) emphasize the role of supports and barriers in career development, but also acknowledge the role of human agency and choice. While the choices of women may be constrained (Eccles, 1994) by personal and contextual factors, 
women still have a choice in how such factors affect career expectations and goals (Fagenson, 1990).

\section{Career Expectations}

Before examining the findings about the manner in which women's perceptions of career supports and barriers influence career outcome expectations, it is important to revisit the definition of outcome expectations. Lent et al. (1996, p. 381) defined outcome expectations as "personal beliefs about the consequences or outcomes of performing particular behaviors." For example, women perceived the development of various skill sets - specifically those in external operations - would lead to higher positions in the organizational hierarchy or opportunities for more decision-making power.

Two primary categories of expectations were derived from participant interviews: (a) job-related expectations and (b) personal expectations. Job-related expectations included perceptions of the professional skills, effort, and commitment required for a career in intercollegiate athletics. Personal expectations included how positive or negative perceptions of and experiences in intercollegiate athletic administration aligned with personal and professional goals. Moreover, barriers and supports influenced jobrelated and personal expectations.

To understand career outcome expectations, it is important to revisit the reasons women in this study chose to pursue careers in athletic administration. During the first few minutes of each interview, participants were asked to discuss how they came to a career in intercollegiate athletics. Fourteen of the women were former student-athletes nine at the collegiate level, five in interscholastic athletics. All of the women described an attraction to intercollegiate athletics through some level of being a fan, a former 
student-athlete, or working with student-athletes and coaches in various capacities outside an athletic department.

Job-related expectations. Participants described pursuing a career in college athletics because they wanted to help positively influence the lives of student-athletes. In other words, women expected a career in intercollegiate athletics would provide them the opportunity to affect the student-athlete experience. As such, participants shared jobrelated expectations that they perceived would align career expectations related to achieving their career goals.

To be a part of intercollegiate athletics, many women described participating in internships or entry-level positions that provided (a) interaction with student-athletes and (b) opportunities to learn and develop skills participants perceived would make them more marketable for the next position. Positions often required the women to take on multiple roles including compliance, sport administration, student and academic services, and/or event management. Julian described herself as "a one-man band." Amanda described her experience at a small school with a "small staff, doing a whole lot of everything. It was a good place to get your feet wet because you got your hands in everything."

The idea behind working in such positions was that women would build the skill sets necessary to affect the lives of student-athletes. Roberta explained, "I actually once said I wanted to be an AD one day because I really want to be closer to student athletes. Well, guess what, you're not." When Donna accepted a position as an associate athletic director, she was excited about supervising coaches. She later admitted, "Once I got the opportunity it was like 'never mind."' Furthermore, several participants perceived a 
more diverse skill set might also result in advancement through the athletic department. A more advanced skill set was particularly important to women interested in becoming Athletic Directors. For example, Vera explained:

I knew I had to develop the skills in the areas of fund raising. I knew that was really important. I didn't have an MBA. I didn't have the business background. But the ability to develop relationships; work with people, energetic person. I think an effective communicator. I thought really working on the fundraising side on behalf of the university and also the department, I thought was an area I could develop some skills. (Vera, p. 7)

Many participants also discussed the expectation of long work hours and travel.

Still, many struggled with the balance between work and life or work and family. In addition, participants discussed the importance of skill acquisition because they perceived it would lead to career advancement. For the aspiring Athletic Directors, vertical mobility was important. For other participants, advancement simply meant assuming more responsibility with the hopes of having a voice and a seat at the table

Personal expectations. Personal expectations for work in intercollegiate athletics were epitomized by Jenny's quote, "I thought everyone would have the student-athletes' best interest in mind." Instead, the several women in this study suggested that the enacted values of the NCAA direct conflict with the values the organization itself espouses. While women recognize college athletics is a business, the fear is that studentathletes are no longer a focus; instead, the priority is financial gain. As Tracy explained,

I think particularly with some of the things we've seen in the last couple months with the direction the NCAA is heading, particularly at the FBS level, it raises my concerns even more about what we're doing and where we are and what the balance is for our students. ... I think that FBS is growing further and further away from what my philosophy is on that. (Tracy, p. 11)

Women described Division I athletics as "out of control," "excessive," "too political," "all about the money," and the NCAA as an organization moving to a "more 
business-oriented NBA model." Cindy suggested NCAA legislation is being created and enacted too quickly "without very much thought" about consequences for student-athletes and the viability of their respective sports. Barb referred to "stupid ass" NCAA legislation, which suggested she felt as though NCAA policies are leading programs in the wrong direction. Finally, Roberta indicated the state of college athletics is the result of "a few men leading the charge and dragging us places that, in our hearts, women in this business know is not the right way." Cindy said she felt women's athletics were taking a backseat to men's athletics. Interestingly, women discussed feeling as though they had a "voice" in administrative decisions of the department, yet few could offer examples of how they were contributing to active change. Additionally, few women could articulate attempts to bring personal and professional values in line.

Perhaps having values incongruent with an organization is not so much a barrier in and of itself; rather it is the challenge these incongruent values pose. For the women in this study, having values incongruent with the NCAA and, therefore, athletic departments, contributed to them questioning their own personal career paths. If a woman perceives the differential between her values and the values of the department to be too great, she may chose to leave the organization or the field of intercollegiate athletics. Judy explained, "If I don't feel like we're (college athletics) is going in the right direction then I have to go somewhere else where I will have an impact." Such a move would influence her ability to advance professionally. Therefore, the challenge posed by incongruent values becomes a barrier. While the women in this study have not chosen to leave the field yet, some have begun to question their abilities to positively 
affect student-athletes in within a structure now predicated on seemingly conflicting values.

\section{Career Goals}

To refresh, Lent et al. (1996, p. 381) defined career goals as "the determination to engage in a particular activity or to affect a particular future outcome." Goals help people organize, guide, and sustain their own behavior, while also providing a mechanism to exercise personal agency (Lent et al.). Supports and barriers influence the manner in which people make decisions about future goals (Betz \& Fitzgerald, 1987; Lent et al., 1994; Savickas 2005). Furthermore, the extent to which outcome expectations are met has the potential to influence career goals (Lent et al., 2000).

When asked about career goals when they began their college athletics work, only two women mentioned the ultimate goal of achieving the level of Athletic Director. In December 2011, those same two women said the position of Athletic Director was no longer a career goal. As the women in this study began to build their careers in intercollegiate athletics, nine women indicated they would like to be an NCAA Division I Athletic Director. As careers evolved, participants' expectations and career goals shifted from a focus on professional skill development and title attainment to an interest in providing a contribution to their respective departments. At the time of data collection, only four participants indicated a desire to pursue the position of Athletic Director. Eight women stated they had no interest in being an Athletic Director at any level, while three would consider the role at NCAA Division II or Division III institutions.

Early in her career, Judy had aspirations to be an Athletic Director, but her career goals changed. She explained 
When I first got into the business when I was 22 years old and I was like "I'm going to be an AD. That's what I'm going to do. I'm going to be an AD. I'm going to be a Division I athletic director. That's what I want to do." As I've gone through the business and I've learned more and I've experienced more me, maybe, still keep that out there. But I really like the internal aspect of it. The internal interaction with student athletes, the internal side of the business. I can do that without being an AD.

Jenny explained, "I didn't come into this profession with the goal of being an Athletic Director. I don't think that's bad or wrong... it's just not my end goal." Similarly, Tina described her goals as "minimal" because she did not wish to become an Athletic Director. Tracy acknowledged, "Some people have a goal of being an Athletic Director. I don't really feel that's me. I'm just not good at the politics." Donna explained she spent the first two-third of her career climbing the career ladder seeking more responsibility. Now Donna described herself as much more focused on looking for ways to help studentathletes.

On the other hand, some women had experiences that encouraged them to pursue the position of Athletic Director. Starting out in academic advising, Vera had few aspirations to achieve an executive position. Over time, however, her goals changed:

Over that 16 year time period my goals changed. "Maybe, I would like to become a director of athletics one day." So that was my path, I would say probably six, seven years into my time at Bradley I started thinking about "You know, I may want to take this on. I may want to take on the role of an athletic director." At that point I started thinking how can I best get there?

As intercollegiate athletic administrators, women in this study identified two primary career goals: (a) contribute to the development of student athletes and (b) advance within an athletic department to a position of influence. Participants perceived achieving a higher position and/or more responsibility in an organization would provide 
greater opportunities to have a "voice" in the departmental decision-making process; therefore, women perceived a greater likelihood of affecting the lives of student athletes. Jenny was particularly vocal about the importance of having a voice in the decision-making process. For her and other participants, having a voice in the decisionmaking process meant "having some influence and not just a voice. Having some level of responsibility that also allows me to execute and not just serve as an advisor." For When I asked Cindy about her career goals, she simple explained, "I would like to contribute." She further discussed that she wanted to contribute to a "better quality of life through education, fantastic competitive experiences, through discipline, and academic support."

Perceived barriers prevented women from feeling as though they were making a contribution. Additionally, when women were not able to advance, they felt limited in their abilities to have a voice in the decision-making process. Moreover, women perceived their lack of decision-making power as prohibiting them from being able to contribute to student-athlete development. The next section discusses how women negotiated and coped with barriers and supports in the context of career expectations and goals.

\section{Negotiation and Coping Strategies}

When confronted with difficult work situations, individuals "with a strong sense of coping self-efficacy (i.e., beliefs regarding one's capabilities to negotiate particular environmental obstacles) are more likely to persevere toward their goals" (Lent et al., p. 46). Coping efficacy is closely related to Savickas' (2002) concept of career adaptability with one important difference. Coping efficacy implies forward progress toward 
professional goals, while adaption suggests more of a compromise to circumstance and a re-evaluation of career goals (Savickas, 2002).

Over the course of interviews with each participant, coping and negotiation strategies emerged that divided the participants into two distinct groups: (a) Future ADs and (b) Career Associates. The "Future AD" group includes the four participants who stated, definitely, the position of Athletic Director was a career goal. "Career Associates" (CAs) include participants who either would not commit to the Athletic Director position being a career goal or were never interested in the position as a career goal. Future ADs were more likely to exhibit coping efficacy (Lent et al., 2000), while CAs tended to compromise to circumstance (Savickas, 2002). A summary of the negotiation strategies and coping mechanisms of career associates and future ADs is presented in Table 3.

Career associates. A few studies on women in intercollegiate athletic administration have suggested that promotion and advancement to executive positions in intercollegiate athletics is not a career goal for women (Grappendorf et al., 2004; Sagas \& Cunningham, 2004b). The findings of this study support this notion. Of the 15 women interviewed, 11 indicated minimal to no desire to pursue the position of Athletic Director. Despite little ambition to pursue the position of Athletic Director, Career Associates remained very passionate about working with student-athletes. This finding is similar to a study by Smith, Santucci, Xu, Cox, and Henderson (2012), which found women in parks and recreation were not interested in upward, or vertical, mobility but preferred directly serving their constituents. 
Table 3

Negotiation Strategies and Coping Mechanisms of Career Associates and Future ADs

\begin{tabular}{|c|c|c|}
\hline Data & Career Associates & Future ADs \\
\hline Characteristics & $\begin{array}{l}\text { Less definition of career path } \\
\text { Change in work priorities } \\
\text { Career stabilization }\end{array}$ & $\begin{array}{l}\text { More defined career path } \\
\text { Better advocates } \\
\text { Forward-thinking } \\
\text { Optimistic }\end{array}$ \\
\hline $\begin{array}{l}\text { Coping mechanisms/ } \\
\text { Negotiation Strategies }\end{array}$ & $\begin{array}{r}\text { Skill } \\
\text { Engage network of } \\
\text { Self- }\end{array}$ & $\begin{array}{l}\text { quisition } \\
\text { entors and supervisors } \\
\text { fection }\end{array}$ \\
\hline Career path & $\begin{array}{l}\text { Do I want the AD position? } \\
\text { Do I have what it takes to get } \\
\text { there? } \\
\text { Do I really want to do what it } \\
\text { takes? }\end{array}$ & $\begin{array}{l}\text { How do I get to the AD } \\
\text { position? } \\
\text { What will it take to get there? } \\
\text { What is the next best move? }\end{array}$ \\
\hline
\end{tabular}

As CAs progressed through their careers, career goals became less defined.

Priorities changed as women became older, developed personal lives, or felt as though

the direction of the NCAA as a governing body was increasingly suspect. Perhaps this is

a function of the "Establishment" phase of career development (Savickas, 2002).

Establishment represents stabilization in a job and career. As the social and work worlds

become more parallel, a person may seek more opportunities (e.g., greater

responsibilities, advancement, better person-environment fit) within his/her organization

or in another organization. Toward the end of the establishment stage, an individual may

begin to contemplate the "next steps" in his/her career. According to Savickas (2002),

"Individuals reach a point where taking care of what they have established, that is,

maintaining, becomes more important than advancing in new directions" (p. 179).

Other women in this study represent the "Management" phase of career

development (Savickas, 2002). During the Management stage, an individual may ask

him/herself, "Is this the career I want to pursue for the next 25 years?" It is at this stage 
that occupational responsibilities and the vocational self-concept are re-evaluated.

Savickas (2002) describes this process as "re-finding, not refining, the self" (p. 179).

Participants also described being "less driven by money" and more focused on job

responsibilities, personal growth, and support.

As Tracy discussed, “As I've gotten older, it's much more about who I work for than what the job is, which was more important when I was younger." When Judy began her career in intercollegiate athletics, she had a timeline - assistant $\mathrm{AD}$ by 30 , associate $\mathrm{AD}$ by 35 , and eventually an Athletic Director. She no longer wants to be an Athletic

Director. Instead, Judy described being more concerned with

What kind of influence am I making? What kind of impact am I making? Where can I make the best use of my skills and use of my time but still feel like I'm not stagnant. I'm not going to stay here just because I'm comfortable here and I like it here. I still want to make a difference. I want to continue to grow.

Roberta described a similar experience in which she began to consider, "How does this job fit who I am? How does it fit in the greater scheme of what I want to be when I grow up? What do I bring to the table now?"

Regardless of the phase, participants exhibited dimensions of career adaptability concern, control, curiosity, and confidence (Savickas, 2005). The women who expressed a definitive goal of becoming an Athletic Director were more likely to engage in coping efficacy. Career adaptability and coping efficacy were influenced by life themes. Life themes influence individuals to make meaningful choices about work roles in the context of other life roles (e.g., mother, spouse/partner, caregiver) (Eccles, 1994; Savickas, 2005).

Future ADs. Four women - Martha, Barb, Vera, and Fritz - stated they would like to be Athletic Directors in NCAA Division I athletic departments. While these 
women described similar barriers and supports affecting their career development, they tended to be better advocates for themselves, forward-thinking, and optimistic. Vera, Martha, and Fritz described situations in which they asked supervisors and mentors for more responsibility.

Fritz, a senior athletic director at a private university, has worked in her athletic department for over two decades. During that time, she has worked with five Athletic Directors. In each circumstance, Fritz advocated and negotiated for responsibilities that would not only make her indispensible to the department, but would also make her a more attractive candidate for an Athletic Director position. She described one moment in which a new Athletic Director came in and wanted to reorganize the department. The AD offered Fritz several options including business operations. Business operations entailed supervision of all departmental budgets - an area with which she had no experience. She accepted the offer and later parlayed the experience into working with the University's capital campaign, which entailed developing a master plan for the construction of several athletic facilities. Fritz explained that advocating and negotiating for responsibilities gave her "the freedom to understand a little bit more what's possible - how (I) can change things up, (I) had a much better grasp of how to make something happen."

Vera and Martha, both pursuing intercollegiate athletics as a second career, explained that early career experiences helped shape their interests in becoming an Athletic Director. When each woman realized her new career goal, she engaged in a planning process, which involved self-reflection and informational interviews with colleagues. Vera and Martha described asking themselves introspective questions such as 
"How do I get (to the AD position)?" "What will it take to get there?" Vera and Martha also conducted informational interviews with current Athletic Directors, including supervisors and mentors. These two women wanted to know "What's the next BEST move?" "How can I add football?" "What other skills do I need to acquire?" The primary difference between future ADs and career associates was in the questions they asked themselves and others based on their perceptions of the responsibilities of the Athletic Director. Career associates were more likely to ask themselves "Do I want the AD position?" "Do I have what it takes to get there?" "Do I really want to learn that skill?"

Crant (2000, p. 436) suggested employees that "take an active role in their approach toward work" exhibit proactive behavior. Proactive people "actively seek information and opportunities for improving things; they don't passively wait for information and opportunities to come to them" (Crant, p. 437). In this study, Future ADs sought opportunities to "build" or "create." For example, a former coach and aspiring architect, Barb described being attracted to "projects." She explained

Every place I've ever gone needed to be built and so (I'm) building it. If we're not building, I'm bored out of my ever loving mind. ... I'm more of a creator than a competitor, there are a lot of people in this industry that sit back. (p. 16)

Similar to CAs, future ADs discussed the importance of enhancing the studentathlete experience; they were more likely, however, to focus on their career trajectories directed toward the position of Athletic Director.

Negotiation strategies. The process of negotiating supports and barriers contributes to an understanding of how women utilize supports to overcome barriers. 
Additionally, negotiation strategies provided insight into factors affecting career decisions. Career Associates and Future ADs had similar career goals: (a) contribute to the development of student athletes and (b) advance within an athletic department to a position of influence. The difference between CAs and Future ADs was the end-point. CAs did not feel it necessary to achieve the position of Athletic Director, while Future ADs identified the position as a career goal. Despite differences in their career trajectories, CAs and Future ADs negotiated supports and barriers in similar ways including: (a) acquisition of necessary skills, (b) engaging in a network of peer and conventional mentors and supervisors, and (c) self-reflection.

Skill acquisition. Acquiring necessary skills was identified as a critical component to professional development. Women perceived skill acquisition to be the first step in professional advancement. A well-developed skill set had two primary benefits. First, "being known" for a particular expertise in, for example, compliance or academic skills helped women feel they were the "go to" person in the department. This built a level of trust and respect between the female administrator and student-athletes, coaches, and colleagues. Women also described being known as the "go to" person as an affirmation of their work and abilities. When recognized for a particular skill, women described feeling as though they contributed to the department.

Second, women perceived skill acquisition as a way to make them more marketable when looking for positions at other institutions. Future ADs were more likely to acquire skills perceived to be beneficial for Athletic Directors. Martha and Vera indicated the need to acquire skills related to supervision, facilities, fundraising, and finance to be a viable candidate for an Athletic Director position. Currently, both women 
She hold an external operations positions which are perceived to be the positions most suited for acquiring the skills necessary to become an Athletic Director (Hoffman, 2010, 2011). Before her current position, Fritz advocated for responsibilities such as budget oversight and facility planning.

Though Judy explained is not sure she wants to be an Athletic Director, she identified the two biggest hindrances to her professional advancement were lack of fundraising experience and administrative responsibility for certain sports. Currently, Judy does not wish to engage in fundraising. The structure of her department does not allow for the direct supervision of sport. It is important to note that while Judy is but one participant in this study, her lack of interest in acquiring skills specific to being an Athletic Director is not unique. Ten of the Career Associates discussed aversions to working with budgets or learning about facility planning. Career Associates described having "no desire" to achieve the position of Athletic Director; therefore, it is not surprising they did not seek to acquire skills such as fundraising, budget oversight, and facility planning. Career Associates, however, perceived skills associated with internal operations such as crisis management, compliance, and academic advising would lead to more having a stronger voice in the department. Hoffman (2011) suggested skills associated with internal operations are not perceived to be transferable to senior-level management positions which require departmental decision-making responsibilities.

All participants perceived skill acquisition as important to achieving a level of respect in the department. Women also described feeling "valued," "affirmed," and an increased sense of self-confidence when they were perceived to be experts within a particular area in the department. When Career Associates had difficulty gaining new 
responsibilities, they began to consider leaving the position for a job perceived as an opportunity for professional growth. Donna described an experience in which she asked for more responsibility:

I wasn't looking to get anything off my plate, I just wanted to get some more responsibility so I could grow professionally. He wasn't interested in allowing me to do that so it was like - well I can stay here and do what I'm doing or I can go somewhere else.

Future ADs were more likely to observed their respective departments to determine how and when new opportunities for skill acquisition would arise. Perhaps seeking an opportunity to grow professionally was also an attempt to find a department in which they would feel more valued.

Engage network of mentors and supervisors. To negotiate barriers (i.e., industry culture, gender, organizational structure), the women in this study engaged support networks of peer and traditional mentors, as well as supervisors, when appropriate. According to Kram and Isabella (1985), "Individuals use and are used by their worlds through evolving relationships" Even if their path has been different from yours, as long as it's someone you can trust and talk to. (Amanda, p. 12)

An important and interesting trend in this study, however, is the number of women (11) who mentioned the positive role of male mentors and supervisors. It is not clear if women consciously chose male mentors because (a) female mentors were not available or (b) male mentors were perceived to have a better understanding of careers in intercollegiate athletics. When discussing the role of mentors, women were more likely to have discussions with male mentors and supervisors about career strategies, while female mentors offered personal support. For example, Martha (p. 10) told a story about a conversation with her mentor and supervisor, a male: 
So, when you have conversations with people about moving to the right school or moving to the right conference, what does that really mean? What have they told you that you need to take into account? What would be a step forward? What would be a step backward? Here is the advice he told me, "If you want to be an $\mathrm{AD}$, (Martha), you've probably got one next step to go, so that steps becomes increasingly important. So, you're next location and the next AD you work with will make or break you. So you need to find the right AD, at the right place."

In fairness, some women did discuss career strategies with female mentors and supervisors. While Betz and Fitzgerald (1987) contended that women in male-dominated professions were not likely to have sufficient numbers to develop a significant peer group, some studies have shown woman have capacity to build networks of their own (Corby \& Stanworth, 2009; Ely \& Meyerson, 2000; Whitmarsh et al., 2007). Women in this study were no exception. Jane shared an example about how she engages a peer network of women in positions similar to hers:

A group of colleagues/friends and I, about six years ago, started a winter weekend getaway. It's all women in college athletics, all in our, to use the high school or college sort of analogy again, in our class or grade. The point is not necessarily to leave work behind, the point is to be able to talk about work. ... It's easier to talk to my friends who are in the business so we pick a weekend every year and that's what we do. We talk about stuff that is going on. We share everything from how did I deal with this or that to where do we think job openings are going to be in the coming year. It's great and we obviously stayed connected throughout the year as well. (Jane, p. 7)

Roberta connected with another female senior associate athletic director in her conference to share perspectives on work and balance. She explained, "Sometimes it's just nice to sit down with someone who will tell you to enjoy the ride." Cindy also offered a similar example of a "fantastic group" of female conference administrators, whom she looked to for advice. She explained that she engaged a supportive network of women in her conference to discuss perspectives on job responsibilities and organizational matters. Cindy felt this network was important because "knowing you're 
not on an island and there are other people going through exactly what you're going through is terrific."

Regardless of the gender of the network or mentor, the importance of engaging a network was clear. First, engaging a network to discuss career strategies indicates women in this study are interested in career advancement in intercollegiate athletics. This may result in more women in decision-making positions or women with more decision-making power in their current roles because they have a more in-depth understanding of the field. Second, the network is another way to maintain interpersonal relationships, another support identified in this study.

Self-reflection. Self-reflection also played an important role in the negotiation of supports and barriers. During self-reflection, participants tended to evaluate their current experiences within the context of their career expectations and goals. Generally, women engaged in self-reflection when seeking guidance from a mentor, encountering a barrier, or considering the possibility of a change in responsibility or position. As Jenny explained:

I' $m$ in a bit of a place of reflection to try and figure out if steps like pursuing an $\mathrm{AD}$ are what I really want to do or are what I will be drawn to because others want that for me. I think that's a really tricky, it's too much of a demanding job to do it because others think you would be good at it and really, really want to see a woman in yet another AD spot or whatever. In five years maybe I'll have an answer to that question. (Jenny, p. 16)

O'Neil and Bilimoria (2005) suggested the process of self-reflection is a characteristic of the career phase "pragmatic endurance" or "reinventive contribution: Similar to Savickas' (2002) Establishment phase, pragmatic endurance acknowledges the multiple responsibilities women encounter both personally and professionally ( $\mathrm{O}^{\prime} \mathrm{Neil}$ \& Bilimoria, 2005). Career Associates were more likely to exhibit pragmatic endurance 
because they understand their career development is heavily dependent on professional others (e.g., mentors, supervisors, colleagues) and personal others (e.g., spouses, children, parents) (O'Neil \& Bilimoria, 2005). Additionally, CAs in the phase of pragmatic endurance are "questioning the essential centrality of careers in their lives, given the other increasing demands on their time" (O’Neil \& Bilimoria, p. 183). For example, Tina, Julian, Amanda, Tracy, and Jane are considering their next steps. They suggested job responsibilities, proximity to family, and work-life balance would play a significant role in their decisions. Each of these women came to these search criteria after reflecting on their current and previous work experiences.

Future ADs were more likely to fall into the "reinventive contribution" phase (O'Neil \& Bilimoria). They have a stable, planned career path and focus more on their contributions to work, their families, and themselves. Future ADs like Barb, were more likely to question the perceived job functions of an Athletic Director by asking, "Is this how I want to spend my day?" Fritz, when presented with the opportunity to be an Athletic Director, considered if it was the "right opportunity." For Fritz, the right opportunity included moving to a school at which her family could reap the benefits of tuition remission. With three daughters approaching high school and college, tuition remission is close to a $\$ 1$ million benefit. She explained:

The amount of time and the investment, personal and professional in time that it would take to feel that I was really setting the right course at (university). I just thought, "You know, do I want to work for the next five years just to make up a tuition benefit."

Finally, in the "twilight" of her career, Donna found herself at a crossroads:

I was again, kind of at a point where I felt like I want to do something a little different and it was partially - okay, what can I do kind of long term and not get totally burned out - where can I make an impact. (Donna, p. 14) 
The process of self-reflection seems to refocus women on the fundamental reasons they pursued a career in intercollegiate athletics - student-athletes. Self-reflection is also a process during which women weigh supports and barriers in current and future positions. Additionally, self-reflection is a process in which participants in this study considered the present state of their careers, as well as future directions. As Judy offered, "It's that debate between how much do I keep pushing my career versus how much do I stay here; change and influence here. It's a debate I have all of the time. There is no real answer."

\section{Summary}

The findings of this study suggest career supports and barriers impact career expectations and career goals. Participants identified supports as interpersonal relationships, professional development activities, and opportunities for career advancement. Barriers included the male-dominated industry culture of intercollegiate athletics and the residual impact culture has on organizational structures in an athletic department. Women employed negotiation strategies and coping mechanisms to manage supports and barriers. The findings of this study are similar to those by Hite and McDonald (2003), Wentling (1996), and Hopkins and O'Neil, (2007). 


\section{CHAPTER V}

\section{SUMMARY AND DISCUSSION}

Assistant and associate athletic directors have been identified as people "in the pipeline" to executive positions as Athletic Directors (Grappendorf et al., 2004;

Lapchick, 2010). Given the underrepresentation of women as Athletic Directors and the concern that women may experience difficulty accessing those positions (Bruening et al., 2008; Burton et al., 2011; Grappendorf et al., 2004; Inglis et al., 1996; Moore et al., 2000; Sagas \& Cunningham, 2004a; Whisenant et al., 2002), there is a growing need to understand the career experiences of women in senior-level management positions in intercollegiate athletics. Such an understanding may provide insight into how and why experiences at the senior level influence decisions to pursue the position of Athletic Director. Therefore, the purpose of this study was to explore the career experiences of female senior managers in intercollegiate athletics.

Six research questions were established to examine the career experiences, expectations, and goals of senior-level women working in NCAA Division I intercollegiate athletic administration:

1) What factors do participants perceive as supports to their career development?

2) What factors do participants perceive as barriers to their career development?

3) How do participants negotiate supports and barriers?

4) In what ways do participants' perceptions of supports and barriers influence their career outcome expectations? 
5) In what ways do participants' perceptions of supports and barriers influence their career goals?

6) What coping strategies do participants employ to reconcile potential differences between career aspirations and career realities?

Research questions were answered through in-depth interviews with 15 women who currently hold titles of assistant athletic director or associate athletic director at NCAA Division I institutions.

This chapter is designed to help the reader understand the career experiences of senior-level female administrators in intercollegiate athletics. Therefore, this chapter (a) explores the career development of female assistant and associate athletic directors through the (b) perceptions of supports and barriers and (c) the negotiation strategies and coping mechanisms participants employed to achieve career goals. The chapter concludes with implications for career theorists, sport managers, and the sport management classroom.

\section{Exploring the Career Development of Senior-Level Female Administrators}

This study explored the career experiences, expectations, and goals of senior level female administrators in intercollegiate athletics through the lens of two career development theories - Career Construction Theory (Savickas, 2002, 2005) and Social Cognitive Career Theory (SCCT) (Lent et al., 1994, 2000). SCCT compliments Career Construction Theory in that it helps build conceptual linkages between the individual, the context of work, life themes, and the influence of perceived supports/barriers on career expectations and goals. 
Participation in sport and the support and involvement of family and trusted adults helped form many of the participants' initial interest of sport as a potential career path. Based on participants' accounts, men appeared to have a strong influence over participants' socialization to sport and sport as a potential career path. Studies have shown men, particularly fathers and brothers, have a strong influence on girls socialization to sport (Dixon, Warner, \& Bruening, 2008; Farrell, Fink \& Fields, 2011; Weiss \& Barber, 1995) and potential careers. Participants discussed the role of female supervisors and mentors in their careers, but offered little about the role of women before entering the field of intercollegiate athletic administration. Socialization, however, is only one component of the formation of a vocational personality. Cunningham et al. (2005), Lapour and Heppner (2009), and Miller (1998) also contended the influence of early career experiences on the formation of career interests and values.

Early career and educational experiences of women in this study influenced them to pursue careers in intercollegiate athletic administration. Early career experiences included internships with the NCAA or in athletic departments, graduate assistantships, or experiences in an entry-level position in sport. For participants, early career experiences offered a glimpse into expectations of a career in intercollegiate athletics. They described working in departments in which they were the only female on staff, long work hours, and the enjoyment of working closely with student-athletes and coaches.

When women decided to pursue administrative careers in intercollegiate athletics, in part because of early experiences, nine of 15 women described a career goal of becoming the Athletic Director for an NCAA athletic department. Participants also identified "making a difference in the lives of student-athletes" and career advancement 
as goals. As participants' careers evolved, expectations and career goals shifted from a focus on professional skill development and title attainment to an interest in providing a contribution to their respective departments. Thus, at the time of data collection, only four participants indicated a desire to pursue the position of Athletic Director. Eight women stated they had no interest in being an Athletic Director at any level, while three would consider the role at NCAA Division II or Division III institutions. From this data, one cannot yet conclude whether gender is a factor in seeking a position such as Athletic Director. Additional research is necessary to compare the career goals of women and men in intercollegiate athletics. A more in-depth exploration of perceived career supports and barriers, however, may help explain the shift in career expectations and goals. The following two sections discuss perceived supports and barriers to career development and the attainment of higher-level positions in intercollegiate athletics.

\section{Supports and Barriers to Career Development}

Barriers and supports are real features of an industry or an organizational environment, but they are also subjective perceptions defined by an individual's lived experience (Albert \& Luzzo, 1999; August \& Quintero, 2001; Astin, 1984; Kanter, 1977; Lent et al., 1994). In other words, the mere perception of a barrier can affect the career decision-making process and, thus, career development (Albert \& Luzzo, 1999; Lent et al., 1994). As such, barriers and supports (Table 4) play an influential role in the careers of women in intercollegiate athletics. 


\section{Table 4}

Supports and barriers to women's career development in intercollegiate athletic administration

\begin{tabular}{l|l}
\hline Support & Barrier \\
\hline Interpersonal relationships & Male-dominated industry culture \\
$\bullet \quad$ Supervisors & Gender \\
- Mentors & "Work-life balance \\
Professional development activities & long work hours, travel schedules) \\
- Networking & Organizational structure \\
- Skill acquisition & Career advancement \\
Career advancement & \\
- Vertical or "upward" mobility & \\
- Increased departmental & \\
\hline
\end{tabular}

Supports are factors perceived to enhance career development and influence career choice, expectations, and goals (Albert \& Luzzo, 1999; Astin, 1984; Betz \& Fitzgerald, 1987; Lent et al., 1994; Savickas, 2002). Women in this study identified supports to their career as (a) interpersonal relationships, (b) professional development activities, and (c) opportunities for advancement.

Interpersonal relationships. Interpersonal relationships included relationships with supervisors and mentors. Supervisors and mentors offered career advice and guidance, personal support, and encouragement. Several studies on women in maledominated professions suggested the importance of interpersonal relationships for maintaining "interconnectedness" through access to social support and balance between life and work (Forest \& Mikolaitis, 1986; Inglis et al., 1996, 2000; Richie et al, 1997; Sagas \& Cunningham, 2004; Whitmarsh, 2007). Additionally, Kanter (1977) suggested that the primary function of a mentor was "to make introductions or train a young person to move effectively through the system" (p. 181). This study also found mentors and supervisors help women navigate social, political, cultural, and structural barriers. Male 
mentors seemed to play a more critical support role to participants. Perhaps this is a reflection of the role fathers, brothers, and interactions with other male figures played in socialization to sport and sport as a potential career field. More research is needed to understand the role of male and female mentors in the vocational socialization of women in intercollegiate athletics.

Professional development activities. The role of professional development activities in career development have been studied in varying degrees in intercollegiate athletics (Cunningham \& Sagas, 2002; Cunningham, Sagas, \& Ashley, 2001; Sagas \& Cunningham, 2004). Sagas and Cunningham (2004) suggested professional development activities included the accrual of social capital and human capital. Social capital includes "resources acquired through individual's networks with subordinates, superiors, and peers" (Sagas \& Cunningham, p. 413). Human capital is the accrual of job-related investments including education, experience, training, and specific competencies (Sagas \& Cunningham). In the context of this study, participants defined professional development activities as a combination of social and human capital including networking and opportunities to gain experience and develop skill sets.

Networking. In this study, participants perceived networks to be an important support to career development. Networks provided opportunities to develop relationships with peers, mentors, and potential employers in intercollegiate athletics. In this study, participants perceived networking to be valuable to their career development. These findings support other sport management studies which suggest participation in formal and informal networks are particularly importance for women's advancement within 
sport organizations (Bower, 2009; Grappendorf \& Henderson, 2008; Hums \& Sutton, 1999; Judd, 1995; Shaw, 2006).

Research suggests that even though women can benefit from network, networks tend to be less beneficial for women than for men (Forret \& Dougherty, 2004; Kumra \& Vinnicombe, 2010). Sagas and Cunningham (2004) found that men were more likely to "reap the benefits" (p. 419) of networking. They also suggested women might be experiencing discrimination in the promotions process. Based on the findings of this study, there is little evidence to suggest discrimination in the hiring and promotions process. More research is needed, however, to understand fully the role of networking in hiring and promotions for men and women in intercollegiate athletics.

Skill acquisition. In addition to networking, participants perceived skill acquisition as vital to career development and success. Participants discussed the importance of learning technical and interpersonal skills. Skills and job competencies are critically important to career development and achieving career expectations, and goals (Richie et al., 1997; Wentling, 1996, 2003; Whitmarsh et al., 2007). Participants identified technical skills such as crisis management, decision-making, effective problem solving, budgeting and finance, compliance and eligibility, and facility operations as critical for professional success. Participants described interpersonal skills as important for facilitating effective communication with student-athletes, coaches, administrators, and network contacts. Sport management researchers suggest relevant skills may include strategic planning, personnel and human resource management, networking, budgeting, and leadership skills (Grappendorf et al., 2004; Knoppers \& Anthonissen, 2007). 
A key finding in this study was that while skill development was deemed important to career advancement, women who described having little to no desire to pursue the position of Athletic Director seemed less likely to seek skill development particularly in finance, fundraising, and budget management. Similarly, the four women who said they would "consider" an Athletic Director position at the NCAA Division II or Division III level rarely advocated for departmental responsibilities that would help them develop skill sets perceived as necessary for an Athletic Director.

Conversely, two of the four women who stated a career goal of becoming an Athletic Director had primary responsibilities in external operations including department finances and budgets, fundraising, marketing and/or sponsorships. The skill sets (e.g., budgeting, fundraising, supervisory responsibility) associated with external operations are perceived to be more transferable to executive positions (Grappendorf \& Lough; Grappendorf et al.; Hoffman; Lapchick).

Opportunities for advancement. According to research, building networks and gaining practical experience to obtain a skill set necessary for advancement are common themes in literature pertaining to the careers of women in sport organizations (Bower, 2008; Claussen \& Lehr, 2002; Hums \& Sutton, 1999; Grappendorf et al., 2004; Hoffman, 2010; Greenhill et al., 2009; Sagas \& Cunningham, 2004). In this study, participants defined advancement as vertical movement through the organizational hierarchy and/or assuming more responsibilities within the department or athletic conference.

Advancement, whether conceptualized through vertical movement in an organizational hierarchy or assuming more departmental responsibility, was contingent upon other supports mentioned in this section. Rarely did women seek out or consider 
new positions without the guidance of a supervisor or mentor. They engaged networks to learn about other opportunities and find support when dealing with difficult personal and/or professional issues. All of the participants in this study attributed their career advancement to (a) the relationships built with supervisors, mentors, and through networks; and (b) a refined skill set.

In the present study, participants identified interpersonal relationships, professional development opportunities, and career advancement as supports to their career development. Career supports gave participants the confidence to assume more job responsibility, consider new professional opportunities, and develop professional interests. Understanding the function of career supports is important because supports provide insight into mechanisms that help women navigate a complex industry.

Participants perceived the cultivation of interpersonal relationships and participation in professional development activities as critical to career advancement. Studies beyond the context of sport management (Richie et al., 1997; Wentling, 1996, 2003; Whitmarsh et al., 2007) and in sport management (Inglis et al., 1996, 2000; Sagas \& Cunningham, 2004; Smith et al., 2012) also suggest the supports identified in this study are important to women's career development. While supports are important to career development, the identification of barriers are equally so. The next section identifies factors women perceive as barriers to their career development.

\section{Barriers to Career Development}

Barriers are factors that can impede career development and the achievement of career goals (Albert \& Luzzo, 1999; Astin, 1984; Betz \& Fitzgerald, 1987; Lent et al., 1994; Savickas, 2002). Participants in this study identified the male-dominated culture of 
intercollegiate athletics and its myriad challenges as barriers to career development. Barriers included: gender, work-life balance, a culture of "grinding and pounding," organizational structure, and limited opportunities for advancement. The combination of these factors in addition to extra-work responsibilities (e.g., children, spouse, parents, friends) presented challenges to participants in their career development, expectations, and goals.

Gender. Research suggests gender as a major barrier to career development, particularly in male-dominated professions (Beatty, 2007; Betz \& Fitzgerald, 1987; Duehr \& Bono, 2006; Schein, 2001, 2007; Wentling, 1996, 2003). More specifically, gender stereotypes have the potential to negatively affect the career development of women (Correll, 2004; Duehr \& Bono, 2006; Gregory, 2009; Schein, 2001, 2007). Sport management research also found gender stereotypes created a barrier for women (Burton et al., 2009; Burton et al., 2011; Claringbould \& Knoppers, 2007; Grappendorf et al., 2004; Whisenant et al., 2002).

In the present study, participants identified gender as a barrier in two ways: (a) gender stereotypes associated with "being a woman" and (b) being adequately prepared to assume the role of Athletic Director. Women identified experiences in which they perceived their physical attributes or personality characteristics were viewed negatively because they were women. Moreover, some women described feeling as though men in positions of authority were "leery" of a woman's ability to supervise athletic programs. While one could perceive participants' experiences as discriminatory and stereotypical, perhaps perceptions are indicative of the fact women have not reached positions in which they have proved competence. 
Several women in this study discussed the paradox of visibility in an athletic department. Given that visibility has the potential to result in praise or criticism, participants suggested the success or failure of one woman has a ripple effect on the way in which all other women vying for similar positions will be perceived. More research is necessary to understand the phenomenon of women's perceptions of readiness for assuming the position of Athletic Director. Addition research on the paradox of visibility is also important for women in intercollegiate athletic administration, as well as for women in male-dominated professions.

Work-life balance. Participants identified long workdays, weekend commitments, travel requirements, and other after-hours engagements (e.g., fundraisers, community benefits) as challenges. For some, the long work hours contributed to burn out or boredom, while other participants described stress-related health problems. Some of the health problems included insomnia, hives, high blood pressure, and anxiety. In addition, long work hours, irregular schedules, and travel requirements, participants in the study suggested the time commitment required for intercollegiate athletics contributed conflict between their roles as employees and family members.

Work-family balance has received a great deal of attention in the sport management literature (Bruening \& Dixon, 2007; Bruening et al., 2008; Dixon \& Bruening, 2005; Dixon \& Bruening, 2007; Greenhill et al., 2009; Inglis et al., 2000). Seven of the women in this study had children and discussed the difficulty of balancing work and family; they considered moving to positions with more regular work hours or less responsibility in order to manage the demands of work and family. Of the eight women who did not have children, six acknowledged the struggle facing women with 
families. While women who were married and/or had children struggled with work-life balance, only one considered "taking a step back" in administrative responsibilities or leaving the field.

Several participants spoke of women they knew who left the field because struggles due time commitment and/or work-family balance, but only four participants indicated potentially leaving intercollegiate athletics in the next five years. Their plans, however, were not definitive. In fact, when asked about career plans in the next five years, 13 participants discussed some type of career advancement in intercollegiate athletics in either title and/or administrative responsibility.

Organizational structure. Several women in this study expressed concern they would be "typecast" or "pigeon-holed" into positions traditionally held by women in athletic departments. Type-casting of occupational roles is a process known as occupational sex segregation (Bieby \& Baron, 1986), and has been identified as a common practice in male-dominated industries, including intercollegiate athletics. For examples, in studies by Grappendorf et al. (2004), Lapchick (2011), the NCAA (2010), and Whisenant et al. (2002) women were more likely to be over-represented in operations internal to the athletic department, while men held a greater proportion of positions in external operations. These studies, however, fail to consider the role of individual agency. Individual agency suggests the individual has a choice in how organizational structures affect career expectations and goals. While the choices of women may be constrained (Eccles, 1994) by personal and contextual factors, women still have a choice in how barriers and supports affect career expectations and goals (Fagenson, 1990). The women in the present study are no exception. 
For example, 12 women in this study held positions in internal operations. Participants indicated positions in internal operations offered more interaction with student-athletes and coaches. Several participants in internal operations indicated they had little interest in external positions because they enjoyed working "behind the scenes" or in a "number two" position. In fact, only two participants who had internal operations responsibilities expressed the desire to pursue the position of Athletic Director. Women in internal positions explained they did not want the responsibility of having to make the "final" decision or perceived their personalities to be a mismatch for a position in external operations.

Metaphorically speaking, it might be useful to compare the athletic department to a house. Internal operations represent day-to-day "housekeeping" responsibilities inside of the house. External operations take care of the external parts of the home such as the yard. In essence, external operations are responsible for the departmental "curb appeal." With this metaphor in place, participants' perceived attraction to internal operations may be attributed to societal constructions of gender roles perpetuated in a male-dominated industry (Beatty, 2007, Eagly, 1987; Schein, 2001, 2007). If we consider the role of individual agency, or choice, it is important to note participants in internal operations perceived those positions as more closely aligned with their personality characteristics, career interests, and goals. Similarly, women in external operations enjoyed their roles as "friendraisers" and in creating the "image" of their respective athletic departments. Therefore, more research is necessary to explore the interaction between individual agency and the perception of gendered organizational structure in athletics. 
Barriers and supports are real features of an industry or an organizational environment, but they are also subjective perceptions defined by an individual's lived experience (Albert \& Luzzo, 1999; August \& Quintero, 2001; Astin, 1984; Kanter, 1977; Lent et al., 1994). In other words, the mere perception of a barrier can affect the career decision-making process (Albert \& Luzzo, 1999; Lent et al., 1994). Barriers and supports play an influential role in the careers of women in intercollegiate athletics. Barriers are reflective of the challenges women have faced over the course of their careers in intercollegiate athletics. Supports were critical factors in helping women overcome barriers. For the women in this study, the respective barriers are not yet insurmountable. The next section begins with a discussion on participants' career expectations and goals, then explores the manner in which women invoke supports to negotiate barriers

\section{Career Expectations and Goals}

It is useful to think of the career development theories and the interplay of supports and barriers discussed in this section as interpretive frameworks for understanding (a) what career decisions women make and (b) why they make these decisions in the context of career expectations and goals. Each support and/or barrier singular or combined - has the potential to influence career development, expectations, and goals (Astin, 1984; Betz, 2004; Coogan \& Chen, 2007; Lent et al., 1994). The exploration of supports and barriers as they pertain to career development, career expectations, and career goals is particularly important for senior level women in intercollegiate athletic administration. Understanding the experiences of women at this level may help researchers and practitioners understand (a) why there are so few female 
Athletic Directors as well as (b) the type of environment in which women's careers may flourish.

Expectations. Two primary themes were derived after examining outcome expectations: (a) job-related expectations and (b) personal expectations. Job-related expectations included perceptions of the professional skills, effort, and commitment required for a career in intercollegiate athletics. Participants described early career experiences in which they "wore many hats." More often than not, assuming multiple roles and responsibilities required extended work hours, odd work schedules, and/or travel on nights and weekends. While the long work hours and odd schedules could prove challenging, participants offered they expected to work extended hours when entering the profession.

Several participants also acknowledged they knew they would be working in a male-dominated profession when choosing a career in intercollegiate athletics. Women who experienced gender stereotyping addressed it passively. In other words, they perceived it to be a product of a male-dominated environment and seemed to expect to encounter such behavior in an intercollegiate athletic environment. As a result, participants were likely to attribute gender stereotypes to a "good ol boys" network, which has the potential to reinforce traditional social and work role by perpetuating perceptions of power and status (Correll, 2004). Interestingly, participants in this study acknowledged the feeling that the "good ol' boys" culture was changing, but they perceived women were primarily responsible for such change. Jenny offered:

I like to say that the women who came before us, changed the landscape. It's our job to change the culture. Anything I would offer you as an answer to that is summarized by that statement. (Women are) around and we're here and we're 
present but the culture doesn't necessarily always reflect that.

Personal expectations included the manner in which positive or negative perceptions of and experiences in intercollegiate athletic administration align with personal and professional goals. Several participants indicated they expected a career in intercollegiate athletics would provide them the opportunity to affect the student-athlete experience. Furthermore, they expected "everyone to have the student-athletes' best interests in mind. Many participants, however, described feeling the NCAA and athletic departments are "moving in the wrong direction." As such, participants began to reconsider their career paths in intercollegiate athletic administration.

Career goals. The literature on career development suggested that individuals encounter barriers internal and external to an organization (Astin, 1984; Betz \& Fitzgerald, 1987; Lent et al., 1994). Many individuals encounter internal and external barriers simultaneously. Women, in particular, may develop coping strategies to negotiate personal and contextual factors unique to their gender (Astin; Betz \& Fitzgerald; O'Neil \& Hopkins, 2007). For example, the findings of the present study suggest women have encountered barriers such as gender stereotypes and inability to access networks or develop skills. Components of industry culture including navigating a male-dominated profession and contending with work-life balance also affected career expectations and goals. Women either successfully negotiated barriers by engaging supports or continued to grapple with the balance between personal and professional obligations.

As intercollegiate athletic administrators, women in this study identified two primary career goals: (a) to contribute to the development of student athletes and (b) 
advance within an athletic department to a position of influence through either title or job responsibilities. Participants perceived achieving a higher position and/or more responsibility in an organization would provide greater opportunities to have a "voice" in the departmental decision-making process and, therefore, a greater likelihood of affecting the lives of student athletes. Perceived barriers prevented women from feeling as though they were contributing to the student-athlete experience. Additionally, when women were not able to advance, they felt limited in their abilities to have a voice in the decision-making process. Moreover, women perceived their lack of decision-making power as an inability to contribute to student-athlete development.

Barriers and supports are real features of an industry or an organizational environment, but they are also subjective perceptions defined by an individual's lived experience (Albert \& Luzzo, 1999; August \& Quintero, 2001; Astin, 1984; Kanter, 1977; Lent et al., 1994). That is, mere perception of a support and/or barrier can affect the career decision-making process (Albert \& Luzzo, 1999; Lent et al., 1994). Vocational personality, career adaptability, and life themes (Savickas, 2005) affect the manner in which women negotiate barriers and/or supports in the context of career expectations and goals.

\section{Negotiation of Barriers and Supports}

The process of negotiating supports and barriers contributes to an understanding of how women utilize supports to overcome barriers. Additionally, negotiation strategies provided insight into factors affecting career decisions. Although participants negotiated supports and barriers in several ways, three major themes still emerged: (a) acquire 
necessary skills, (b) engage a network of lateral and traditional mentors and supervisors, and (c) self-reflection.

Acquiring necessary skills. Participants perceived skill acquisition as an important component to career advancement. More importantly, women perceived the acquisition of skills as the ultimate support. In other words, women felt if they had a strong work ethic and could learn new skills, they would advance through the organizational hierarchy. If vertical advancement was not the goal, the process of "continual learning" seemed to aid in job satisfaction.

Corby and Stanworth (2009) and Wentling (2003) found that opportunities to acquire skills and experience were vitally important to women seeking or already in management positions. Furthermore, skills and job competencies are critically important to career development, expectations, and goals (Richie et al., 1997; Wentling, 1996, 2003; Whitmarsh et al., 2007). Developing skills and competencies can increase performance quality, self-efficacy, and the likelihood women will persist in the face of barriers (Betz, 2004; Wentling, 2003). Several women in this study mentioned feelings of increased self-confidence when they assumed more responsibility and described feeling affirmed when colleagues recognized them for their work.

Engaging a network. Another form of negotiation included engaging a network of mentors and supervisors to discuss career strategies and career concerns. O'Neill et al. (2004) suggested seeking career guidance could result in rapid career advancement and development for women. The findings of this study suggest participants are interested in career advancement in intercollegiate athletics, but definitions of advancement differ. Regardless of definition, such an interest in career advancement may result in more 
women in decision-making positions or women with more decision-making power in their current roles because they have a more in-depth understanding of the field. Second, the network is another way to maintain interpersonal relationships, another support identified in this study. The relationships women developed through networks and mentoring were important to helping women manage career experiences, expectations, and goals. Participants described networks that were sources of camaraderie, commiseration, and change.

Self-reflection. Self-reflection also played an important role in the negotiation of supports and barriers. During self-reflection, participants tended to evaluate their current experiences within the context of their career expectations and goals. Generally, women engaged in self-reflection when seeking guidance from a mentor, encountering a barrier, or considering the possibility of a change in responsibility or position. O'Neil and Bilimoria (2005) suggested the process of self-reflection is a characteristic of the career phase "pragmatic endurance" or "reinventive contribution: Similar to Savickas' (2002) Establishment phase, pragmatic endurance acknowledges the multiple responsibilities women encounter both personally and professionally (O’Neil \& Bilimoria, 2005).

\section{Coping Strategies}

To reconcile the differences between career expectations and goals, participants engaged in coping strategies. Coping strategies are designed to reduce the perception of conflict between the individual and the structure in question (e.g., work, family, organizational policies; Lent et al., 2000; Savickas, 2002). Strategies emerged that divided the participants into two distinct groups: (a) career associate athletic directors (Career Associates) and (b) Future ADs. "Career Associates" (CAs) include participants 
who either would not commit to the Athletic Director position as a career goal or were never interested in the position as a career goal. In addition, CAs were more likely to adapt their career expectations and goals based on the supports and barriers they encountered. The "Future AD" group includes the four participants who stated, definitely, the position of Athletic Director was a career goal. Future ADs were more likely to exhibit coping efficacy (Lent et al., 2000), while CAs tended to compromise to circumstance (Savickas, 2002). Coping efficacy implies forward progress toward professional goals (Lent et al., 2000), while adaption suggests more of a compromise to circumstance (Savickas, 2002).

Career associates. A few studies on women in intercollegiate athletic administration have suggested that promotion and advancement to executive positions in intercollegiate athletics is not a career goal for women (Grappendorf et al., 2004; Sagas \& Cunningham, 2004b). The findings of this study support this notion. Of the 15 women interviewed, 11 indicated minimal to no desire to pursue the position of Athletic Director. As women progressed through their careers, career goals became less defined and less directive. Priorities changed as women became older, developed personal lives, or felt as though the direction of the NCAA as a governing body was increasingly suspect.

Perhaps this is a function of the "Establishment" phase of career development (Savickas, 2002). Establishment represents stabilization in a job and career. During this stage, an individual seeks to implement a vocational self-concept. During establishment, the vocational self-concept becomes more congruent with the requirements of the social and vocational worlds. As the social and work worlds become more parallel, a person may seek more opportunities (e.g., greater responsibilities, advancement, better person- 
environment fit) within his/her organization or in another organization. Toward the end of the establishment stage, an individual may begin to contemplate the "next steps" in his/her career. According to Savickas (2002), "Individuals reach a point where taking care of what they have established, that is, maintaining, becomes more important than advancing in new directions" (p. 179).

Other women in this study represent the "Management" phase of career development (Savickas, 2002). During the Management stage, an individual may ask him/herself, "Is this the career I want to pursue for the next 25 years?" It is at this stage that occupational responsibilities and the vocational self-concept are re-evaluated. Savickas (2002) describes this process as "re-finding, not refining, the self" (p. 179). Career associates described being "less driven by money" and more focused on job responsibilities, personal growth, and support. As Tracy discussed, "As I've gotten older, it's much more about who I work for than what the job is, which was more important when I was younger."

Wentling (1996) suggested women lowered career aspirations when they encountered barriers such as family responsibilities, burnout, or lack of company commitment to professional advancement. While Career Associates and Future ADs encountered similar challenges and engaged in different coping strategies, it is difficult to conclude that CAs "lowered" their aspirations. Instead, findings of this study suggest the role of individual agency in career development. For example, some CAs discussed accepting a new job to be closer to family for enhanced work-life balance. Other CAs described seeking out positions that would allow a closer connection to student-athletes. 
Many CAs perceived advancing in the organizational hierarchy would give them less opportunity to directly affect the student-athlete experience. In short, CAs made career choices that would align their personal and professional career goals and values. None of the women in this study described feeling as though they "lowered" their expectations or career goals. Many, however, admitted to reconsidering their career expectations and goals based on experiences in their personal and professional lives. This finding is supported by research by Hite and McDonald (2003), which found women adjust career aspirations and goals due to life circumstance.

Future ADs. Four women stated they had a career goal to be an Athletic Director in NCAA Division I athletic departments. While these women described similar barriers and supports affecting their career development, they tended to be better advocates for themselves, more forward-thinking, and optimistic. Vera, Martha, and Fritz described situations in which they asked supervisors and mentors for more responsibility. They also engaged in a process of career planning which involved self-reflection and discussions with colleagues of varying experience levels within Division I athletic administration. In other words, Future ADs perceived and actively pursued opportunities for advancement.

Studies (Hopkins \& O’Neil, 2007; Wentling, 2003) suggest the perception of more opportunity in a new company and more on-the-job time commitment tended to increase a woman's aspiration to higher levels of management (Hopkins \& O'Neil, 2007; Wentling, 2003). We cannot conclude from the findings of this study that more opportunity and commitment increased aspirations to higher levels of management. We can conclude, however, that the women in this study who aspired to the position of 
Athletic Director engaged in coping strategies that positioned them to achieve their career goals.

Future ADs were more likely to acquire skills perceived to be beneficial for Athletic Directors. Such skills included supervision, facility planning, and fundraising. Future ADs have a stable, planned career path and focus more on their contributions to work, their families, and themselves. When considering the next steps in their career paths, Future ADs asked themselves, "How do I get (to the AD position)?" "What will it take to get there?". They wanted to know "What's the next BEST move?" "How can I add football?" "What other skills do I need to acquire?" Additionally, Future ADs were more inclined to discuss financial aspects (e.g., salary, tuition benefits) of a job.

The primary difference between Future ADs and Career Associates was in the questions they asked themselves and others based on their perceptions of the responsibilities of the Athletic Director. Career Associates were more likely to ask themselves "Do I want the AD position?" "Do I like the responsibilities ADs have in a department?" "Do I have what it takes to get there?" "Do I really want to learn that skill?"

Summary. Participants in this study negotiated barriers and supports through various coping strategies. Coping strategies helped participants align their personal and professional goals, though many participants - particularly CAs - continued to struggle with barriers both internal and external to the organization. While multiple studies attribute organizational barriers to the lower number of women in intercollegiate athletic administration or a male-dominated industry culture, it is imperative that we remember the role of individual agency. In other words, the individual has a choice in how supports 
and barriers affect career expectations and goals. The majority of participants used language including "choice," "I chose," or "I wanted" when discussing career decisions. Therefore, each woman exercised individual agency in her career decisions.

\section{Implications}

The implications for this study are divided into four sections including implications for (a) career development theorists, (b) sport managers, (c) the sport management classroom, and (d) future researchers.

\section{Implications for Career Development Theorists}

This study contributes to theoretical literature in several ways. First, this study is unique in that it combined Career Construction Theory (Savickas, 2002, 2005) and Social Cognitive Career Theory (Lent et al., 1994, 2000) to provide a better understanding of the dynamic interplay between the individual, work context, and personal life themes on career experiences as they influence career expectations and goals.

Second, the findings of this study shed light on the social contexts and variables contributing to the construction of personal and professional identities (Astin, 1984; Betz \& Fitzgerald, 1987; Coogan \& Chen, 2007; Fagenson, 1990; Forrest \& Mikolaitis, 1986) of women in intercollegiate athletic administration. In other words, this study extends what is known about supports and barriers contributing to the career development of women in a male-dominated industry, specifically NCAA Division I intercollegiate athletics. It also provides a more in-depth look at how women negotiate barriers and engage supports in the pursuit to achieve personal and professional career expectations and goals. As Career Associates progress through careers in intercollegiate athletics, 
career goals and aspirations seem to plateau or become less clear. Conversely, Future ADs discussed strategic plans to achieve the career goal of Athletic Director.

As suggested by career development theorists (Astin, 1984; Eccles, 1994; Lent et al., 1994, 2000; Savickas, 2002, 2005), it is important to understand the choices made within the context of career development. Supports and barriers affect women differently and at different stages of their careers. Additionally, barriers may prove challenging when career expectations and career goals become less clear. It is difficult to predict, however, how and when barriers present the most challenge because contextual factors at work and outside of work occur in combinations unique to each woman.

In short, this study provides a better understanding of the dynamic processes contributing to women's career experiences, expectations, and goals in intercollegiate athletic administration. Furthermore, the findings of this study, can help women be more proactive in personal and career decisions in anticipation of perceived career barriers and supports. Finally, The findings of this study, however, can help women and men be more proactive in personal and career decisions in anticipation of perceived career barriers.

\section{Implications for Sport Managers}

More women work in intercollegiate athletics than ever before, yet the proportion of women as senior- and executive-level managers in general is declining (Acosta \& Carpenter, 2010; Lapchick, 2010). Previous research in sport has suggested that increasing the proportion of women in the senior management (i.e., assistant and associate athletic directors) "pipeline" would result in more female Athletic Directors (Moore, 2008; Whisenant et al., 2002). Studies have found that career satisfaction may result in the retention of women in intercollegiate athletic administration (Inglis et al., 
1996, 2000). With fewer women likely to exit the profession, the proportion of women in administration may increase, leading to more role models/mentors, and greater networking opportunities.

Athletic departments and professional organizations such as the NCAA, National Association of Collegiate Women Athletic Administrators, (NACWAA), and National Association of Collegiate Directors of Athletics (NACDA) dedicated to promoting the professional development of administrators need to be particularly attentive to understanding women's career expectations and goals. The findings of this study suggest not all women strive to attain the position of Athletic Director due to personal obligations and professional interests. Regardless of career goals, women can benefit from conference programs and seminars geared toward skill development and building networks. Moreover, professional development opportunities (ex - Women's Leadership Symposium, NACWAA HERS) have the potential to connect women with mentors and collegial networks that can offer career guidance and are supportive of their personal and career goals.

Sagas and Ashley (2001) found that a positive work environment (e.g., collegial support, inclusion, work conditions) may help retain female coaches. The findings of this study also suggest a positive work environment may reduce the influence of career barriers. More specifically, it is important for men and women working in intercollegiate athletics to understand women are not "fighting for one seat at the table." Male and female administrators should work to create more seats the proverbial "table." Studies have shown organizations with a more diverse (i.e., gender and race) staff are more productive (Catalyst, 2011 ; Claringbould \& Knoppers, 2008; Elstad \& Ladegard, 2010). 
As previously discussed, several women in this study perceived a shift in the maledominated culture of intercollegiate athletics to one that is more inclusive of gender. Therefore, both men and women in decision-making positions should consider developing and implementing policies designed create a more inclusive environment, which encourages professional development and the integration of work and life roles (O’Neil, Bilimoria, \& Saatcioglu, 2004). Formal inclusive policies may include parental leave and access to benefits. Informal policies may require a shift in organizational culture to one that is more inclusive of families. Such a shift may include familyfriendly departmental picnics or a supervisor's support of children at athletic and departmental events.

In a similar vein, many participants suggested the NCAA should reconsider the purpose and role of the Senior Woman Administrator. Several participants understood the historical significance of the SWA role, but perceived it contributed to the "glass ceiling" for women in intercollegiate athletic administration. In other words, women perceived the only position in which women could be influential was the Senior Woman Administrator, even though the SWA is not a "line" position on an athletic department, but rather an NCAA designation. Only one woman at each school can hold the SWA title, but the SWA should not be the only role for women in intercollegiate athletic administration.

\section{Implications for the Sport Management Classroom}

Nearly 350 undergraduate and graduate sport management programs exist around the world (NASSM, 2012). Several sport management scholars (DeSensi, Kelley, Blanton, \& Bleitel, 1990; DeSensi, 1994; Hums, 1994; Moore, 2008; Moore, Parkhouse, 
\& Konrad, 2004; Parks \& Roberton, 2002) and scholars from other disciplines (Leverett, Parker, \& McDonald, 2007; Levsen, Goettel, Chong, \& Farris, 2001) have argued that obtaining equity in the workplace begins with obtaining equity in the classroom. The academic classroom provides many opportunities to discuss and explore the organizational culture of intercollegiate athletics. Furthermore, addressing perceived barriers and supports in the classroom environment could help prepare all students interested in intercollegiate athletic administration for the experiences they may face. It should be noted, however, that perceived barriers and supports might influence an individual's intention to pursue a career in intercollegiate athletics (Cunningham et al. 2005).

While several women in this study suggested women were responsible for changing the culture, the classroom offers an opportunity for both young men and women to discuss and explore change in intercollegiate athletic departments. Furthermore, the classroom offers an environment to discuss and break down stereotypes about the intercollegiate athletic environment and culture. Valuing differences and personal experiences promotes awareness, tolerance, and intrapersonal and interpersonal development (DeSensi, 1994). Educational programs can help foster a multicultural environment (DeSensi, 1994; Moore 2008; Moore, Parkhouse, \& Konrad, 2004).

Second, many sport management academic programs require students to participate in volunteer activities or internships before graduation. Educators and practitioners can use these opportunities to promote participation with organizations that have a reputation for gender equity and inclusion. Additionally, educators and practitioners can help students establish networks and positive learning partnerships (see 
King \& Baxter-Magolda, 2004). The Learning Partnership Model (King \& BaxterMagolda, 2004) is useful in helping students achieve their personal and professional goals in the context an organization or society. Learning partnerships require the student and professor or student and practitioner to engage in a mutual partnership of learning and discovery (King \& Baxter-Magolda, 2004). The Learning Partnership Model offers educators the unique opportunity to work with students to identify their career interests, aspirations, and goals. In addition, students have the opportunity to explore career interests and potentially redefine aspirations and goals based on their early career experiences (Cunningham et al., 2005).

Third, Moore et al. (2004) suggested that the under-representation of women in sport organization managerial positions might be improved by increasing the number of women in sport management preparation programs. Furthermore, DeSensi (1994) contended that the "recruitment and retention of culturally diverse students" (p. 69) are necessary steps in valuing diversity in education and the future sport industry. Hancock and Hums (2011) found that percentage of women enrolled in undergraduate Sport Management academic programs remains below 25\%. Therefore, faculty must become more proactive at recruiting and retaining women in sport management programs. Faculty members are responsible for creating academic and professional environments in which both men and women can thrive.

\section{Directions for Future Research}

This study explored the career development of senior-level women in intercollegiate athletic administration through the lens of Career Construction Theory (Savickas, 2002, 2005) and Social Cognitive Career Theory (Lent et al., 1994, 1996, 
2002). Using career development frameworks offers a fresh perspective on the experiences of women in a male-dominated profession, specifically college athletics. Women identified personal characteristics and contextual factors as supports and/or barriers to their respective career paths. Examining the career development of seniorlevel women in intercollegiate athletics provides several areas that would benefit from future study including: (a) the role of value incongruence, (b) a more in-depth evaluation of the SWA title, (c) the organizational structures of athletic departments, and (d) a comparative study of the career development of men in intercollegiate athletics.

Value incongruence. Women entered intercollegiate athletic administration because they felt strongly about supporting the growth and development of the studentathlete. As the participants progressed in their careers, they became increasingly more concerned that the focus of intercollegiate athletics was shifting from a focus on the student to a focus on money. As a result, some of the women considered leaving the field, though none expressed intention to do so. At what point, however, do incongruent values lead to attrition from the field? Are men also experiencing incongruent values based on the perceived direction of intercollegiate athletics? Does value incongruence lead to lower levels of motivation and performance? More research is needed to answer these questions.

Role of the Senior Woman Administrator. Several women addressed the role of the Senior Woman Administrator. While women understood the historical importance of the position, many felt as though it aided in the perception of a "glass ceiling." While the appearance of a "glass ceiling" has not deterred the women in this study from pursuing a career in intercollegiate athletics, there was a concern that the title of SWA would 
become a career goal for women, rather obtaining the position and responsibilities of an Athletic Director. Studies have explored the SWA in terms of roles and responsibilities (Hoffman, 2010; Tiell \& Dixon, 2008), decision-making power (Claussen \& Lehr, 2002; Grappendorf et al., 2008), and supervisor support (Sagas \& Cunningham, 2004). Additional research is necessary to understand how men and women perceive the function of the SWA and its importance to the organizational structure of an intercollegiate athletic department.

Organizational structure. Organizational structure includes vertical mobility, role of the supervisor, and work responsibilities. The number of employment opportunities in intercollegiate athletics is finite. Vertical mobility in the administration of intercollegiate and professional sport organizations is limited (Acosta \& Carpenter, 2010; Lapchick, 2009; Sagas \& Ashley, 2001). While a few women mentioned the lack of vertical mobility, the majority discussed the role of the supervisor as either a support or barrier. Finally, organizational structure was also perceived as a support and/or barrier to skill acquisition and diversification. Women feared that they would be "pigeon-holed" or "typecast" into positions perceived to be "soft," such as compliance, academic advising, and event management, yet the majority of women in this study held "soft" internal positions. All participants agreed that external operations including marketing and promotions, development and fundraising, and budgeting were skills essential to advancement. Many career associates, however, were not interested in assuming responsibilities in external operations.

Kanter (1977) suggested organizational structure rather than gender precludes a woman's advancement through an organization. In other words, the inability to develop 
a more marketable skill set is dependent upon the position a person holds in the organizational hierarchy. Schein $(2001,2007)$, however, suggested gender stereotyping of managerial positions contributes to hiring, placement, and promotion. Findings in this study suggest both gender and organizational structure play a role in perpetuating gender stereotypes. Therefore, more research is necessary to explore and understand the manner in which work responsibilities are divided among assistant and associate athletic directors, specifically by gender.

Men in intercollegiate athletics. Women identified gender as a barrier to career development. Research on women in intercollegiate athletics also suggests gender as a barrier to professional growth and advancement (Burton et al., 2009; Burton et al., 2011; Grappendorf et al., 2004; Whisenant et al., 2002). Other studies suggest power is gendered and favors men in sport organizations (Knoppers \& Anthonissen, 2007; Sartore \& Cunningham, 2006). To better understand the role of gender in intercollegiate athletics administration, it is important to also understand the career development of men. Until we explore the career experiences of men, and examine areas such as values incongruence or work-family balance for example, it is difficult to determine adequately assess the role of gender in the career development of individual's pursuing careers in intercollegiate athletics.

\section{Conclusion}

This study explored the career experiences of female assistant and associate athletic directors in NCAA Division I athletic departments through career development frameworks of Career Construction Theory and Social Cognitive Career Theory. This study adds to the limited literature on the experiences of women in the administrative 
"pipeline" of intercollegiate athletics. Furthermore, this study provided insights and perspectives of women currently working in intercollegiate athletics. It offers a depiction of the career experiences of 15 women who described the importance of career supports and the negotiation of barriers in the pursuit of career expectations and goals. 


\section{REFERENCES}

Acosta, R. V., \& Carpenter, L. J. (2010). Women in intercollegiate sport: A longitudinal study - thirty-three year update, 1972-2010. Retrieved from http://www.acostacarpenter.org/

Aicher, T. J., \& Sagas, M. (2009). An examination of homologous reproduction and the effects of sexism. Journal for the Study of Sports and Athletes in Education, 3(3), 375-386.

Albert, K. A., \& Luzzo, D. A. (1999). The role of perceived barriers in career development: A social cognitive perspective. Journal of Counseling and Development, 77(4), 431-436,

Alice Paul Institute. (2011). The ERA: A brief introduction. Retrieved from http://www.equalrightsamendment.org/overview.htm

Ancis, J. R., \& Phillips, S. D. (1996). Academic gender bias and women's behavioral agency self-efficacy. Journal of Counseling \& Development, 75, 131-137.

Anderson, M. (1992). The history of women and the history of statistics. Journal of Women's History, 4(1), 14-36.

Andrew, C., Coderre, C., \& Denis, A. (1990). Stop or go: Reflections of women managers on factors influencing their career development. Journal of Business Ethics, 9, 361-367. doi:10.1007/BF00380334 
Astin, H. S. (1984). The meaning of work in women's lives: A sociopsychological model of career choice and work behavior. The Counseling Psychologist, 12(3/4), 117126. doi: $10.1177 / 0011000084124002$

August, R. A., \& Quintero, V. C. (2001). The role of opportunity structures in older women workers' careers. Journal of Employment Counseling, 38, 62-81.

Bandura, A. (1986). Social foundations of thought and action: A social cognitive theory. Englewood Cliffs, NJ: Prentice Hall.

Beasley, R., Lomo-David, E., \& Seubert, V. (2001). Telework and gender: Implications for the management of information technology professionals. Industrial Management \& Data System, 101(9), 477-482.

Beatty, J. E. (2007). Women and invisible social identities: Women as the Other in organizations. In D. Bilimoria and S. K. Piderit (Eds.), Handbook on women in business and management (pp. 34-56). Northampton, MA: Edward Elgar Publishing.

Betz, N. E. (1994). Basic issues and concepts in career counseling for women. In W. B. Walsh \& S. H. Osipow (Eds.), Career counseling for women (pp. 1-41). Hillsdale, NJ: Lawrence Erlbaum Associates.

Betz, N. E. (2004). Contributions of self-efficacy theory to career counseling: A personal perspective. The Career Development Quarterly, 52, 340-353.

Betz, N. E. (2006). Basic issues and concepts in the career development and counseling of women. In W. B. Walsh \& M. J. Heppner (Eds.), Handbook of career counseling for women ( $2^{\text {nd }}$ ed., pp. 45-74). Manwah, NJ: Lawrence Erlbaum Associates. 
Betz, N. E., \& Fitzgerald, L. F. (1987). The career psychology of women. Orlando, FL: Academic Press.

Bloomberg, L. D., \& Volpe, M. (2008). Completing your qualitative dissertation. Los Angeles, CA: Sage.

Bower, G. G. (2008) Career paths and advice for women wanting to obtain a management position within the health and fitness industry. Women in Sport and Physical Activity Journal, 17(1), 29-37.

Bower, G. G. (2009). Effective mentoring relationships with women in sport: Results of a meta-ethnography. Advancing Women in Leadership Journal, 29(3), Retrieved from http://advancingwomen.com/awl/awl_wordpress/

Brown, D. (2002). Introduction to theories of career development and choice. In D. Brown \& Associates (Eds.), Career choice and development (4 ${ }^{\text {th }}$ ed., pp. 3-23). San Francisco, CA: Jossey-Bass.

Bruening, J. E., \& Dixon, M. A. (2007). Work-family conflict in coaching II: Managing role conflict. Journal of Sport Management, 21, 471-496.

Bruening, J. E., Dixon, M. A., Tiell, B., Osbourne, B., Lough, N., \& Sweeney, K. (2008). Work-life culture of collegiate athletics: Perceptions of supervisors. International Journal of Sport Management, 9, 250-272.

Burke, R. J. (2007). Career development of managerial women: Attracting and managing talent. In D. Bilimoria and S. K. Piderit (Eds.), Handbook on women in business and management (pp. 109-131). Northampton, MA: Edward Elgar Publishing. 
Burton, L. J., Barr, C. A., Fink, J. S., \& Bruening, J. E. (2009). "Think athletic director, think masculine?": Examination of gender typing of managerial subroles within athletic administration position. Sex Roles, 61, 416-426.

Burton, L. J., Grappendorf, H., \& Henderson, A. (2011). Perceptions of gender in athletic administration: Utilizing role congruity theory to examine (potential) prejudice against women. Journal of Sport Management, 25, 36-45.

Byars-Winston, A. M., \& Fouad, N. A. (2008). Math and science social cognitive variables in college students contributions of contextual factors in predicting goals. Journal of Career Assessment, 16(4), 425-440.

Catalyst. (2011a). First for U.S. women. Retrieved from http://www.catalyst.org/publication/211/firsts-for-us-women

Catalyst. (2011b). Statistical overview of women in the workplace. Retrieved from http://www.catalyst.org/publication/219/statistical-overview-of-women-in-theworkplace

Catalyst. (2011c). Women in academia. Retrieved from http://www.catalyst.org/publication/327/women-in-academia Catalyst. (2011d). U.S. women in business. Retrieved from http://www.catalyst.org/publication/132/us-women-in-business

Catalyst. (2011e). Women in management in the United States: 1960 to present. Retrieved from http://www.catalyst.org/publication/207/women-in-managementin-the-united-states-1960-present

Catalyst. (2011f). Women in medicine. Retrieved from http://www.catalyst.org/publication/208/women-in-medicine 
Catalyst. (2011g). Women leaving \& reentering the workforce. Retrieved from http://www.catalyst.org/publication/249/women-leaving-re-entering-the-workforce

Chelladura, P. (2005). Managing organizations ( $2^{\text {nd }}$ ed.). Scottsdale, AS: Holcomb Hathaway.

Claringbould, I., \& Knoppers, A. (2008). Doing and undoing gender in sport governance. Sex Roles, 58, 81-92.

Claussen, C. L., \& Lehr, C. (2002). Decision making authority of senior woman administrators. International Journal of Sport Management, 3, 215-228.

Clopton, A. W., \& Sagas, M. (2009). Shattering the glass ceiling? Examining the impact of perceived gender discrimination on promotional opportunities of male and female coaches in women's athletics. International Journal of Sport Management, $10(1), 1-13$.

Coogan, P. A., \& Chen, C. P. (2007). Career development and counseling for women: Connecting theories to practice. Counseling Psychology Quarterly, 20(2), 191204.

Corby, S., \& Stanworth, C. (2009). A price worth paying? Women and work - Choice, constraint, or satisficing. Equal Opportunities International, 28(2), 162-178.

Correll, S. J. (2004). Constraints into preferences: Gender, status, and emerging career aspirations. American Sociological Review, 69(1), 93-113.

Crant, J. M. (2000). Proactive behavior in organizations. Journal of Management, 26(3), 435-462. 
Creswell, J. W. (2007). Qualitative inquiry and research design $\left(2^{\text {nd }}\right.$ ed). Thousand Oaks, CA: Sage.

Creswell, J. W. (2008). Experimental designs educational research: Planning, conducting, and evaluating quantitative and qualitative research $\left(3^{\mathrm{rd}} \mathrm{ed}.\right)$. Columbus, $\mathrm{OH}$ : Pearson.

Cullen, D. L., \& Luna, G. (1993). Women mentoring in academe: Addressing the gender gap in higher education. Gender \& Education, 5(2), 125-137.

Cunningham, G. B. (2008). Creating and sustaining gender diversity in sport organizations. Sex Roles, 58, 136-145.

Cunningham, G. B., Bruening, J., Sartore, M. L., Sagas, M., \& Fink, J. S. (2005). The application of social cognitive career theory to sport and leisure career choices. Journal of Career Development, 32(2), 122-138.

Cunningham, G. B., Doherty, A. J., \& Gregg, M. J. (2007). Using social cognitive career theory to understand head coaching intentions among assistant coaches of women's teams. Sex Roles, 56, 365-372.

Cunningham, G. B., \& Sagas, M. (2002). The differential effects of human capital for male and female Division I basketball coaches. Research Quarterly for Exercise and Sport, 73, 489-495.

Cunningham, G. B., Sagas, M., \& Ashley, F. B. (2001). Occupational commitment and intent to leave the coaching profession: Differences according to race. International Review for the Sociology of Sport, 36, 131-148.

Cunningham, G. B., Sagas, M., Dixon, M., Kent, A., \& Turner, B. A. (2005). Anticipated career satisfaction, affective occupational commitment, and intentions to enter the 
sport management profession. Journal of Sport Management, 19, 43-57.

Cunningham, G. B., \& Sagas, M. (2003). Treatment discrimination among assistant coaches of women's teams. Research Quarterly for Exercise and Sport, 74(4), 455-466.

Davey, K. M. (2008). Women's accounts of organizational politics as a gendering process. Gender, Work, and Organization, 15(6), 650-671.

Davis, F. (1999). Moving the mountain: The women's movement in America since 1960. Chicago, IL: University of Illinois Press.

Dawis, R. V. (2005). The Minnesota theory of work adjustment. In S. D. Brown and R. W. Lent (Eds.) Career development and counseling: Putting theory and research to work (pp. 3-23). Hoboken, NJ: John Wiley \& Sons.

DeSensi, J. T. (1994). Multiculturalism as an issue in sport management. Journal of Sport Management, 8, 63-74.

Dixon, M. A., \& Bruening, J. E. (2005). Perspectives on work-family conflict in sport: An integrated approach. Sport Management Review, 8, 227-253.

Dixon, M. A., \& Bruening, J. E. (2007). Work-family conflict in coaching I: A top-down perspective. Journal of Sport Management, 21, 377-406.

Dixon, M. A., Warner, S. M., \& Bruening, J. E. (2008). More than just letting them play: Parental influences on women's lifetime sport involvement. Sociology of Sport Journal, 25(4), 538-559.

Duehr, E. E., \& Bono, J. C. (2006). Men, women and managers: Are stereotypes finally changing? Personnel Psychology, 59, 815-846. 
Dunn-Jensen, L. M., \& Stroh, L. K. (2007). Myths in the media: How the news media portray women in the workforce. In D. Bilimoria and S. K. Piderit (Eds.), Handbook on women in business and management (pp. 13-33). Northampton, MA: Edward Elgar Publishing.

Eagly, A. (1987). Sex differences in social behavior: A social role interpretation. Hillsdale, NJ: Erlbaum.

Eastman, M. F. \& Woolcott, L. T. (1878). Memorial of Mary F. Eastman, Henrietta L. T. Woolcott, and others, officers of the Association for the Advancement of Women, praying that the tenth census may contain a just enumeration of women as laborers and producers. Senate Misc. Doc, $45^{\text {th }}$ Cong., 2 d sess. (Serial 1786).

Eccles, J. S. (1994). Understanding women's educational and occupational choices. Psychology of Women Quarterly, 18, 585-609.

Edwards, A., \& Skinner, J. (2009). Qualitative research in sport management. Burlington, MA: Elsevier.

Ehrhart, J. K., \& Sandler, B. R. (1987). Looking for more than a few good women in traditionally male fields. Washington. DC: National Association for Women in Education.

Elder, G. H., \& O'Rand. (1995). Adult lives in a changing society. In K. S. Cook, G. A. Fine, \& J. S. House (Eds.) Sociological perspectives on social psychology (pp. 452-475). Needham Heights, MA: Allyn and Bacon.

Elstad, B., \& Ladegard, G. (2010). Women on corporate boards: Key influencers or tokens? Journal of Management and Governance. DOI: 10.1007/s10997-010$9165-y$ 
Ely, R. J. (1995). The power in demography: Women's social constructions of gender identity at work. Academy of Management Journal, 38(3), 589-634.

Ely, R. J., \& Meyerson, D. E. (2000). Theories of gender in organizations: A new approach to organizational analysis and change. Research in Organizational Behavior, 22, 103-151.

Emslie, C., \& Hunt, K. (2009). 'Live to work' or 'Work to live'? A qualitative study of gender and work-life balance among men and women in mid-life. Gender, Work, and Organization, 16(1), 151-172.

Eshner, E. A., Thomas, C., \& Murphy, S. E. (2001). Comparison of traditional, step ahead, and peer mentoring on protégés support, satisfaction, and perceptions of career success. Journal of Business and Psychology, 15(3), 419-436.

Fagenson, E. A. (1990). A the heart of women in management research: Theoretical and methodological approaches and their biases. Journal of Business Ethics, 9, 267274.

Farmer, H. S. (1976). What inhibits achievement and career motivation in women? The Counseling Psychologist, 6(2), 12-15.

Farmer, H. S. (2006). History of career counseling for women. In W. B. Walsh \& M. J. Heppner (Eds.), Handbook of career counseling for women ( $2^{\text {nd }}$ ed., pp. 1-34). Manwah, NJ: Lawrence Erlbaum Associates.

Farrell, A., Fink, J. S., \& Fields, S. (2011). Women's sport spectatorship: An exploration of men's influence. Journal of Sport Management, 25(3), 190-201. 
Fitzgerald, M. P., Sagaria, M. D., \& Nelson, B. (1994). Career patterns of athletic directors: Challenging the conventional wisdom. Journal of Sport Management, 8 , $14-26$.

Forret, M. L., \& Dougherty, T. W. (2004). Networking behaviors and career outcomes: Differences for men and women? Journal of Organizational Behavior, 25, 419437.

Forrest, L., \& Mikolaitis, N. (1986). The relational component of identity: An expansion of career development theory. The Career Development Quarterly, 35(2), 76-88.

Frome, P. M., Alfeld, C. J., Eccles, J. S., \& Barber, B. L. (2006). Why don't they want a male-dominated job? An investigation of young women who changed their occupational aspirations. Educational Research and Evaluation, 12(4), 359-372.

Gallos, J. V. (1993). Women's experiences and ways of knowing: Implications for teaching and learning in the organizational behavior classroom. Journal of Management Education, 17(1), 7-26.

Gatrell, C., \& Copper, C. L. (2007). (No) cracks in the glass ceiling: Women managers, stress, and the barriers to success. In D. Bilimoria \& S. K. Piderit (Eds.), Handbook on women in business and management (pp. 57-77). Northampton, MA: Edward Elgar Publishing.

Glaser, B. G., \& Strauss, A. L. (1967). The discovery of grounded theory. Chicago, IL: Aldine Publishing.

Glesne, C. (2011). Becoming qualitative researchers $\left(4^{\text {th }}\right.$ ed.). Boston, MA: Pearson. Gottfredson, L. (1996). Gottfredson's theory of circumscription and compromise. In D. 
Brown and L. Brooks (Eds.) Career choice and development $\left(3^{\text {rd }}\right.$ ed., pp. 179232). San Francisco, CA: Jossey-Bass.

Grappendorf, H., \& Henderson, A. C. (2008). Hegemonic masculinity, homosociality and collaboration within the field of sport management: Exploring the issues. Advancing Women in Leadership, 26.

Grappendorf, H., \& Lough, N. (2006). An endangered species: Characteristics and perspectives from female NCAA division I athletics directors of both separate and merged athletic departments. The Sport Management and Related Topics Journal, $2(2), 6-20$

Grappendorf, H., Lough, N., \& Griffin, J. (2004). Profiles and career patterns of female NCAA division I athletic directors. International Journal of Sport Management, $5(3), 243-261$.

Grappendorf, H., Pent, A., Burton, L., \& Henderson, A. (2008). Gender role stereotyping: A qualitative analysis of senior woman administrators' perceptions regarding financial decision making. Journal of Issues in Intercollegiate Athletics, 1, 26-45.

Green, J., \& Thorogood, N. (2004). Qualitative methods for health research ( ${ }^{\text {nd }} \mathrm{ed}$.). Thousand Oaks, CA: Sage.

Greenhill, J., Auld, C., Cuskelly, G., \& Hooper, S. (2009). The impact of organizational factors on career pathways for female coaches. Sport Management Review, 12(4), 229-240.

Gregory, M. R. (2009). Inside the locker room: Male homosociability in the advertising industry. Gender, Work, and Organization, 16(3), 323-347. 
Guillaume, C., \& Pochic, S. (2009). What would you sacrifice? Access to top management and work-life balance. Gender, Work, and Organization, 16(1), 1436.

Hansen, J. C. (2005). Assessment of interests. In S. D. Brown \& R. W. Lent (Eds.), Career development and counseling: Putting theory and Research to work (pp. 281-304). Hoboken, NJ: John Wiley \& Sons.

Hite, L. M., \& McDonald, K. S. (2003). Career aspirations of non-managerial women: Adjustment and adaptation. Journal of Career Development, 24(4), 221-234.

Hoffman, J. L. (2010). The dilemma of the Senior Woman Administrator role in intercollegiate athletics. Journal of Issues in Intercollegiate Athletics, 3, 53-75.

Hoffman, J. L. (2011). Inside the huddle: Gender stereotyping work among senior-level women athletic administrators. International Journal of Sport Management, 12, 255-274.

Holland, J. L. (1959) A theory of vocational choices. Journal of Counseling Psychology, $6,336-342$.

Holland, J. L. (1997). Making vocational choices: A theory of vocational personalities and work environments ( $3^{\text {rd }}$ ed.). Odessa, FL: Psychological Assessment Resources.

Hums, M. A., \& Sutton, W. A. (1999). Women working in the management of professional baseball: Getting to first base? Journal of Career Development, $26(2), 147-158$. 
Inglis, S., Danylchuk, K. E., \& Pastore, D. L. (1996). Understanding retention factors in coaching and athletic management positions. Journal of Sport Management, 10, 237-249.

Inglis, S., Danylchuk, K. E., \& Pastore, D. L. (2000). Multiple realities of women's work experiences in coaching and athletic management. Women in Sport \& Physical Activity, 9(2), 1-27.

Itzin, C., \& Newman, J. (1995). Gender, culture, and organizational change: Putting theory into practice. New York, NY: Routledge.

Jablin, F. M. (2001). Organizational entry, assimilation, and exit. In F. M. Jablin \& L. L. Putnam (Eds.), The new handbook of organizational communication: Advances in theory, research and methods (pp. 732-818). Thousand Oaks, CA: Sage.

Johnson, M. K., \& Mortimer, J. T. (2002). Career choice and development from a sociological perspective. In D. Brown \& Associates (Eds.), Career choice and development ( $4^{\text {th }}$ ed., pp. 37-81). San Francisco, CA: Jossey-Bass.

Judd, M. R. (1995). A gender comparison of competencies important for success in college athletic administration. Physical Educator, 52(1), 8-14.

Kaiser, C. R., \& Miller, C. T. (2001). Stop complaining! The social costs of making attributions to discrimination. Personality and Social Psychology Bulletin, 27, 254-263.

Kanter, R. M. (1977). Men and women of the corporation. New York, NY: Basic Books.

King \& Baxter-Magola, M. B. (2004). Creating learning partnerships in higher education. In M. Baxter Magolda \& P. M. King (Eds.), Learning Partnerships (pp. 303-332). San Francisco, CA: Jossey-Bass. 
Kleinberg, S. J. (1999). Women in the United States, 1830-1945. New Brunswick, NJ: Rutgers University.

Knoppers, A. (1992). Explaining male dominance and sex segregation in coaching: Three approaches. Quest, 44, 210-227.

Knoppers, A., \& Anthonissen, A. (2007). Gendered managerial discourses in sport organizations: Multiplicity and complexity. Sex Roles, 58(1), 93-103.

Knoppers, A., Meyer, B. B., Ewing, M., \& Forest, L. (1991). Opportunity and work behavior in college coaching. Journal of Sport and Social Issues, 15, 1-20.

Kram, K. E. (1983). Phases of the mentor relationship. Academy of Management Journal, $26,608-625$.

Kram, K. E., \& Isabella, L A. (1985). Mentoring alternatives: The role of peer relationships in peer development. Academy of Management Journal, 28(1), 110132.

Kumra, S., \& Vinnicombe, S. (2010). Impressing for success: A gendered analysis of a key social capital accumulation strategy. Gender, Work and Organization, 17(5), $521-546$.

Lapchick, R. (2009). 2009 racial and gender report card. Retrieved from http://web.bus.ucf.edu/sportbusiness/?page=1445

Lapchick, R. (2010). 2010 racial and gender report card. Retrieved from http://web.bus.ucf.edu/sportbusiness/?page=1445

Lapour, A. S., \& Heppner, M. J. (2009). Social class privilege and adolescent women's perceived career options. Journal of Counseling Psychology, 56(4), 477-494. 
Latham, A., \& Swiercz, P. M. (2009). Flexible work practices: For women only? Competition Forum, 7(2), 371-384.

Lee, M. A., \& Mathers, M. (2008, June). Population bulletin: U.S. labor force trends. Retrieved from Population Resource Bureau: www.prb.org/pdf08/63.2uslabor.pdf

Lent, R. W., Brown, S. D., \& Hackett, G. (1994). Toward a unifying social cognitive theory of career and academic interest, choice, and performance. Journal of Vocational Behavior, 45, 79-122.

Lent, R. W., Brown, S. D., \& Hackett, G. (2000). Contextual supports and barriers to career choice: A social cognitive analysis. Journal of Counseling Psychology, 47, $36-49$.

Lindley, L. (2005). Perceived barriers to career development in the context of social cognitive career theory. Journal of Career Assessment, 13(3), 271-287.

Lovett, D. J., \& Lowry, C. D. (1994). "Good old boys" and "good old girls" clubs: Myth or reality. Journal of Sport Management, 8, 27-35.

Lyons, H. Z., Brenner, B. R., \& Lipman, J. (2010). Patterns of career and identity interference for lesbian, gay, and bisexual young adults. Journal of Homosexuality, 57, 503-524.

Marshall, C., \& Rossman, G. B. (2011). Designing qualitative research $\left(5^{\text {th }} \mathrm{ed}\right.$.). Thousand Oaks, CA: Sage.

Maume, D. J. (1999). Occupational segregation and career mobility of white men and women. Social Forces, 77(4), 1433-1459.

McCracken, G. (1988). The long interview. Thousand Oaks, CA: Sage. 
Miles, M. B., \& Huberman, M. (1994). Qualitative data analysis: An expanded resource book ( $2^{\text {nd }}$ ed). Thousand Oaks, CA: Sage.

Miller, L. K. (1998). Promoting career opportunities for girls and women in the sport industry. Journal of Physical Education, Recreation, and Dance, 69(5), 32-35.

Moore, M.E. (2008). Gender openness in managerial education: A sport management focus. Gender in Management: An International Journal, 23(5), 355-370.

Moore, M.E., Parkhouse, B.L., \& Konrad, A.M. (2001). Women in sport management: Advancing the representation through HRM structures. Women in Management Review, 16(2), 51-61.

Moore, M.E., Parkhouse, B.L., \& Konrad, A.M. (2004). Diversity programs: Influencing female students to sport management? Women in Management Review, 19(6), 304-316.

NACDA. (2011). The national directory of college athletics. Retrieved from http://www.nacdadirectory.com/login.aspx

NACWAA. (2011). Vision, mission, and values. Retrieved from http://www.nacwaa.org/about-nacwaa/mission

National Center for Education Statistics. (2010). Fast facts. Retrieved from http://nces.ed.gov/fastfacts/display.asp?id=72

NCAA. (2011). Division I manual 2011-2012: Constitution, operating bylaws, administrative bylaws. Retrieved from http://ncaapublications.com/p-4224-20112012-ncaa-division-i-manual.aspx

Niles, S.G., \& Harris-Bowlesby, J. (2002). Career development interventions in the 21 st century. Upper Saddle River, NJ: Merrill Prentice Hall. 
O'Neil, D. A., \& Bilimoiria, D. (2005). Women's career development phases. Career Development International, 10(3), 168-189.

O’Neil, D. A., Bilimoria, D., \& Saatcioglu, A. (2004). Women's career types: Attributions of satisfaction with career success. Career Development International, 9(4/5), 478-499.

O’Neil, D. A., Hopkins, M. M., \& Bilimoria, D. (2008). Women's careers at the start of the $21^{\text {st }}$ century: Patterns and paradoxes. Journal of Business Ethics, 80, 727-743. Oplatka, I., \& Tamir, V. (2009). "I don't want to be a school head": Women deputy heads' insightful constructions of career advancement and retention. Educational Management Administration \& Leadership, 37, 216-237.

Parsons, F. (1909). Choosing a vocation. New York, NY: Agathon Press.

Pastore, D. L., Inglis, S., \& Danylchuk, K. E. (1996). Retention factors in coaching and athletic management: Differences by gender, position, and geographic location. Journal of Sport \& Social Issues, 20(4), 427-441.

Patton, M. (2002). Qualitative research and evaluation methods. Thousand Oaks, CA: Sage Publications.

Patton, W., \& McMahon, M. (2006). The systems theory framework of career development and counseling: Connecting theory and practice. International Journal for the Advancement of Counseling, 28(2), 153-166.

PBS. (2002). Timeline: The pill. Retrieved from http://www.pbs.org/wgbh/amex/pill/timeline/timeline2.html Pellegrino, G., D'Amato, S., \& Weisberg, A. (2011). The gender dividend: Making the business case for investing in women. United Kingdom: Deloitte. 
Phelan, J. E., Moss-Racusin, C. A., \& Rudman, M. A. (2008). Competent yet out in the cold: Shifting criteria for hiring reflect backlash toward agentic women. Psychology of Women Quarterly, 32(4), 406-413.

Ponterotto, J. G. (2006). Brief not on the origins, evolution, and meaning of the qualitative research concept "thick description." The Qualitative Report, 11(3), 538-549.

Powell, G. N., \& Graves, L. M. (2003). Women and men in management ( $\left.3^{\text {rd }} \mathrm{ed}.\right)$. Thousand Oaks, CA: Sage.

Psathas, G. (1968). Toward a theory of occupational choice for women. Sociology and Social Research, 52, 253-268.

Quarterman, J., DuPree, A., \& Willis, K. (2006). Challenges confronting female intercollegiate athletics directors of NCAA member institutions by division. College Student Journal, 40(3), 528-548.

Richardson, M. S. (1975). Self-concepts and role concepts in the career orientation of college women. Journal of Counseling Psychology, 19, 436-448.

Ritchie, B. S., Fassinger, R. E., Linn, S. G., Johnson, J., Prosser, J., \& Robinson, S. (1997). Persistence, connection, and passion: A qualitative study of the career development of highly achieving African American-Black and White women. Journal of Counseling Psychology, 44(2), 133-148.

Ritchie, J., Lewis, J., \& Elam, G. (2003). Designing and selecting samples. In J. Ritchie \& J. Lewis (Eds.), Qualitative research practice. A guide for social science students and researchers (pp.77-108) Thousand Oaks, CA: Sage. 
Rosenberg, R. (1992). Divided lives: American women in the twentieth century. New York, NY: Hill and Wang.

Rosenfeld, R. A. (1992). Job mobility and career processes. Annual Review of Sociology, $18,39-61$.

Rounds, J. B., \& Armstrong, P. I. (2005). Assessment of needs and values. In S. D. Brown \& R. W. Lent (Eds.), Career development and counseling: Putting theory and Research to work (pp. 305-329). Hoboken, NJ: John Wiley \& Sons.

Ruggerio, K. M., \& Marx, D. M. (1999). Less pain and more to gain: Why high status group members blame their failure on discrimination. Journal of Personality and Social Psychology, 77, 774-784.

Ruggerio, K. M., \& Taylor, D. M. (1995). Coping with discrimination: How disadvantaged group members perceive discrimination that confronts them. Journal of Personality and Social Psychology, 68, 826-838.

Ruggerio, K. M., \& Taylor, D. M. (1997). Why minority group members perceive or do not perceive the discrimination that confronts them: The role of self-esteem and perceived control. Journal of Personality and Social Psychology, 72, 373-389.

Russell, J. E. (2006). Career counseling for women in management. In W. B. Walsh \& M. J. Heppner (Eds.), Handbook of career counseling for women $\left(2^{\text {nd }}\right.$ ed., pp. 453-512). Manwah, NJ: Lawrence Erlbaum Associates.

Sagas, M., \& Ashley, F. B. (2001). Gender differences in the intent to leave coaching: Testing the role of personal, external, and work-related variables. International Journal of Sport Management, 2(4), 297-314.

Sagas, M., \& Cunningham, G. B. (2004a). Does having "the right stuff" matter? Gender 
differences in the determinants of career success among intercollegiate athletic administrators. Sex Roles, 50(5/6), 411-421.

Sagas, M., \& Cunningham, G. B. (2004b). The impact of supervisor support on perceived career outcomes of the senior woman administrator. International Journal of Sport Management, 5(3), 229-242.

Saldana, J. (2009). The coding manual for qualitative researchers. Los Angeles, CA: Sage.

Sartore, M. L. (2006). Categorization, performance appraisals, and self-limiting behavior: The impact on current and future performance. Journal of Sport Management, 20, $535-553$

Sartore, M. L., \& Cunningham, G. B. (2007). Explaining the under-representation of women in leadership positions of sport organizations: A symbolic interactionist perspective. Quest, 59, 244-265.

Savickas, M. L. (2002). Career construction: A developmental theory of vocational behavior. In D. Brown \& Associates (Eds.), Career choice and development $\left(4^{\text {th }}\right.$ ed.) (pp. 149-205). San Francisco, CA: Jossey-Bass.

Savickas, M. L. (2005). Theory and practice of career construction. In S. D. Brown and R. W. Lent (Eds.) Career development and counseling: Putting theory and research to work (pp. 42-70). Hoboken, NJ: John Wiley \& Sons.

Schein, V. E. (2001). A global look at psychological barriers to.women's progress in management. Journal of Social Issues, 57, 675-688.

Schein, V. E. (2007). Women in management: Reflections and projections. Women in Management Review, 22(1), 6-18. 
Seidman, I. (2006). Interviewing as qualitative research ( $3^{\text {rd }}$ ed.). New York, NY: Teachers College Press.

Shaw, S. (2006). Scratching the back of "Mr. X": Analyzing gendered social processes in sport organizations. Journal of Sport Management, 20, 510-534.

Smith, M. D. (2005). Women in athletic administration: "A time for change!" Factors affecting the career paths of female administrators and directors of intercollegiate athletics. Unpublished dissertation. Ohio University, Athens, Ohio.

Smith, C., Santucci, D., Xu, S., Cox, A., \& Henderson, K. A. (2012). "I love my job, but...:" A narrative analysis of women's perceptions of their careers in parks and recreation. Journal of Leisure Research, 44(1), 52-69.

Spokane, A. R., \& Cruza-Guet, M. C. (2005). Holland's theory of vocational personalities in work environments. In S. D. Brown \& R. W. Lent (Eds.) Career development and counseling: Putting theory and research to work (pp. 24-41). Hoboken, NJ: John Wiley \& Sons.

Stangl, J. M., \& Kane, M. J. (1991). Structural variables that offer explanatory power for the underrepresentation of women coaches since Title IX: The case of homologous reproduction. Sociology of Sport Journal, 8, 47-60.

Stringer, K. J., \& Kerpelman, J. L. (2010). Career identity development in college students: Decision making, parental support, and work experience. Identity, 10, 181-200. DOI: $10.1080 / 15283488.2010 .496102$

Swanson, J. L., \& Fouad, N. A. (2010). Career theory and practice: Learning through case studies ( $2^{\text {nd }}$ ed.). Los Angeles, CA: Sage. 
Tiell, B., \& Dixon, M. A. (2008). Roles and tasks of the Senior Woman Administrator (SWA) in intercollegiate athletics. Journal for the Study of Sports and Athletes in Education, 2(3), 339-361.

Toossi, M. (2002). A century of change: The U.S. labor force, 1950-2050. Retrieved from the Bureau of Labor Statistics website: www.bls.gov/opub/mlr/2002/05/art2full.pdf

U.S. Bureau of Labor Statistics. (2009). Table A-2. Employment status of the civilian population by race, sex, and age. Retrieved from http://www.bls.gov/news.release/empsit.t02.htm

U.S. Bureau of Labor Statistics. (2010). Women in the labor force: A databook. Retrieved from http://www.bls.gov/cps/wlf-databook2010.htm.

Walker, N. A., \& Bopp, T. (2011). The underrepresentation of women in the maledominated workplace: Perspectives of female coaches. Journal of Workplace Rights, 15(1), 47-64.

Weiss, M. R. \& Barber, H. (1995). Socialization influences of college female athletes: A tale of two decades. Sex Roles, 33(1/2), 129-140.

Weiss, D., Dawes, R., England, G., \& Lofquist, H. (1967). Manual for the Minnesota Satisfaction Questionnaire. Minneapolis, MN: University of Minnesota, Industrial Relations Center.

Wentling, R. M. (1996). A study of the career development and aspirations of women in middle management. Human Resource Development Quarterly, 7(3), 253-270.

Wentling, R. M. (2003). The career development and aspirations of women in middle management - revisited. Gender in Management, 18(5), 311-324. 
Whisenant, W. A., Pedersen, P. M., \& Obenour, B. L. (2002). Success and gender: Determining the rate of advancement for intercollegiate athletic directors. Sex Roles, 47(9/10), 485-491.

White, B. (1995). The career development of successful women. Women in Management Review, 10(3), 4-15.

Whitmarsh, L., Brown, D., Cooper, J., Hawkins-Rogers, Y., \& Wentworth, D. K. (2007). Choices and challenges: A qualitative exploration of professional women's career patterns. The Career Development Quarterly, 55, 225-236.

Wolcott, H. F. (1994). Transforming qualitative data. Thousand Oaks, CA: Sage.

World Health Organization. (2011). Gender, women, and health. Retrieved from http://www.who.int/gender/whatisgender/en/

Young, A. M., \& Perrewe, P. L. (2000). What did you expect? An examination of career related support and social support among mentors and protégés. Journal of Management, 26(4), 611-632. 


\title{
APPENDICES
}

\section{Appendix A}

\author{
Recruitment Letter
}

October 5, 2011

Dear

You are being invited to participate in a research study career experiences and expectations of female assistant and associate athletic directors in intercollegiate athletics. The purpose of this study is to examine the career experiences of women in intercollegiate athletics, as well as how those experiences influence career expectations and goals. I am requesting one interview of approximately 90 minutes, a copy of your most recent resume, and a short description of your day-to-day responsibilities as an assistant or associate athletic director. The interviews will take place in November and December. There are no known risks for your participation in this research study. The information collected may not benefit you directly. However, the information you provide will help professionals and academics understand the experiences of women currently in assistant and associate athletic director positions. Additionally, the experiences you share will also help women seeking such positions understand the personal and professional challenges and benefits accompanying senior level positions. All data collected from participants will be stored at the University of Louisville. Participant files will be kept in a secured office in a locked file cabinet. Electronic data including digital recording of interviews, participant correspondence, and interview transcripts will be kept on a password protected computer.

Individuals from the Department of Health and Sport Sciences, the Institutional Review Board (IRB), the Human Subjects Protection Program Office (HSPPO), and other regulatory agencies may inspect these records. In all other respects, however, the data will be held in confidence to the extent permitted by law. Should the data be published, your identity will not be disclosed.

Taking part in this study is voluntary. By participating in the interview you agree to take part in this research study. You do not have to answer any questions that make you uncomfortable. You may choose not to take part at all. If you decide to be in this study you may stop taking part at any time. If you decide not to be in this study or if you stop taking part at any time, you will not lose any benefits for which you may qualify. 
If you have any questions, concerns, or complaints about the research study, please contact: Meg Hancock at (502) 852-8297 or Dr. Mary A. Hums at (502) 852-5908.

If you have any questions about your rights as a research subject, you may call the Human Subjects Protection Program Office at (502) 852-5188. You can discuss any questions about your rights as a research subject, in private, with a member of the Institutional Review Board (IRB). You may also call this number if you have other questions about the research, and you cannot reach the research staff, or want to talk to someone else. The IRB is an independent committee made up of people from the University community, staff of the institutions, as well as people from the community not connected with these institutions. The IRB has reviewed this research study.

If you have concerns or complaints about the research or research staff and you do not wish to give your name, you may call 1-877-852-1167. This is a 24 hour hot line answered by people who do not work at the University of Louisville.

Sincerely,

Meg Hancock

Ph.D. Student

University of Louisville
Mary A. Hums, Ph.D.

Professor, Sport Administration

University of Louisville 


\title{
Appendix B
}

\author{
Solicitation Email
}

November 29, 2011

Good morning, (participant) --

As partial fulfillment of my Ph.D. in Educational Leadership and Organizational Development with a concentration in Sport Administration, I am conducting a study of the career experiences and expectations of female assistant and associate athletic directors in intercollegiate athletics. The purpose of this study is to examine the career experiences of women in intercollegiate athletics, as well as how those experiences influence career expectations and goals.

Given your position as an associate athletic director, I would like to invite you to participate in my study. I am requesting one interview of approximately 60 to 90 minutes, a copy of your most recent resume, and a short description of your day-to-day responsibilities as an associate athletics director. The interviews will take place in December and January. If you agree to participate, please respond to this email or contact me at 502-235-8836 to schedule a time for an interview.

Your feedback is vital to the success of this study. More importantly, your responses will help professionals and academics understand the experiences of women currently in assistant and associate athletic director positions. Additionally, the experiences you share will also help women seeking such positions understand the personal and professional challenges and benefits accompanying senior level positions.

I hope you will consider my request. I look forward to hearing from you.

Sincerely,

Meg Hancock

Ph.D. Student

University of Louisville 


\section{Appendix C}

Subject Informed Consent

\section{WOMEN IN INTERCOLLEGIATE ATHLETICS: AN EXPLORATION OF THE CAREER DEVELOPMENT OF FEMALE SENIOR ADMINISTRATORS}

\section{Introduction and Background Information}

You are invited to participate in a research study. The study is being conducted by Meg Hancock and Dr. Mary Hums, Ph.D. The study is sponsored by the University of Louisville, Department of Heath and Sport Sciences. The study will take place at multiple colleges and universities in Kentucky, Ohio, and Indiana. Approximately 35 subjects will be invited to participate.

\section{Purpose}

The purposes of this study are to (a) explore the career experiences and expectations of women in senior-level intercollegiate athletic administration and (b) identify perceived career barriers and supports to (c) gain a better understanding of how the negotiation of barriers and supports influences career development, expectations, and goals.

\section{Procedures}

In this study, you will be asked to participate in one interview approximately 75 to 90 minutes in length. You will also be asked to submit a current resume and job description. During the interview, you may decline to answer any questions that may make you uncomfortable. You may also decline to provide a current resume and/or job description.

\section{Potential Risks}

There are no foreseeable risks other than possible discomfort in answering personal questions. There may also be unforeseen risks.

\section{Benefits}

The information collected may not benefit you directly. The information learned in this study may be helpful to others.

\section{Confidentiality}

Total privacy cannot be guaranteed. Your privacy will be protected to the extent permitted by law. Should the data be published, your identity will not be disclosed. All data collected from participants will be stored at the University of Louisville. Participant files will be kept in a secured office in a locked file cabinet. Electronic data including digital recording of interviews, participant correspondence, and interview transcripts will be kept on a password-protected computer.

\section{Conflict of Interest}

This study does not involve a conflict of interest.

\section{Voluntary Participation}


Taking part in this study is voluntary. You may choose not to take part at all. If you decide to be in this study you may stop taking part at any time. If you decide not to be in this study or if you stop taking part at any time, you will not lose any benefits for which you may qualify. You will be told about any changes that may affect your decision to continue in the study.

\section{Research Subject's Rights, Questions, Concerns, and Complaints}

If you have any concerns or complaints about the study or the study staff, you have three options. You may contact the principal investigator, Dr. Mary Hums, at (502) 852-5908.

If you have any questions about your rights as a study subject, questions, concerns or complaints, you may call the Human Subjects Protection Program Office (HSPPO) (502) 852-5188. You may discuss any questions about your rights as a subject, in secret, with a member of the Institutional Review Board (IRB) or the HSPPO staff. The IRB is an independent committee composed of members of the University community, staff of the institutions, as well as lay members of the community not connected with these institutions. The IRB has reviewed this study.

If you want to speak to a person outside the University, you may call 1-877-852-1167. You will be given the chance to talk about any questions, concerns or complaints in secret. This is a 24 hour hot line answered by people who do not work at the University of Louisville.

This paper tells you what will happen during the study if you choose to take part. Your signature means that this study has been discussed with you, that your questions have been answered, and that you will take part in the study. This informed consent document is not a contract. You are not giving up any legal rights by signing this informed consent document. You will be given a signed copy of this paper to keep for your records.

Signature of Subject/Legal Representative Date Signed

Signature of Investigator

Date Signed

LIST OF INVESTIGATORS

Dr. Mary A. Hums

Meg Hancock
PHONE NUMBERS

(502) 852-5908

(502) 852-8297

Date Written 10/5/2011 


\section{Appendix D}

\section{Interview Protocol}

\section{Preliminary Information for the Interviewer}

- Discuss informed consent with interviewee.

- Explain that responses will be kept confidential.

- Inform the interviewee that other individuals (Dr. Mary Hums, Dr. Melissa Evans-Andris) will have access to the data collected in this study.

- Thank interviewee at the beginning and end of the interview.

\section{Life History and Background}

1) Tell me a little bit about yourself.

a. What was your experience with sport growing up?

b. Educational background

c. Early career experiences (Astin, 1984; Betz \& Fitzgerald, 1987)

2) What were your original career aspirations? (Gottfredson, 1996; Savickas, 2002, 2005; Swanson \& Fouad, 2010)

a. What did you want to be "when you grew up?"

b. How have those aspirations changed? Why? When did they start changing? What do you think prompted that?

3) How did you become interested in intercollegiate athletics as a career?

a. What initially attracted you to a career in intercollegiate athletics?

b. What motivated you to pursue a career in intercollegiate athletics?

4) When you began your career in intercollegiate athletics, what were some of your career goals? (Lent et al., 1994; O’Neil et al., 2004; Savickas, 2005)

5) Tell me about your current job. (Lent et al., 1994; Savickas, 2005)

a. Day-to-day responsibilities

b. What was attractive to you about your current position?

\section{Career Experiences}

RQ 1) What factors do participants perceive as supports to their career development?

6) Tell me about some of the best supports to your career. (O'Neil et al., 2004; Hopkins \& O'Neil, 2007; O'Neil et al., 2008; Swanson \& Fouad, 2010).

7) Discuss how you perceive these supports have affected your career development.

8) Are there any supports that you have not experienced, but believe would be beneficial to your career development?

9) Please describe one or two of the most positive moments you have experiences during your career in intercollegiate athletics.

PROBES:

What made the experience positive? In what ways did the experience affect your career expectations? Career goals? 
RQ 2) What factors do participants perceive as barriers to their career development?

10) Described some of the barriers you have faced in your career in intercollegiate athletics (O'Neil et al., 2004; Hopkins \& O'Neil, 2007; O'Neil et al., 2008; Swanson \& Fouad, 2010).

11) Discuss how you perceive these barriers have affected your career.

12) Please tell me about what you perceive to be barriers to women in intercollegiate athletics.

\section{RQ 3) How do participants negotiate supports and barriers?}

13) Please describe one or two of the challenges you have experienced over your career in intercollegiate athletics. (Lent et al., 1994, 2000; Savickas, 2005)

14) Tell me about some of the key transition points in your career. (NOTE: The interviewer may ask this question in the context of data collected during the interview or from the participant's resume.)

a) What did you consider when making those decisions?

b) How did you make those decisions?

c) Was there a particular person who influenced you? How? Why?

15) When experiencing a difficult situation at work, what kind of coping strategies did you use to handle the situation?

16) Describe your level of satisfaction with your career. Current position?

a. What has contributed to your satisfaction? Dissatisfaction? How? Why?

RQ 4) In what ways did participants' perceptions of barriers and supports influence career outcome expectations? (These questions will be asked in reference to the barriers/supports participants identified earlier in the interview. The interviewer will also allow for new barriers/ supports to emerge.)

17) What expectations did you have about your career when you began working in intercollegiate athletics? (Lent et al., 1994)

18) Have your expectations changed? How and why?

RQ 5) In what ways did participants' perceptions of barriers and supports influence career goals? (These questions will be asked in reference to the barriers/supports participants identified earlier in the interview. The interviewer will also allow for new barriers/ supports to emerge.)

19) Tell me some of your career goals now. How have your goals changed over time? How and why?

20) If you had not pursued a career in intercollegiate athletics, what do you think you would be doing now?

Wrap-Up and Advice

21) Where do you see yourself in 5 years? 10 years? 
22) What advice would you share to younger women seeking to advance in intercollegiate athletic administration?

\section{Participant Demographics}

Demographic information is for record-keeping purposes only and will not be used to identify responses. Demographic responses will be presented in aggregate form.

Age:

Race: African-American Asian/ Asian-American

Hispanic Native American

White Other (Specify:

Highest Level of Education:

High School Some College Two-Year (Associate) Degree

Four-Year Degree Some Graduate School Master's Degree

Other (Specify:

Current Job Title:

Number of years working in intercollegiate athletics:

Number of years working with current institution:

Number of years in current position:

NCAA Division:

NCAA D-I (FBS/FCS) NCAA D-II NCAA D-III

Salary: $\quad<\$ 24,999 \quad \$ 25,000-\$ 34,999 \quad \$ 35,000-\$ 44,999$

$\$ 45,000-\$ 54,999 \quad \$ 55,000-\$ 64,999 \quad \$ 65,000-\$ 74,999 \quad>\$ 75,000$ 


\begin{tabular}{|c|c|c|c|c|c|c|c|c|c|c|c|c|c|c|c|c|c|c|c|c|c|c|}
\hline & $\begin{array}{l}Q \\
1\end{array}$ & & $\begin{array}{l}\mathrm{Q} \\
3\end{array}$ & $\begin{array}{l}\mathrm{Q} \\
4\end{array}$ & $\begin{array}{l}Q \\
5\end{array}$ & $\begin{array}{l}\mathrm{Q} \\
6\end{array}$ & $\begin{array}{l}\mathrm{Q} \\
7\end{array}$ & $\begin{array}{l}\mathrm{Q} \\
8\end{array}$ & $\begin{array}{l}\mathrm{Q} \\
9\end{array}$ & \begin{tabular}{|l|}
$\mathrm{Q}$ \\
1 \\
0
\end{tabular} & $\begin{array}{l}\mathrm{Q} \\
1 \\
1\end{array}$ & $\begin{array}{l}\mathrm{Q} \\
1 \\
2\end{array}$ & $\begin{array}{l}Q \\
1 \\
3\end{array}$ & \begin{tabular}{|l|}
$\mathrm{Q}$ \\
1 \\
4 \\
\end{tabular} & $\begin{array}{l}\mathrm{Q} \\
1 \\
5 \\
\end{array}$ & $\begin{array}{l}Q \\
1 \\
6\end{array}$ & $\begin{array}{l}\mathrm{Q} \\
1 \\
7\end{array}$ & $\begin{array}{l}Q \\
1 \\
8\end{array}$ & $\begin{array}{l}\mathrm{Q} \\
1 \\
9\end{array}$ & $\begin{array}{l}\mathrm{Q} \\
2 \\
0\end{array}$ & $\begin{array}{l}Q \\
2 \\
1\end{array}$ & $\begin{array}{l}\mathrm{Q} \\
2 \\
2\end{array}$ \\
\hline $\begin{array}{l}\text { RQ 1: What factors } \\
\text { do participants } \\
\text { perceive as } \\
\text { supports to their } \\
\text { career } \\
\text { development? }\end{array}$ & & & $\mathrm{X}$ & & $\mathrm{X}$ & $\mathrm{X}$ & $\mathrm{X}$ & $X$ & & & & & $\mathrm{X}$ & & & & & & & & & \\
\hline $\begin{array}{l}\text { RQ 2: What factors } \\
\text { do participants } \\
\text { perceive as barriers } \\
\text { to their career } \\
\text { development? }\end{array}$ & & & & & & & & & $\mathrm{X}$ & $X$ & $X$ & $X$ & $X$ & & & & & & & & & \\
\hline $\begin{array}{l}\text { RQ 3: How do } \\
\text { participants } \\
\text { negotiate supports } \\
\text { and barriers? }\end{array}$ & & & & & & & & & & & & & $\mathrm{X}$ & $X$ & & & & & & & & \\
\hline $\begin{array}{l}\text { RQ 4: In what } \\
\text { ways did } \\
\text { participants' } \\
\text { perceptions of } \\
\text { barriers and } \\
\text { supports influence } \\
\text { career outcome } \\
\text { expectations? }\end{array}$ & & & $\mathrm{X}$ & & & & & & & & & & & $\mathrm{X}$ & $\mathrm{X}$ & $\mathrm{X}$ & & & & & & \\
\hline $\begin{array}{l}\text { RQ 5: In what } \\
\text { ways did } \\
\text { participants' } \\
\text { perceptions of } \\
\text { barriers and } \\
\text { supports influence } \\
\text { career goals? }\end{array}$ & & & $X$ & $X$ & & & & & & & & & & & & & $\mathrm{X}$ & $\mathrm{X}$ & & & & \\
\hline $\begin{array}{l}\text { RQ 6: What coping } \\
\text { strategies do } \\
\text { participants employ } \\
\text { to reconcile } \\
\text { potential } \\
\text { differences } \\
\text { between career } \\
\text { aspirations and } \\
\text { career realities? }\end{array}$ & & & & & & & & & & & & $\mathrm{X}$ & $\mathrm{X}$ & $X$ & $\mathrm{X}$ & & $\mathrm{X}$ & & & & & \\
\hline Life History & $\mathrm{X}$ & $\mathrm{X}$ & $\mathrm{X}$ & $\mathrm{X}$ & & & & & & & & & & & & & & & & & & \\
\hline Advice & & & & & & & & & & & & & & & & & & & $\mathrm{X}$ & $\mathrm{X}$ & $\mathrm{X}$ & $X$ \\
\hline
\end{tabular}




\title{
CURRICULUM VITAE
}

\author{
Meg G. Hancock \\ 110a Studio Arts/HPES \\ University of Louisville \\ Louisville, KY 40292
}

\section{EDUCATION}

Ph.D.

2012

University of Louisville

Educational Leadership \& Organizational

Development

Specialization: Sport Administration

M.S.

2005

Miami University

College Student Personnel/Higher Education

Concentrations: Student Development,

Organizational Leadership

B.A. $2003 \quad$ Randolph College

(formerly Randolph-Macon Woman's College)

Sociology and Anthropology

\section{ACADEMIC \& PROFESSIONAL POSITIONS}

University of Louisville, Louisville, KY

August 2009 to present

Sport Administration Program, Department of Health and Sport Sciences

Instructor (August 2010 to present)

Teach undergraduate and graduate lecture classes and supervise internships. Taught large lecture class of $90+$ students, and serve as faculty advisor for student organization.

Advise approximately 75 undergraduate students. Co-coordinator for COSMA

Accreditation candidacy application and self-study.

Classes taught include:

- SPAD 281, Principles of Sport Management (Introductory Course)

- SPAD 382, Organizational Behavior

- SPAD 401, Career Development in Sport

- SPAD 402/692, Internship supervisor for approximately 20 undergraduate and Master's students each semester

- SPAD 625, Organizational Behavior (Masters-level) 
Graduate Research Assistant/Teaching Assistant (August 2009 to July 2010)

Teaching duties included lecturer for undergraduate core classes, team teaching for special topics graduate/undergraduate class, teaching assistance for undergraduate and graduate classes, and intern supervision. Classes taught or assisted with, and guest lectures include:

Instructor, SPAD 382 Organizational Behavior

Co-Instructor, SPAD 529 Women in Sport (undergraduate and Master's-level)

Co-facilitator, SPAD 521 Independent Study in Sport Administration

Teaching assistant, SPAD 390 Sport Governance

Intern supervisor, SPAD 402 Internships

Guest lecturer for multiple undergraduate and graduate SPAD courses:

Title IX and Intercollegiate Athletics. SPAD 390 Sport Governance. Fall 2009, Fall 2010, Spring 2011, Fall 2011, Spring 2012

Sexuality and sport. SPAD 284 Issues and Ethics in Sport. Spring 2010, Summer 2010, Fall 2010

Gender and sport. SPAD 281 Principles in Sport Administration. Spring 2010, Summer 2010, Fall 2010, Spring 2011, Fall 2011

Qualitative research methods. SPAD 604 Research methods. Spring 2011, Fall 2011, Spring 2012

Leadership in Organizations. SPAD 625 Organizational Behavior. Spring 2011

Ethics in sport. SPAD 390 Sport Governance. Fall 2010

Olympism and the Olympics. SPAD 390 Sport Governance. Fall 2009

International Professional Sport. SPAD 390 Sport Governance. Fall 2009

North American Professional Sport. SPAD 390 Sport Governance. Fall 2009

Major Games in Amateur Sport. SPAD 390 Sport Governance. Fall 2009

Amateur Sport in the Community. SPAD 390 Sport Governance. Fall 2009

Research duties included literature review and budget development for two grant proposals, one federal competitive grant, and one international grant. Also assisted with several research projects related to Sport for Development and Peace. 


\section{Assistant Dean of First-Year Students/ Director of Orientation}

Implemented activities, programs, and policies designed to aid first-year students in their adjustment to a select, diverse, and highly competitive liberal arts environment. Planned and coordinated a comprehensive orientation program and first-year programming initiatives related to orientation goals and objectives.

- Managed budget of nearly $\$ 70,000$ and allocated funds to departments and programs responsible for orientation programs

- Advised and prepared first-year students involved in major misconduct for appearance before the College Committee on Standards

- Adjudicated students involved in minor misconduct

- Consulted with faculty members, administrators, and parents about individual students and applicable College policies.

\section{Assistant Athletic Director for Student Enhancement}

Initiated, developed, and implemented academic and life skills programming for nearly 1,000 student-athletes. Collaborated regularly with athletic administration, campus offices, and 34 varsity coaches to facilitate and promote workshops and speakers.

- Coordinated the T.E.A.M. Concept Leadership Academy, Team Faculty Advisor Program, community service programs, and professional development sessions for coaches and athletic training staff

- Administered programming and administrative budget of $\$ 60,000+$

- Advised the Student-Athlete Advisory Committee (SAAC)

\section{RESEARCH AND SCHOLARLY ACTIVITIES}

\section{Publications}

\section{Peer Reviewed Journals}

Hancock, M. G., Lyras, A., \& Ha, J. P. (in review). Sport for development programs for girls and women: A global assessment. Journal of Sport for Development.

Hancock, M. G., \& Hums, M. A. (2011). Participation by transsexual and transgender athletes: Ethical dilemmas needing ethical decision making skills. Journal of the International Council of Sport Science and Physical Education (ICCSPE) Bulletin, 62.

\section{Book Chapters}

Hums, M. A., \& Hancock, M. G. (2012). Sport management: Bottom lines and higher callings? In A. Gillentine, R. E. Baker, \& J. Cuneen (Eds.) Critical Essays in Sport Management: Exploring and Achieving a Paradigm Shift. Scottsdale, AZ: Holcomb Hathaway. 


\section{Academic Presentations}

Hancock, M. G., \& Greenwell, T. C. (2012, May). The selection of a sport management major: Factors influencing student choice from a consumer-oriented perspective. To be presented at the annual conference of the North American Society for Sport Management, Seattle, Washington.

Hancock, M. G., \& Hums, M. A. (2012, May). Women in intercollegiate athletics: An exploration of the career development of female assistant and associate athletic directors. To be presented at the annual conference of the North American Society for Sport Management, Seattle, Washington.

Hums, M. A., Wolff, E., \& Hancock, M. G. (2012, March). Sport for development and peace: Initiatives, challenges, and pathways forward. Presented at the National Association for Sport and Physical Education for the 2012 AAHPERD National Convention and Exposition, Boston, MA.

Hancock, M. G., \& Hums, M. A. (2011, June). If you build it, will they come?: A demographic assessment of sport management graduate and undergraduate students.

Presented at the annual conference of the North American Society for Sport Management, London, Ontario, Canada.

Hancock, M. G., Mahoney, T. Q., Hambrick, M. E., \& Moorman, A. M. (2011, March). "After I complained...": An analysis of non-discrimination and retaliation policies of university athletic departments involved in Title IX litigation. Presented at the annual conference of the Sport Law and Recreation Association, Savannah, GA.

Mahoney, T. Q., Hancock, M. G., Hambrick, M. E., \& Moorman, A. M. (2011, March). Title IX retaliation claims on the rise in college athletics: An analysis of athletic departments' mishandling of sex discrimination claims. Presented at the annual conference of the Sport Law and Recreation Association, Savannah, GA.

Hancock, M. G, Lyras, A., \& Ha, J. (2010, June). Global assessment of sport for development programs for girls and women. Presented at the annual conference of the North American Society for Sport Management, Tampa, FL.

Welty Peachey, J., Lyras, A., Borland, J., Hancock, M., \& Cohen, A. (2010, June). Sport for social change: A Methodological Proposition for Assessing the Impact of Street Soccer USA on Effecting Positive Life Changes Among the Homeless. Paper presented at the Power of Sport Summit, International Association of Sport for Development and Peace, Boston, MA, USA.

Hums, M.A., Lyras, A., \& Hancock, M. G. (2010, June). Tools for teaching about sport for development and peace in the sport management classroom. 
Presented at the annual conference of the North American Society for Sport Management, Tampa, FL.

Hums, M.A., Lyras, A., \& Hancock, M. G. (2009, November). The Ashoka Foundation's Sport for a Better World Competition: Sport for development and peace in action. Presented at the annual conference of the North American Society for the Sociology of Sport, Ottawa, Canada.

Lyras, A., Wolff, E., Hancock, M. G, \& Selvaraju, U. (2009, November). Sport for development global initiative. Presented at the annual conference of the North American Society for the Sociology of Sport, Ottawa, Canada.

Hancock, M. G. (2008, January). Building a T.E.A.M. concept. Presented at the annual conference of the National Consortium for Academics and Sport Conference, Orlando, FL.

\section{GRANT FUNDING and AWARD ACTIVITIES}

Hancock, M. G. (2011). Diversity in Sport and Physical Activity Grant. Funded by Texas $A \& M$ University in the amount of $\$ 750$.

Hancock, M. G. (2011). Dr. M. Celeste Nichols Professional Development Award. Funded by the University of Louisville Women's Center in the amount of $\$ 420$.

Hancock, M. G. (2011). International Student Travel Grant. Funded by the University of Louisville International Student Office in the amount of $\$ 331$.

Hancock, M. G. (2011). College of Education and Human Development Graduate Student Travel Award. Funded by the University of Louisville College of Education and Human Development in the amount of \$231.

Hancock, M. G. (Summer, 2010). Samuels Family Scholarship. Funded by the University of Louisville College of Education and Human Development in the amount of $\$ 1,437$.

Lyras, A. \& Hancock, M. G. (2010). Youth I.D.E.A.L.S. Bureau of Educational and Cultural Affairs (ECA): International Sports Programming Initiative. Unfunded, $\$ 337,184$.

Lyras, A., Hancock, M. G., \& Ha, J. (2009).Olympism, Peace, and Development: Governance, theory, and practice. Postgraduate research program, International Olympic Committee. Unfunded, $\$ 10,000$. 
Hancock, M. G. Travel to Tampa, FL for the 2010 North American Society of Sport Management (NASSM) Conference. Funded by the University of Louisville in the amount of $\$ 300$.

Hancock, M. G. Travel to Ottawa, Canada for the 2009 North American Sociology of Sport (NASSS) Conference. Funded by the University of Louisville College of Education and Human Development in the amount of $\$ 300$.

\section{SERVICE, MEMBERSHIP, and LEADERSHIP}

\section{Professional}

Article Editor, Sage Open Publications

Reviewer, Journal of Issues in Intercollegiate Athletics

Contributor, Journal of Sport Management Digest

Member, National Association of Collegiate Women Athletics Administrators

- Educational \& Professional Development Committee, February 2012 to present

- NACWAA/HERS Graduate, Indianapolis, IN, June 2007

Member, North American Society for Sport Management (NASSM)

Member, Sport \& Recreation Law Association (SRLA)

\section{University}

Advisor, Sport Administration Club, University of Louisville

Co-Coordinator, COSMA Accreditation, University of Louisville

Member, Sport Administration Master's Admissions Committee, University of

Louisville

Member, Sport Administration Program Committee, University of Louisville

Participant, Graduate Teaching Academy, University of Louisville, Member, Multiple search committees, University of Louisville \& Dartmouth

College

Chair, Orientation Planning Committee, Dartmouth College

Creator and Facilitator, T.E.A.M. Concept Leadership Academy, Dartmouth

College

\section{Community}

Mentor, Louisville Youth Group, Louisville, KY

Volunteer, Girls on the Run, Louisville

Volunteer, Supplies Overseas, Louisville, KY

Volunteer, Ford Ironman, Louisville, KY

Volunteer, Kentucky Derby Festival, Louisville, KY

Volunteer, Center for Women and Families, Louisville, KY

Volunteer, Raised \$2,000 for Home of the Innocents, Louisville, KY

Rider, Raised $\$ 500$ for Bike to Beat Cancer, Louisville, KY 


\section{HONORS}

2012 Red \& Black Scholar-Athlete Faculty Mentor, University of Louisville

2012 Diversity in Sport Grant Recipient, Texas A\&M University

2011 Dr. M. Celeste Nichols Graduate Student Award, University of Louisville

2011 Red \& Black Scholar-Athlete Faculty Mentor, University of Louisville

2011 Faculty Guest Coach, Women's Lacrosse, University of Louisville

2010 U.S. Delegate, International Olympic Academy (cancelled due to economic crisis in Greece)

2001 Woman of the Year, Randolph-Macon Woman's College

2003 Outstanding Sociology/Anthropology Senior Thesis, Randolph-Macon Woman's College

2002 Maude Huff Fife Scholarship, Randolph-Macon Woman's College

- Scholarship for a rising Junior who best personifies R-MWC

2002 Alpha Kappa Delta, Randolph-Macon Woman's College

2001 Team Captain, R-MWC Varsity basketball (NCAA, D-III)

2001 Student Mentor of the Year, Randolph-Macon Woman's College 